\title{
Design of heterogeneous catalysts
}

\author{
Frey, Anne Mette
}

Publication date:

2009

\section{Document Version}

Publisher's PDF, also known as Version of record

Link back to DTU Orbit

\section{Citation (APA):}

Frey, A. M. (2009). Design of heterogeneous catalysts. Technical University of Denmark.

\section{General rights}

Copyright and moral rights for the publications made accessible in the public portal are retained by the authors and/or other copyright owners and it is a condition of accessing publications that users recognise and abide by the legal requirements associated with these rights.

- Users may download and print one copy of any publication from the public portal for the purpose of private study or research.

- You may not further distribute the material or use it for any profit-making activity or commercial gain

- You may freely distribute the URL identifying the publication in the public portal

If you believe that this document breaches copyright please contact us providing details, and we will remove access to the work immediately and investigate your claim 


\section{Anne Mette Frey}

\section{Design of heterogeneous catalysts}

PhD Thesis, November 2008

Center for Sustainable and Green Chemistry

Department of Chemistry

Technical University of Denmark 
Design of heterogeneous catalysts 


\section{Preface}

The present thesis is an overview of the research results obtained during my $\mathrm{PhD}$ studies and it is submitted in candidacy for the $\mathrm{PhD}$ degree from the Technical University of Denmark. The project is entitled "Design of heterogeneous catalysts". Three selected reactions have been investigated in detail during the studies, namely the methanation reaction, the FischerTropsch process, and the ammonia-based selective catalytic reduction (SCR). These reactions will be described in three separate parts. Each part will give an introduction to the subject, explain the aim of my work, describe the experiments, the results, and present the conclusions.

During my $\mathrm{PhD}$ studies a number of side projects have been running, which should be mentioned to complete the picture of the work. I have supervised two master students working within the field of $\mathrm{NH}_{3}$-SCR and one master student working with preparation of perovskite materials for use in solid oxide fuel cells. The fuel cell project has involved coordination chemistry, ball-milling, and flame spray pyrolysis. I have also supervised a group of bachelor students working on a project with ruthenium compounds as FischerTropsch catalysts. Together with another $\mathrm{PhD}$ student, I have been working on a research project involving direct synthesis of hydrogen peroxide. Furthermore, I have taken part in building a methanation test set-up and been slightly involved in the building of a new SCR test set-up. However, focus in my thesis is on the three selected reactions mentioned above.

The work has mainly taken place at the Center for Sustainable and Green Chemistry (CSG) at the Technical University of Denmark (DTU) from November 2005 to November 2008 under supervision of Professor Claus Hviid Christensen. In the period from July 2008 to November 2008 Docent Rasmus Fehrmann took over the formal responsibility as supervisor. The work regarding the methanation and the $\mathrm{NH}_{3}-\mathrm{SCR}$ has been carried out at DTU. The work in CSG has been interrupted for a period of one semester in the autumn 2007, where I visited Professor Krijn de Jong and his research group at Utrecht University, The Netherlands and worked with the Fischer-Tropsch reaction.

The $\mathrm{PhD}$ project was funded by the Danish National Research Foundation. 


\section{Acknowledgments}

Now the end of my PhD work is close, and I owe thanks to a lot of people who have been involved directly or indirectly in my research during the last three years.

The main part of my work has taken place in CSG at DTU and I would like to express my sincere gratitude to all the people in the center who have contributed to my work and to making my time enjoyable. Several of the $\mathrm{PhD}$ students in the center have been very helpful with ideas, suggestions, and proofreading during all last three years and especially during the last couple of month while writing my thesis. I really appreciate it! Some special thanks should be given:

First of all to my supervisor Claus Hviid Christensen for giving me the possibility to make my $\mathrm{PhD}$ within the highly important and interesting area of catalysis, in a highly dynamic working environment where new things are always happening. I would also like to thank Docent Rasmus Fehrmann for taking over the practical responsibility in the absence of Claus the last months.

I appreciate all the possibilities that have been given to me regarding traveling to conferences etc. In connection to that a special thanks should be given to Betina for being excellent travel company and room mate on almost all of these trips. I think we have had incredibly much fun both during these trips and at work - being very motivating also for the research.

I would also like to thank Anne for very nice company and for sharing the never ending GC frustrations during our studies and for a careful proofreading of my entire thesis.

I would like to thank Arkady, Kasper, and Louise for nice cooperation within the methanation project, especially Arkady for his suggestions to my experimental work and thesis. I would like to thank Henrik for a nice cooperation making perovskite materials, and Johannes, Selcuk, and Martin for the cooperation within the SCR projects. I would also like to thank Rasmus for a nice and inspiring collaboration during our hydrogen peroxide project.

I have had the possibility of sharing office with several different $\mathrm{PhD}$ student and post docs, thank you: Arkady, Johannes, Andrey, Kake, and Uffe for contributing to a nice atmosphere. I have enjoyed all the coffee, chocolate and "calendar lights"- breaks with all of you as well as nice scientific discussions despite our rather diverse projects.

Special thanks are also given to Jens Nørskov and Thomas Bligaard at CAMP, DTU for nice cooperation in relation to DFT calculations and to Jens Sehested from Haldor Topsøe A/S for 
cooperation related to the methanation project. Søren Dahl and Nan Topsøe from Haldor Topsøe are thanked for nice collaboration in relation to the SCR project.

Within my private life in Denmark thanks is given to my family and friends - especially my parents, and my brother, Thomas, and my sister, Maria, should be mentioned here. A special thank is also given to Ulla, for always being a good friend, supportive and for listening to a lot of work/chemistry talk from time to time.

My stay in the Netherlands has been one of the most inspiring and fruitful periods of my $\mathrm{PhD}$. I am grateful to a lot of people for contributing to this. First of all to Professor Krijn de Jong who let me visit him and his research group at Universiteit Utrecht. From the first day I enjoyed the friendly, well-structured and intellectually inspiring atmosphere. I would also like to thank Associated Professor Harry Bitter for his interest in my work and for fruitful discussions. Special thanks should be given to Johan for showing me how everything works in the lab, being nice working together with and for helping with practical problems that arise when being in another country - including help with correcting and improving my Dutch. I would also like to thank Cor for helping with and explaining the TEM experiments. A few PhD students, Mariska, Adjan, Niels, Paul and Emiel, who have been extremely helpful with respect to experimental problems when needed, should be mentioned here too. Finally, I would like to thank all members of the Inorganic Chemistry and Catalysis group at Utrecht Universiteit for making my stay at the university a great time in coffee-breaks, at borrels etc. My social life outside work would not have been so cheerful if I had not met so many nice and kind Dutch people. I really appreciate both the company and the friendly help to correct and help me when speaking Dutch (and for talking English with me, when needed). Thus, I would like to thank all those who have contributed to making my time in Utrecht joyful.

Furthermore, I would like to thank Kemisk Forenings Rejsefond, Otto Mønsteds Fond and Oticon Fonden for making my stay in the Netherlands economically possible.

I would like to thank The Danish National Research Foundation for funding my $\mathrm{PhD}$ stipend.

Anne Mette Frey, November 11, 2008 


\section{List of publications and presentations during the $\mathrm{PhD}$ project}

\section{International journals}

den Breejen, J. P., Frey, A. M., Sietsma, J. R. A., Bitter, J. H., de Jong, K. P., ”Cobalt on Silica Catalysts for the Fischer-Tropsch Synthesis and the Effect of Manganese Promotion”, in preparation for J. Catal. 2008

Frey, A. M., Mert, S., Due-Hansen, J., Fehrmann, R., Christensen, C.H., "Fe-BEA Zeolite Catalysts for $\mathrm{NH}_{3}$-SCR", submitted Catal. Lett. 2008

Johannessen, T., Schmidt, H., Frey. A. M., Christensen, C.H., "Improved Automotive $\mathrm{NO}_{\mathrm{x}}$ Aftertreatment System: Metal Ammine Complexes as $\mathrm{NH}_{3}$ Source for SCR Using FeContaining Zeolite Catalysts", submitted Catal. Lett. 2008

Kustov, A., Frey, A. M., Larsen, K. E., Johannessen, T., Nørskov, J., Christensen, C. H., “CO Methanation over Supported Bimetallic Ni-Fe Catalysts: from Computational Studies Towards Catalyst Optimization”, Appl. Catal. A 320, 2007, 98

Sehested, J., Larsen, K. E., Kustov, A. L., Frey, A. M., Johannessen, T., Bligaard, T., Andersson, M. P., Nørskov, J. K., Christensen, C. H., "Discovery of New Technical Methanation Catalysts Based on Computational Screening”, Top. Catal. 24, 2007, 9

\section{Other journals}

Klitgaard, S. K., Egeblad, K., Falsig, H., Frey, A. M., Jørgensen, B., Hansen, D., Johansen, L., Christensen, C. H., "Guld og flyvende grise - en opdagelsesrejse ind i nanokemiens verden”, LMFK-Bladet 3, 2007, 24

\section{Book chapters}

Frey, A. M., Klerke, A., Due-Hansen, J., Christensen, C. H., "Biobrændsel- et varmt alternativ", Nye Kemiske Horisonter, DTU, 2007, 8 


\section{Oral contributions}

Frey, A. M., Mert, S., Due-Hansen, J., Fehrmann, R., Christensen, C.H., "Improved $\mathrm{NO}_{\mathrm{x}}$ Removal with Novel Iron-based Zeolite Catalysts", $2^{\text {nd }}$ EuCheMS Chemistry Congress, Turin, Italy, September 16-20, 2008

den Breejen, J. P., Sietsma, J. R. A., Frey, A. M., Bitter, J. H., de Jong, K. P., "Silicasupported Cobalt Catalysts in the Fischer-Tropsch Synthesis: Particle Size Distribution and Manganese Promotion", 9th Netherlands' Catalysis and Chemistry Conference, Noordwijkerhout, The Netherlands, March 3-5, 2008

Frey, A. M., Sehested, J., Larsen, K. E., Kustov, A. L., Johannessen, T., Bligaard, T., Andersson, M. P., Nørskov, J. K., Christensen, C. H., "Methanation: Optimization of an Industrial Important Process", Summer School, Sandbjerg Gods, Denmark, August 1214,2007

Frey, A. M., Christensen, C. H, Kustov, A. L., Larsen, K. E., Sehested, J., Bligaard, T., Andersson, M. P., Nørskov, J. K., "Novel Methanation Catalysts Discovered by Computational Screening”, Keynote lecture, 20th North American Catalysis Society Meeting, Houston, USA, June 17-22, 2007

Frey, A. M., Sehested, J., Larsen, K. E., Kustov, A. L., Johannessen, T., Bligaard, T., Andersson, M. P., Nørskov, J. K., Christensen, C. H., "Discovery and Development of Alloy Catalysts for Methanation by Combining Computational Screening and Experimental Methods", European Conference on Combinational Catalytical Research and HighThroughput Technologies, Bari, Italy, April 22-25, 2007

Frey, A. M., Sehested, J., Larsen, K. E., Kustov, A. L., Johannessen, T., Bligaard, T., Andersson, M. P., Nørskov, J. K., Christensen, C. H. "Discovery of New Technical Methanation Catalysts Based on Computational Screening”, The Nordic Symposium on Catalysis, Trondheim, May 28-30, 2006 


\section{Posters}

Hansen, M. K., Frey, A. M., Holm, M. S., Christensen, C. H., ” A Study of Conventional and Mesoporous Fe-BEA Materials for $\mathrm{NH}_{3}-\mathrm{SCR}$, $2^{\text {nd }}$ EuCheMS Chemistry Congress, Turin, Italy, September 16-20, 2008

Frey, A. M., Mert, S., Due-Hansen, J., Fehrmann, R., Christensen, C.H., "Development of New and Improved Fe-Zeolite $\mathrm{NH}_{3}$-SCR Catalysts for Automotive Applications", $14^{\text {th }}$ International Congress on Catalysis, Seoul, Korea, July 13-15, 2008

den Breejen, J. P., Frey, A. M., Siestma, J. R. A., Bitter, J. H., de Jong, K. P., “Cobalt in Silica Catalysts for the Fischer-Tropsch Synthesis: the Effect of Calcination and Manganese Promotion", $14^{\text {th }}$ International Congress on Catalysis, Seoul, Korea, July 13-15, 2008

Frey, A. M., Mert, S., Due-Hansen, J., Fehrmann, R., Christensen, C.H., “A Novel Study of Fe-based Zeolites as $\mathrm{NH}_{3}$-SCR Catalysts", Annual Meeting in the Danish Chemical Society, Odense, June 13, 2008

Frey, A. M., Mert, S., Due-Hansen, J., Fehrmann, R., Christensen, C.H., "Novel Fe-based Zeolites with Improved $\mathrm{NH}_{3}$-SCR Activity", 9th Netherlands' Catalysis and Chemistry Conference, Noordwijkerhout, The Netherlands, March 3-5, 2008

Frey, A. M., Sehested, J., Larsen, K. E., Kustov, A. L., Johannessen, T., Bligaard, T., Andersson, M. P., Nørskov, J. K., Christensen, C. H., "Investigation of New Methanation Catalysts Discovered by Combining Computational and Experimental Studies", Europacat VIII, Turku, Finland, August 26-31, 2007

Frey, A. M., Sehested, J., Larsen, K. E., Kustov, A. L., Johannessen, T., Bligaard, T., Andersson, M. P., Nørskov, J. K., Christensen, C. H., "Methanation: Optimization of an Industrial Important Process", Summer School, Sandbjerg Gods, Denmark, August 1214,2007 
Frey, A. M., Sehested, J., Larsen, K. E., Kustov, A. L., Johannessen, T., Bligaard, T., Andersson, M. P., Nørskov, J. K., Christensen, C. H., "Coal-to-Gas: New Methanation Catalysts Discovered by Combining Computational and Experimental Methods", 3rd International Conference on Green and Sustainable Chemistry, Delft, The Netherlands, July $1-5,2007$

Frey, A. M., Sehested, J., Larsen, K. E., Kustov, A. L., Johannessen, T., Bligaard, T., Andersson, M. P., Nørskov, J. K., Christensen, C. H., "Methanisering: På vej til nye katalysatorer ved kombination af computerberegninger og eksperimenter", Annual Meeting in the Danish Chemical Society, Odense, June 7, 2007.

Frey, A. M., Sehested, J., Larsen, K. E., Kustov, A. L., Johannessen, T., Bligaard, T., Andersson, M. P., Nørskov, J. K., Christensen, C. H., “CO-removal from Biohydrogen Produced by Steam Reforming: Discovery of New Catalysts Based on Fundamental Insight", 1st International IUPAC Conference on Green-Sustainable Chemistry, Dresden, Germany, September 11-15, 2006.

Frey, A. M., Sehested, J., Larsen, K. E., Kustov, A. L., Johannessen, T., Bligaard, T., Andersson, M. P., Nørskov, J. K., Christensen, C. H., "New Methanation Catalysts: From Computational Screening Towards Industrial Use”, Summer School, Fuglsøcenteret, Ebeltoft, June 11-16, 2006.

Frey, A. M., Sehested, J., Larsen, K. E., Kustov, A. L., Johannessen, T., Bligaard, T., Andersson, M. P., Nørskov, J. K., Christensen, C. H., ”Opdagelse af nye katalysatorer til methanisering”, Annual Meeting in the Danish Chemical Society, Odense, June 8, 2006. 


\section{Abstract}

The title of my PhD thesis is "Design of Heterogeneous Catalysts". Three reactions have been investigated: the methanation reaction, the Fischer-Tropsch reaction, and the $\mathrm{NH}_{3}$-based selective catalytic reduction (SCR) of NO.

The experimental work performed in connection with the methanation reaction was inspired by a computational screening, suggesting that alloys such as $\mathrm{Ni}-\mathrm{Fe}, \mathrm{Co}-\mathrm{Ni}$, and $\mathrm{Co}-\mathrm{Fe}$ should show superior activity to the industrially used nickel catalyst. Especially the Ni-Fe system was considered to be interesting, since such alloy catalysts should be both more active and cheaper than the Ni catalyst. The results from the screening were experimentally verified for $\mathrm{CO}$ hydrogenation, $\mathrm{CO}_{2}$ hydrogenation, and simultaneous $\mathrm{CO}$ and $\mathrm{CO}_{2}$ hydrogenation by bimetallic Ni-Fe catalysts. These catalysts were found to be highly active and selective. The $\mathrm{Co}-\mathrm{Ni}$ and $\mathrm{Co}-\mathrm{Fe}$ systems were investigated for $\mathrm{CO}$ hydrogenation. For both systems a maximum in catalytic activity was found for some of the bimetallic catalysts being superior to the monometallic catalysts. This resulted in volcano curves for all investigated systems.

In the Fischer-Tropsch reaction promotion of cobalt catalysts with manganese was studied. Previously it has been shown that calcination of cobalt catalyst in a $\mathrm{NO} / \mathrm{He}$ mixture resulted in improved catalytic activity compared to standard air calcined samples, since more homogenous cobalt particles with a narrow particle size distribution were formed. Unfortunately the $\mathrm{C}_{5+}$ selectivity decreased. Since $\mathrm{Mn}$ is known to improve $\mathrm{C}_{5+}$ selectivity the addition of this promoter, combined with NO calcination, was studied. The influence of parameters such as Co:Mn ratio, drying conditions, and reduction temperatures on the catalytic performance were investigated. The promotion strategy turned out to work well, and the best catalyst prepared had a $\mathrm{C}_{5+}$ yield almost a factor of two higher than a standard air calcined Co catalyst.

In the $\mathrm{NH}_{3}$-SCR reaction it is desirable to develop an active and stable catalyst for $\mathrm{NO}_{\mathrm{x}}$ removal in automotive applications, since the traditionally used vanadium-based catalyst pose an environmental risk. The focus was put on iron-containing zeolite catalysts, since these recently have shown great potential as catalysts for the process. A number of different zeolites were compared. BEA was found to be the most active, thus focus was put on this material. Different preparation techniques were studied for conventional BEA zeolites with various iron content. These materials turned out to be very interesting, exhibiting high catalytic activity; in some cases they were even more active than the conventional vanadium-based catalyst. 


\section{Dansk resumé}

Titlen for min ph.d. afhandling er "Design af heterogene katalysatorer". Tre reaktioner er blevet undersøgt: methanisering, Fischer-Tropsch-reaktionen og den $\mathrm{NH}_{3}$-baserede selektive katalytiske reduktion $\left(\mathrm{NH}_{3}-\mathrm{SCR}\right)$ af $\mathrm{NO}$.

Det eksperimentelle arbejde, der er blevet udført i forbindelse med methaniseringsreaktionen, er inspireret af en computerbaseret screening, der postulerer at Ni-Fe-, Co-Ni- og Co-Felegeringer har højere aktivitet end den industrielt anvendte Ni katalysator. Specielt Ni-Fesystemet er interessant, idet sådanne legeringskatalysatorer skulle være både bedre og billigere end en monometallisk Ni-katalysator. Resultaterne fra screeningen blev verificeret eksperimentelt for $\mathrm{CO}$-hydrogenering, $\mathrm{CO}_{2}$-hydrogenering og samtidig $\mathrm{CO}$ - og $\mathrm{CO}_{2}$ hydrogenering for de bimetalliske Ni-Fe-katalysatorer, som viste sig at være meget aktive og selektive. Co-Ni- og Co-Fe-systemerne blev undersøgt i CO-hydrogenering, og for begge systemer blev et maksimum i katalytisk aktivitet fundet for nogle af de bimetalliske katalysatorer. I visse tilfælde var de bimetalliske katalysatorer således bedre end de monometalliske katalysatorer, hvilket resulterede i vulkankurver.

I forbindelse med Fischer-Tropsch reaktionen blev Mn undersøgt som promoter af Cokatalysatorer. Det er tidligere vist, at kalcinering af en Co katalysator med $\mathrm{NO} / \mathrm{He}$ resulterer i højere katalytisk aktivitet end ved kalcinering i luft, da mere homogene Co-partikler med en snævrere partikelstørrelsesfordeling opnås. Desværre mindskes $\mathrm{C}_{5+}$-selektiviteten samtidig. Da Mn er kendt for at øge $\mathrm{C}_{5+}$-selektiviteten, blev effekten af at have denne promoter tilstede undersøgt, samtidig med at prøven blev kalcineret i NO/He. Betydningen af parametre som Co:Mn forholdet, tørringsprocedurer og reduktionstemperatur for den katalytiske aktivitet blev kortlagt. Strategien med Mn virkede som ønsket, og den bedste af de fremstillede katalysator havde et næsten dobbelt så højt $\mathrm{C}_{5+-}$-udbytte, som en luftkalcineret Co-katalysator. I $\mathrm{NH}_{3}$-SCR-reaktionen er det ønskeligt at udvikle en katalysator til fjernelse af $\mathrm{NO}_{\mathrm{x}}$, der er aktiv og stabil i biler, idet den traditionelt anvendte vanadiumkatalysator udgør en miljømæssig risiko. Fokus i det eksperimentelle arbejde blev lagt på jernholdige zeolitter, da det for nylig er opdaget, at disse virker som lovende katalysatorer. Forskellige zeolitter blev fremstillet, og da BEA var den mest aktive, blev dette materiale undersøgt i nærmere detaljer. Forskellige præparationsmetoder blev anvendt til at fremstille konventionelle BEA-zeolitter med variabelt Fe-indhold. Disse katalysatorer er meget interessante og lovende, da de udviste særdeles høj katalytisk aktivitet - i nogle tilfælde sågar højere aktivitet end for en vanadium reference katalysator. 
Design of heterogeneous catalysts 


\section{Table of contents}

1 General introduction .............................................................................................

$1.1 \quad$ Outline

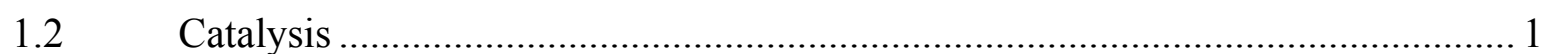

The importance of catalytic reactions ........................................................... 1

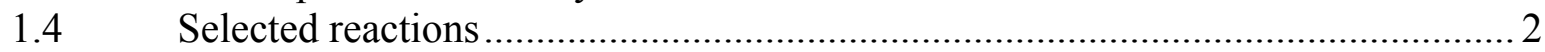

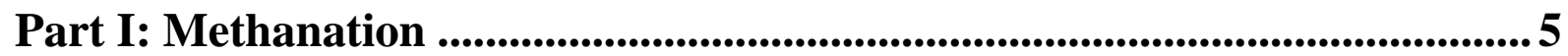

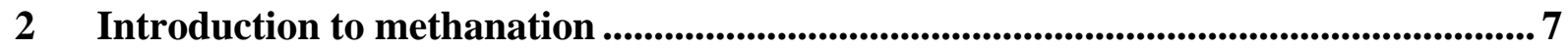

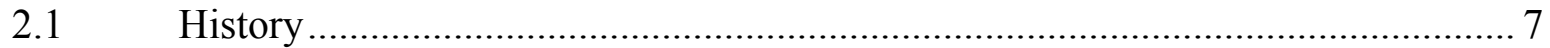

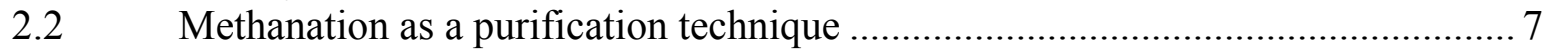

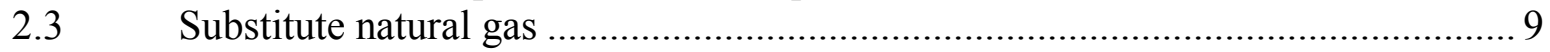

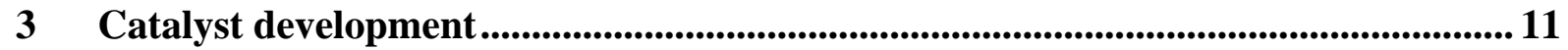

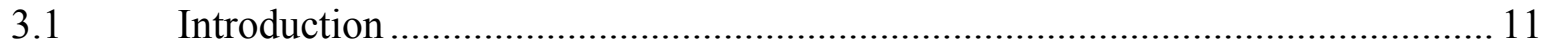

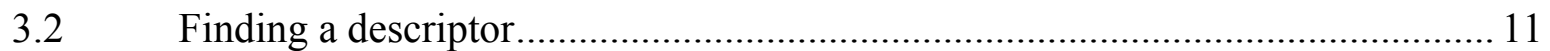

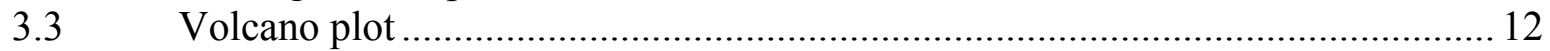

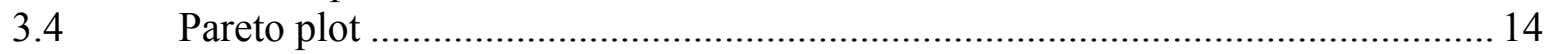

Other catalytic applications for the alloy systems.......................................... 15

4 CO hydrogenation using Ni-Fe catalysts............................................................. 17

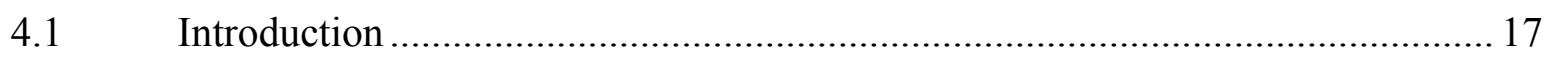

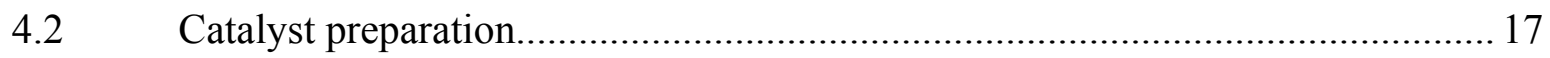

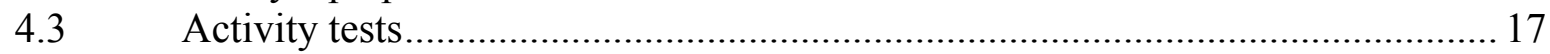

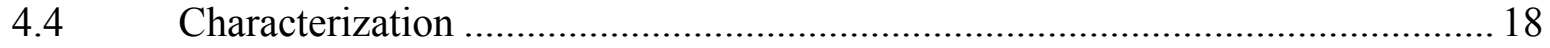

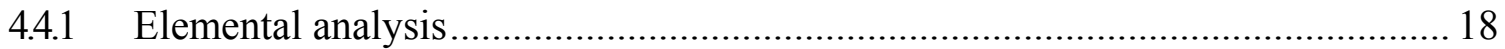

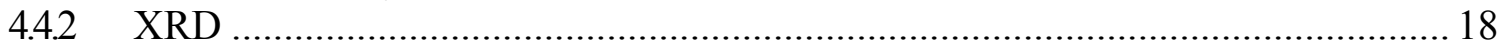

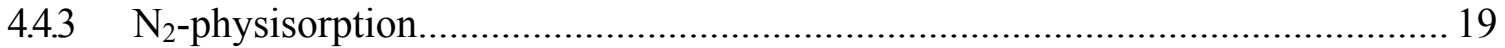

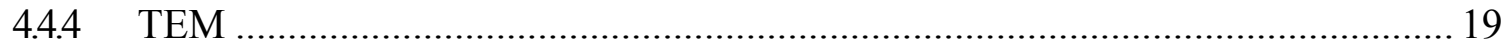

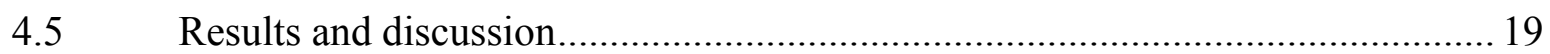

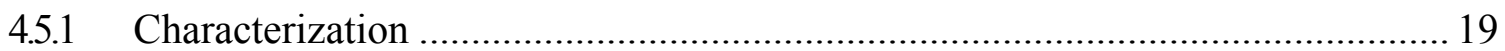

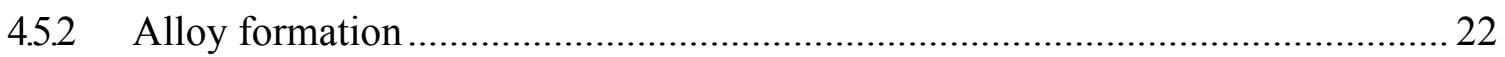

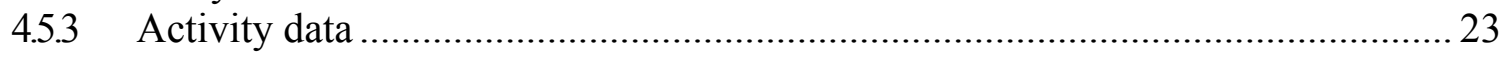

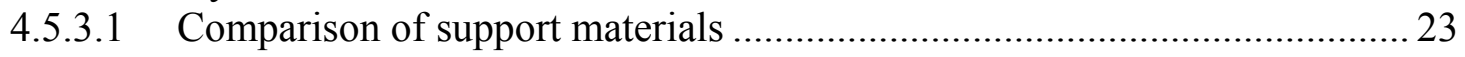

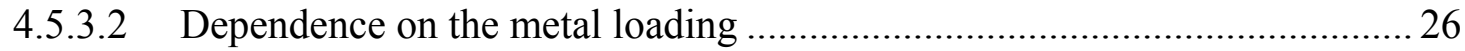

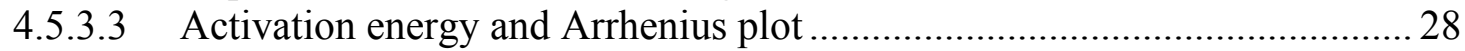

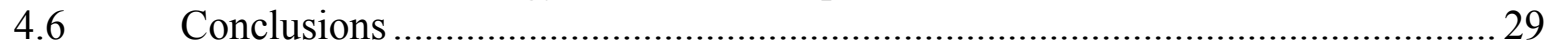

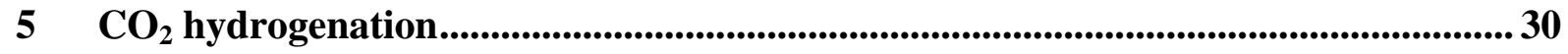

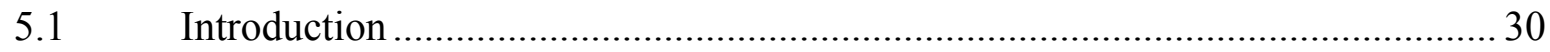

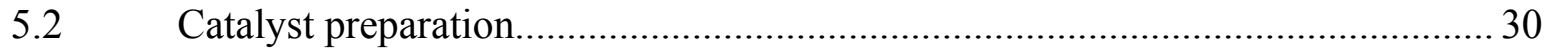

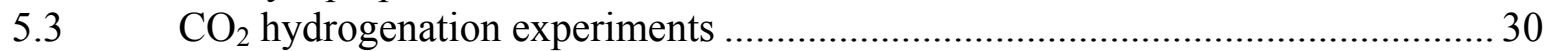

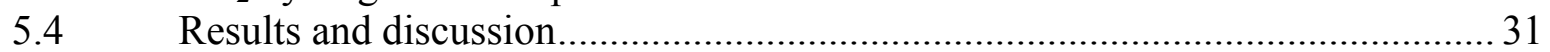

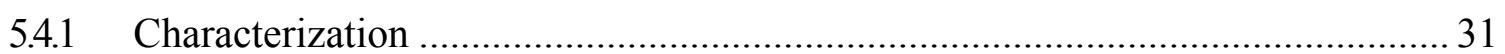

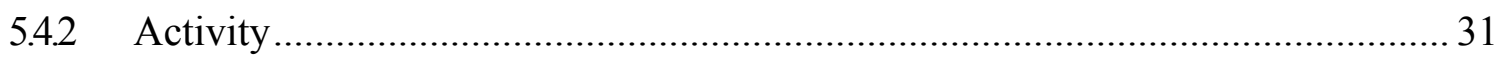

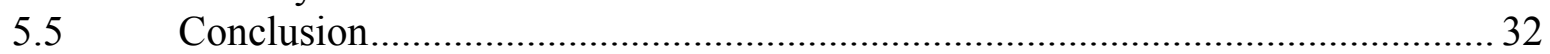


6 Simultaneous $\mathrm{CO}$ and $\mathrm{CO}_{2}$ hydrogenation .................................................................... 33

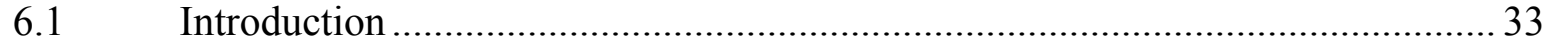

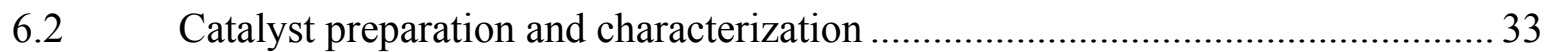

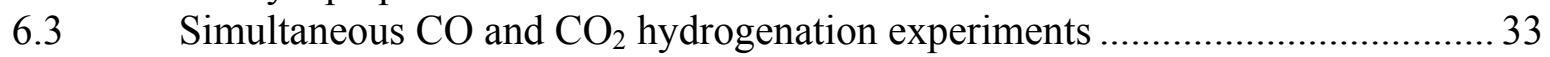

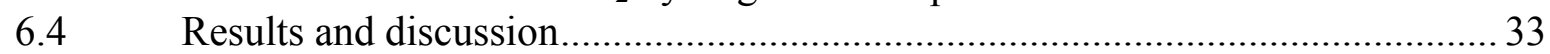

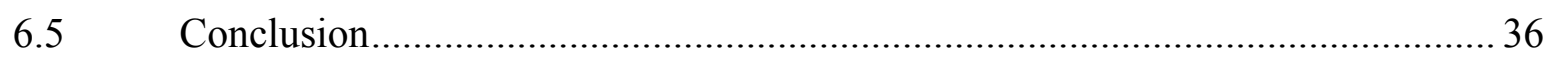

7 Bimetallic Co-Fe and Co-Ni catalysts for $\mathrm{CO}$ hydrogenation...................................37

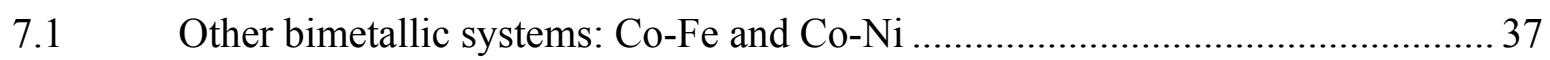

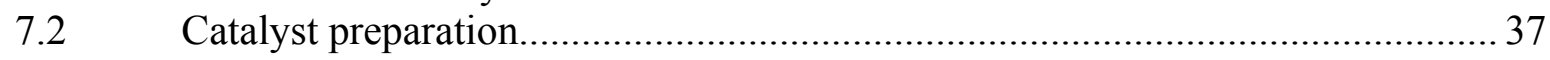

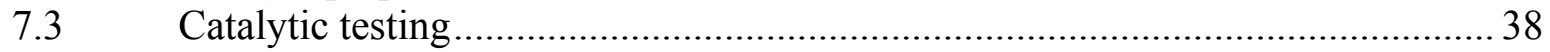

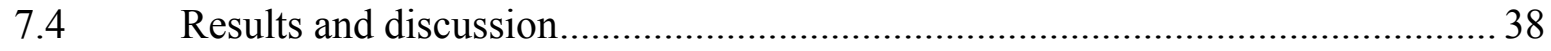

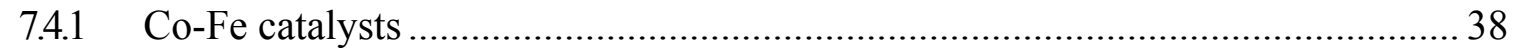

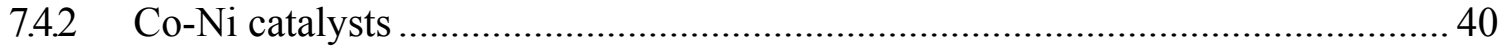

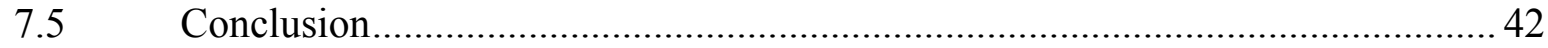

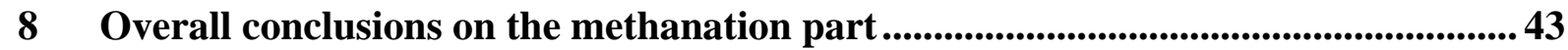

Part II: The Fischer-Tropsch Process ................................................................... 45

9 The Fischer-Tropsch process ........................................................................4

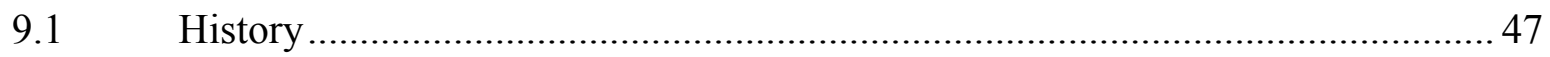

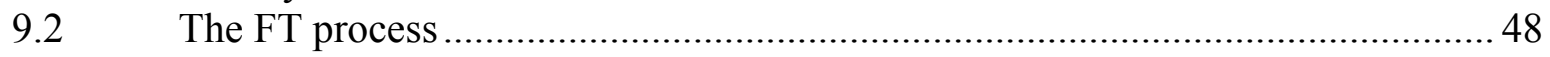

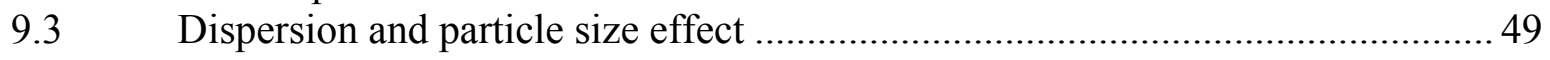

10 Manganese promoted cobalt catalysts.......................................................................52

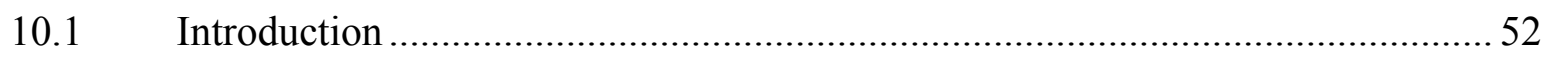

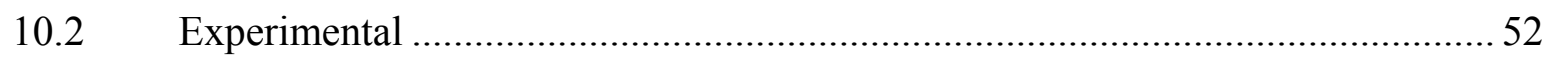

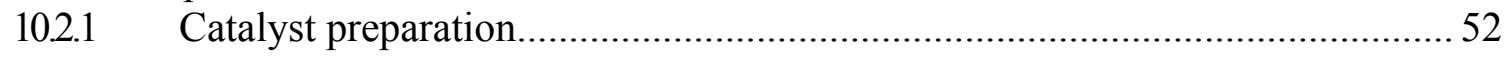

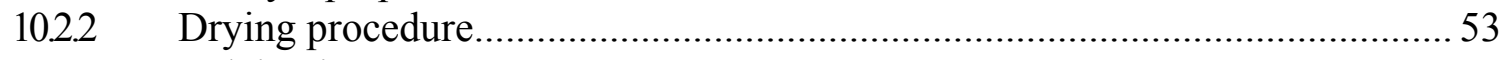

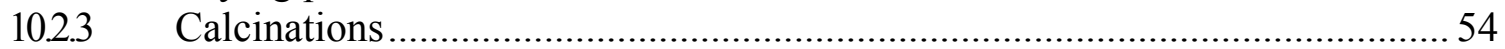

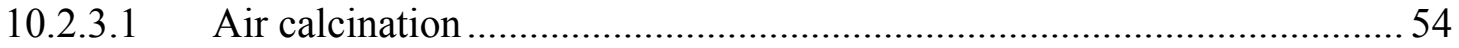

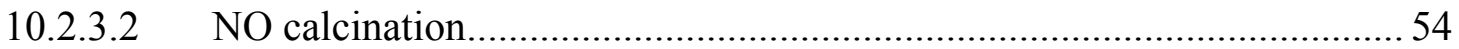

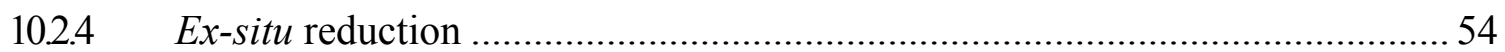

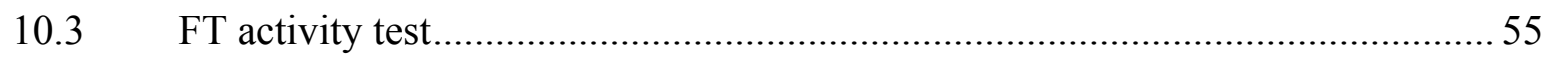

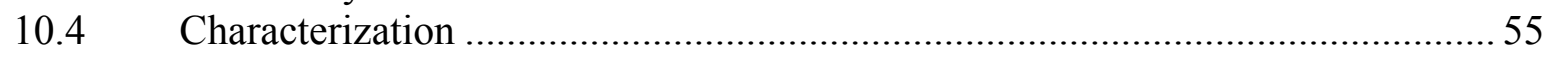

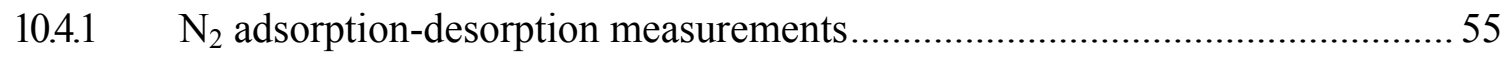

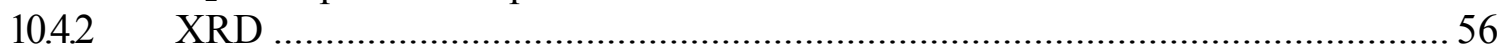

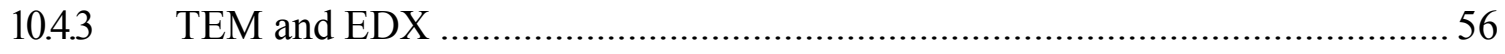

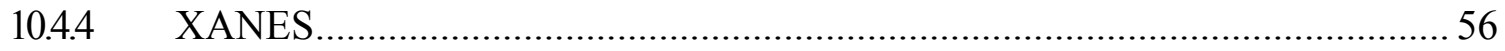

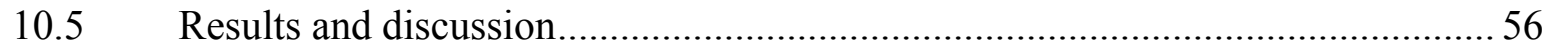

10.5.1 Activity of manganese promoted cobalt catalysts............................................56

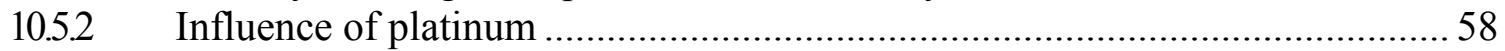

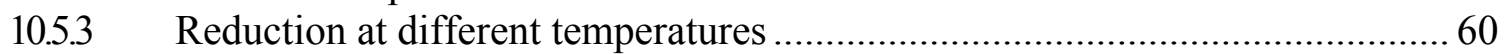

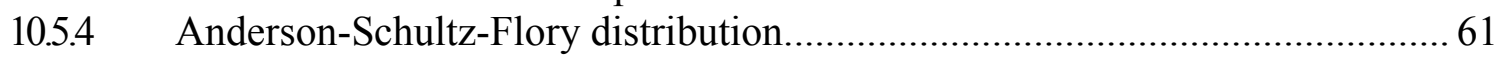

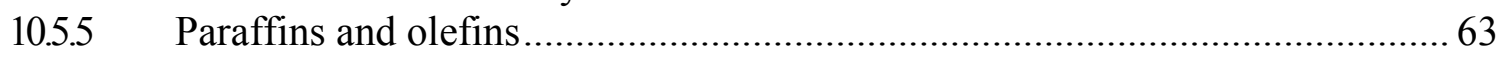

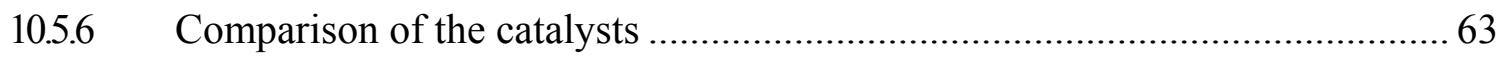

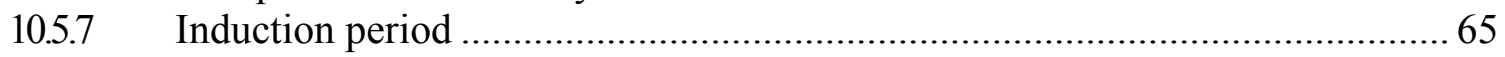

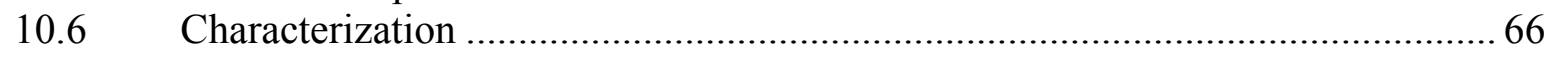

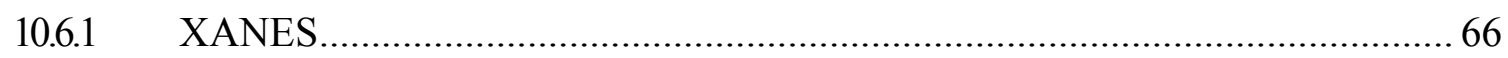




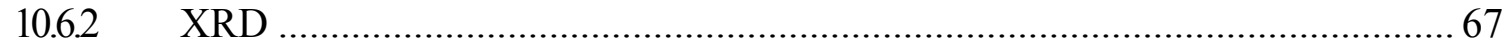

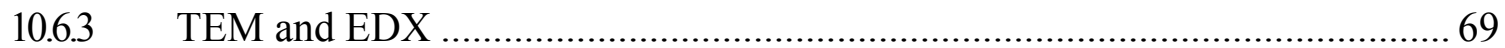

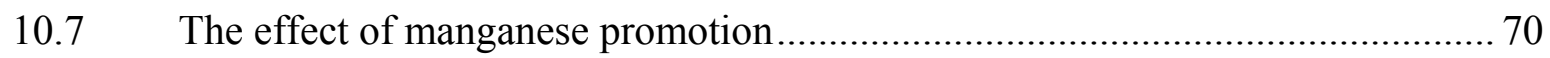

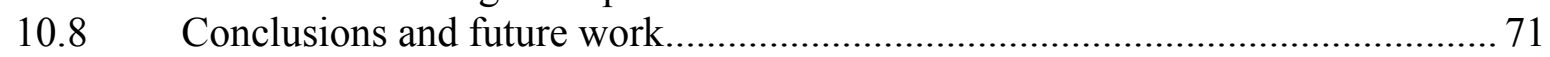

Part III: $\mathrm{NH}_{3}$-based selective catalytic reduction of NO ................................ 73

11 A new $\mathrm{NH}_{3}$-SCR system for automotive applications ................................................. 75

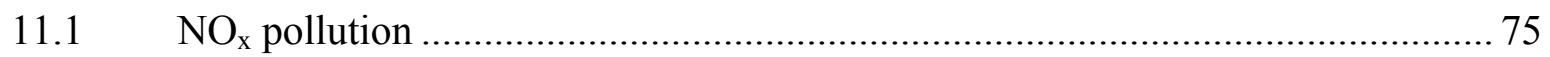

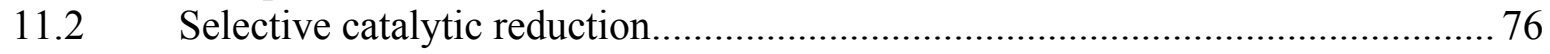

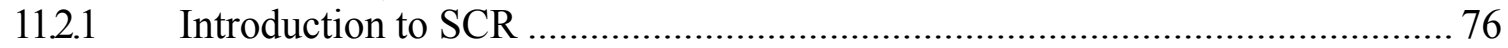

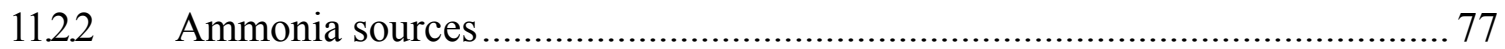

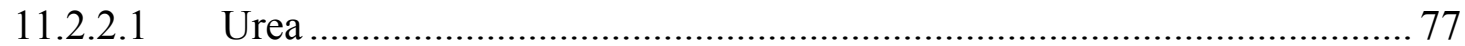

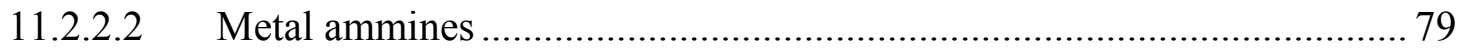

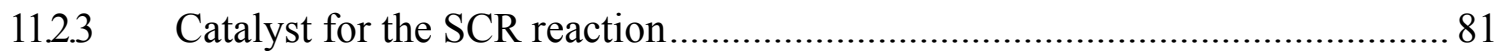

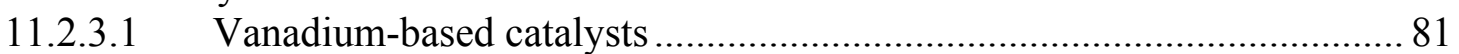

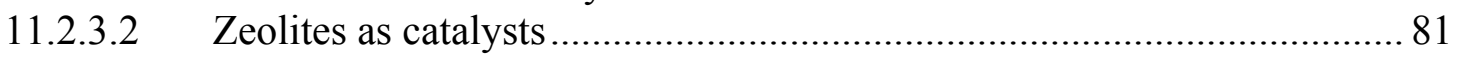

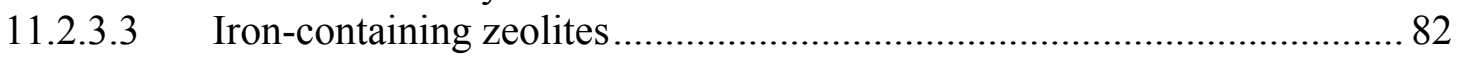

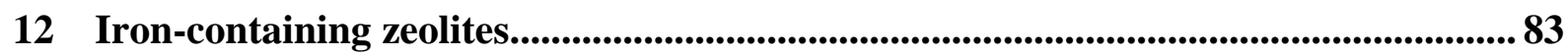

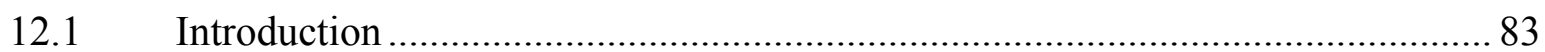

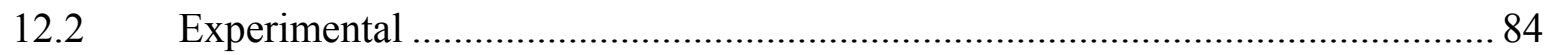

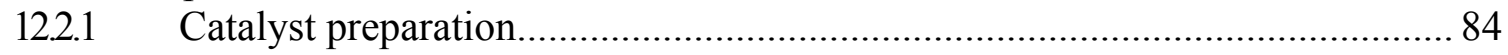

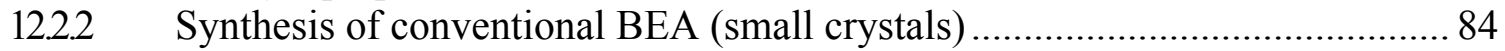

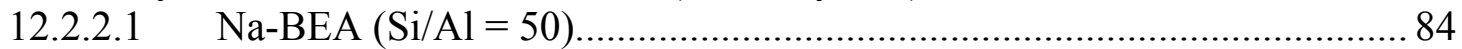

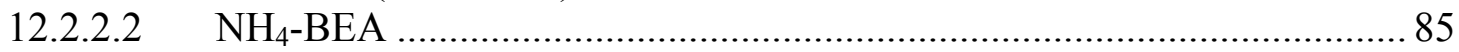

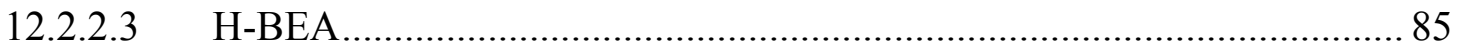

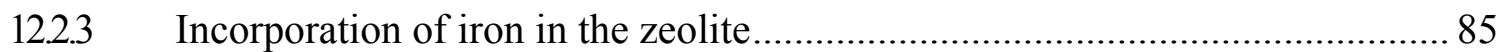

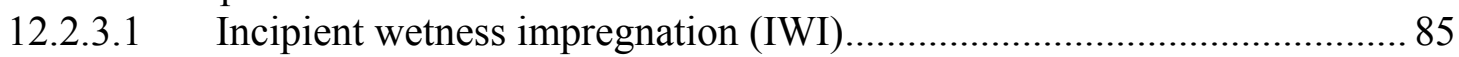

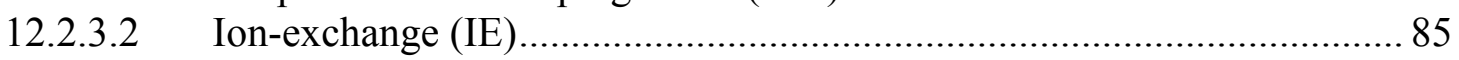

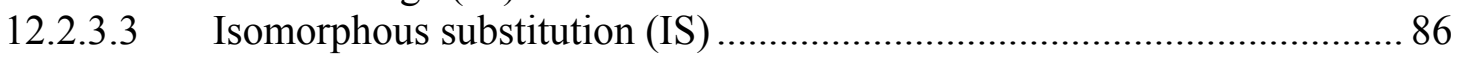

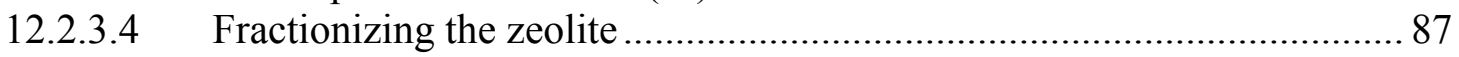

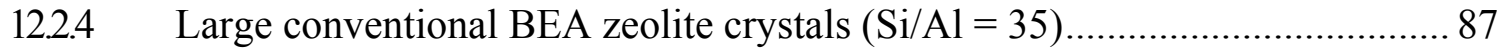

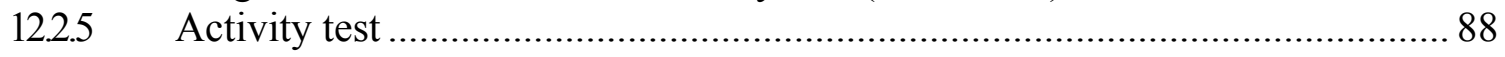

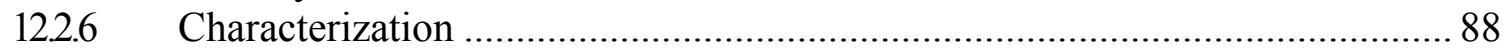

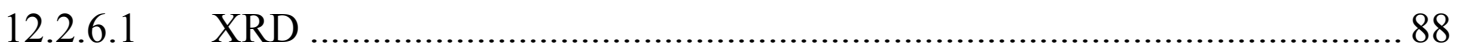

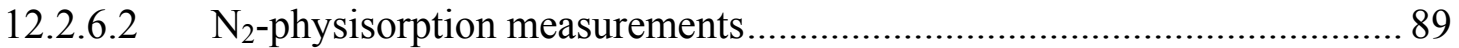

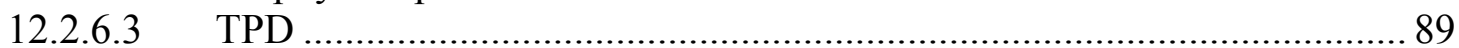

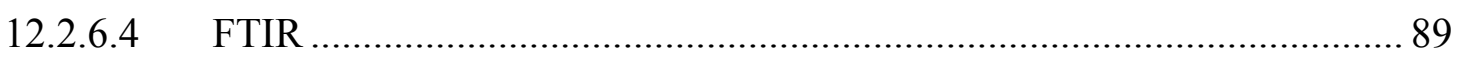

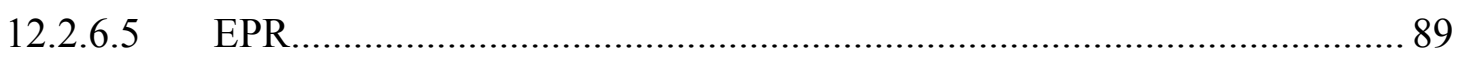

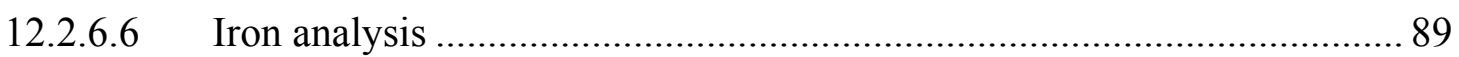

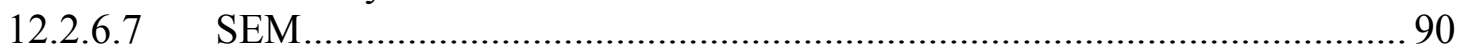

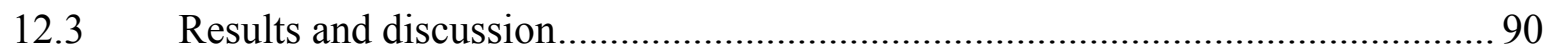

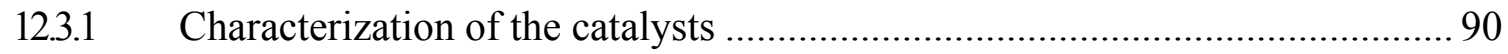

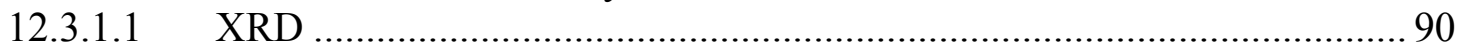

12.3.1.2 BET areas, pore volumes, and isotherms ............................................. 91

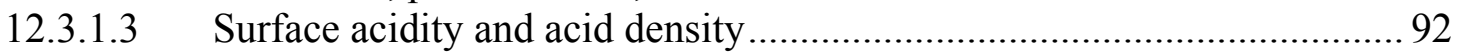

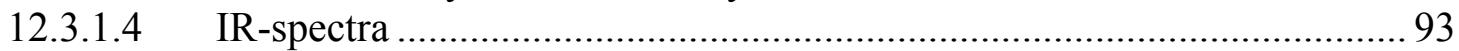

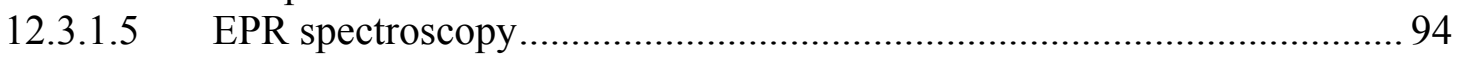




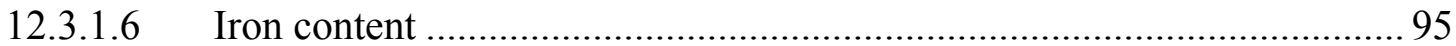

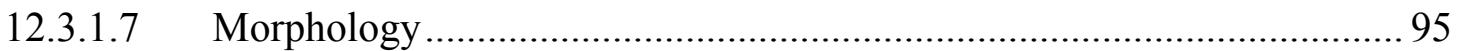

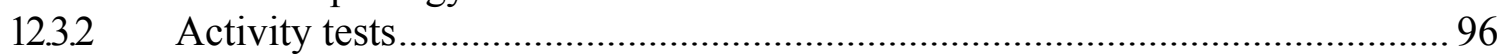

12.3.2.1 Comparison of different zeolite catalysts ............................................. 96

12.3.2.2 Influence of the iron content ............................................................ 97

12.3.2.3 Investigation of different iron incorporation methods ........................... 98

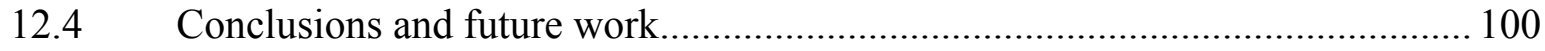

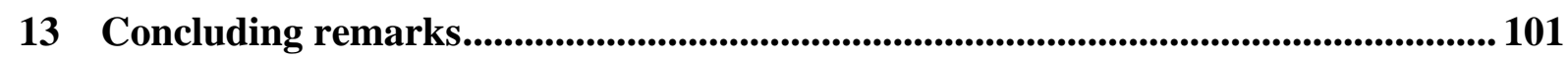

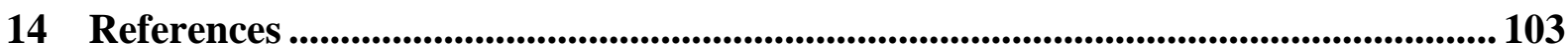




\section{General introduction}

\subsection{Outline}

A short introduction to catalysis and the influence of catalysis on the world of today will be given in this chapter. The reactions investigated in this $\mathrm{PhD}$ project and their impact on today's society will be discussed and an outline for the scientific work presented in this thesis will be sketched.

\subsection{Catalysis}

The discovery of catalysis is almost 200 years old, and dates back to the Swedish scientist Jöns Jakob Berzelius who in 1835 rationalized previous work done by a number of researchers such as Faraday and Döbereiner ${ }^{1}$. Berzelius found that a number of reactions only took place if a certain substance, a catalyst, was present to initialize the process. However, catalysis has been used for thousands of years e.g. in the production of ethanol using yeast long before the concept of catalysis was discovered and rationalized.

A catalyst can be described simply as a substance that increases the reaction rate without being consumed. A more precise definition of a catalyst and catalysis is given by IUPAC ${ }^{2}$ as 'A substance that increases the rate of a reaction without modifying the overall standard Gibbs energy change in the reaction; the process is called catalysis'.

Catalysis is often subdivided in groups such as heterogeneous, homogeneous, and biocatalysis $^{3}$. The present work is focused on heterogeneous catalysis, which is characterized by the catalyst, reactants, and products forming at least two phases. In the cases investigated here the reactions are gas-phase reactions and solid catalysts are used.

Many different kinds of materials can be used as catalysts. As examples, the different catalyst materials which have been studied in this thesis can be mentioned: monometallic catalysts, promoted metal catalysts, and bimetallic alloy systems on oxide supports as well as metalcontaining zeolite catalysts. However, a wide range of other materials can also be used ${ }^{3}$.

\subsection{The importance of catalytic reactions}

The influence of catalysis on today's society is enormous, since catalysts are applied in efficient and clean production routes within many different areas. Some of the areas where 
catalysis plays a key role are food production, energy production, petroleum industry, the production of chemicals and pharmaceuticals, and environmental protection ${ }^{4}$.

Most chemical products are produced using catalysis and approximately $90 \%$ of today's chemical processes rely on catalysis ${ }^{5}$. Some of the largest processes, which are based on heterogeneous catalysis, are: cracking and hydrotreating of crude oil, gasoline production from naphta, alkylations, polymerizations, production of vinyl chloride and acrylo nitrile, epoxidation of ethylene, steam reforming of methane, water-gas shift reaction, methanation, production of ammonia, ammonia oxidation and production of sulfuric acid ${ }^{6}$. Many of these processes lead to the fuels, polymers, and some of the inorganic- and organic products which are produced in the largest amounts in the world today. Catalysis plays a huge role in many other processes as well, so the examples listed above are just to give an idea about the importance of the concept. It should be mentioned that heterogeneous catalysts are the most abundant used type of catalyst for industrial applications. In some cases the catalyst is necessary for the reaction to take place; in other cases it increases the effectiveness of the process. Such an increase in effectiveness of an industrial process is in most cases beneficial for the environment, since it reduces waste products, utilizes the reactants more efficiently, uses lower temperatures and therefore less energy, $\operatorname{etc}^{7}$. However, catalysis can also be used as a direct mean to protect the environment and lower the pollution of many harmful compounds. A classical example is the three-way catalysts, where $\mathrm{NO}, \mathrm{CO}$, and hydrocarbons are removed in the exhaust of gasoline driven cars $^{6}$. Since legislation is used more and more to lower the amounts of dangerous compounds released to the surroundings, catalysts are expected continuously to play an important role within the field of environmental protection. The impact catalysis has on the society is also seen economically: It is estimated that $35 \%$ of the global gross domestic product (GPD) originates from catalytic processes ${ }^{4}$. In U.S. the gross national product (GNP) of fuels and chemicals derived and produced using catalysis is estimated to be $17 \%{ }^{4}$ and on average in the industrial world the number is in the same range.

\subsection{Selected reactions}

Due to the tremendous number of catalytic reactions and the corresponding heterogeneous catalyst systems it is impossible to cover the area fully in a $\mathrm{PhD}$ study. Thus, in this work three highly important heterogeneous catalytic reactions have been chosen as case studies. The thesis consists of three separate and independent parts, treating each of these reactions. 
In Part I the methanation reaction is described. The methanation reaction is highly important as a purification technique in processes such as ammonia production, where the hydrogen must be free of $\mathrm{CO}$ and $\mathrm{CO}_{2}$ in order not to poison the catalyst used for the ammonia synthesis. A short introduction to the reaction will be given, followed by a description of a computational screening leading to new suggestions for attractive catalysts. In the following chapters the experimental work carried out in this study will be described in detail. The purpose of the work was to verify the results from the computational screening experimentally. The bimetallic Ni-Fe system has therefore been investigated for $\mathrm{CO}, \mathrm{CO}_{2}$, and simultaneous $\mathrm{CO}$ and $\mathrm{CO}_{2}$ hydrogenation. Furthermore, Co-Fe and $\mathrm{Co}-\mathrm{Ni}$ catalysts have been studied for CO hydrogenation.

In Part II a study regarding the Fischer-Tropsch process is presented. The Fischer-Tropsch reaction is very interesting, since it is a way to produce synthetic liquid fuels from natural gas, coal or biomass. This makes it possible to supply the world with transportation fuels for a long period of time. A short presentation of the reaction and the historical background will be given along with the background for the experimental study, using a special calcination method based on nitric oxide in order to obtain small particles with a narrow particle size distribution. In the following chapter experimental work regarding manganese promotion of cobalt catalysts in combination with an NO calcination method is described. The catalytic properties of such materials are compared with a traditional air calcined cobalt catalyst.

In Part III the ammonia-based selective catalytic reduction, $\mathrm{NH}_{3}-\mathrm{SCR}$, is studied. This reaction is important in automotives as well as for stationary applications where $\mathrm{NO}_{\mathrm{x}}$ needs to be removed in order to protect the environment. Stricter legislation, for the allowed $\mathrm{NO}_{\mathrm{x}}$ concentration in exhaust, demands development of improved catalysts for this reaction. In the first chapter in this section the challenges in automotive SCR will be discussed along with a suggestion for a solution to some of these challenges. In the following chapter the experimental work regarding zeolite catalysts, especially iron-containing BEA, will be discussed. 
Design of heterogeneous catalysts 


\section{Part I}

Methanation 
Design of heterogeneous catalysts 


\section{Introduction to methanation}

\subsection{History}

The methanation reaction was discovered more than a century ago, in 1902, by Paul Sabatier and Jean-Baptiste Senderens ${ }^{8}$.

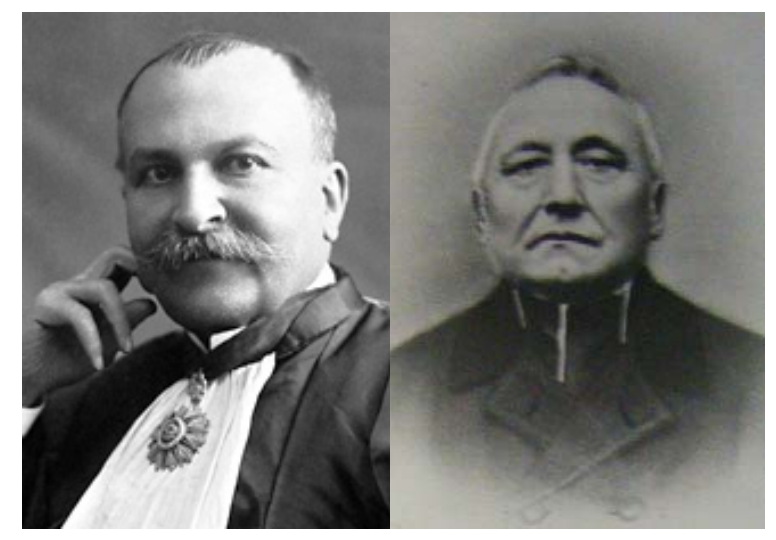

Figure 2.1 P. Sabatier (left) and J. B. Senderens (right).

The methanation reaction is the catalytic reaction where carbon monoxide reacts with hydrogen to form methane and water as described by the reaction scheme:

$$
\mathrm{CO}+3 \mathrm{H}_{2} \rightarrow \mathrm{CH}_{4}+\mathrm{H}_{2} \mathrm{O}
$$

The exothermic reaction has a standard formation enthalpy of $-207 \mathrm{~kJ} / \mathrm{mol}$ while the standard Gibbs energy for the reaction is $-142 \mathrm{~kJ} / \mathrm{mol}$. The traditional catalyst used for industrial applications is based on nickel on alumina ${ }^{9,10}$. Despite the fact that the reaction has been well known for more than 100 years, and furthermore is a classical, well-studied reaction in heterogeneous catalysis, new discoveries and improvements can still be made, as it will be shown in the following.

\subsection{Methanation as a purification technique}

In order to understand the importance of methanation it is necessary to look a bit into its applications. The reaction is mainly used as a method for purification of gas $^{3}$. It is highly important in several reactions to purify e.g. hydrogen before use. The most important example is the ammonia production, where even small amounts of $\mathrm{CO}$ will poison the ammonia catalyst $^{11,12}$. Ammonia is normally produced by the Haber-Bosch process, where nitrogen and hydrogen reacts over a catalyst to form ammonia. Ammonia is one of the chemicals in the world produced in highest quantity. Approximately $80 \%$ of the produced ammonia is used 
for fertilizing agricultural crops. Other utilizations are explosives, plastics, fibers, pharmaceuticals, and dyes ${ }^{13}$.

In Figure 2.2 a sketch of an ammonia plant is shown ${ }^{13}$. A large part of the CO present in the gas can be oxidized to $\mathrm{CO}_{2}$ in the so-called water-gas shift reaction:

$$
\mathrm{CO}+\mathrm{H}_{2} \mathrm{O} \rightarrow \mathrm{CO}_{2}+\mathrm{H}_{2}
$$

The main part of the $\mathrm{CO}_{2}$ formed this way can be removed by a couple of different procedures based on adsorption using e.g. potassium carbonate or 2-aminoethanol as adsorption media ${ }^{12}$. However, small amounts of $\mathrm{CO}$ and $\mathrm{CO}_{2}$ are left after such procedures.

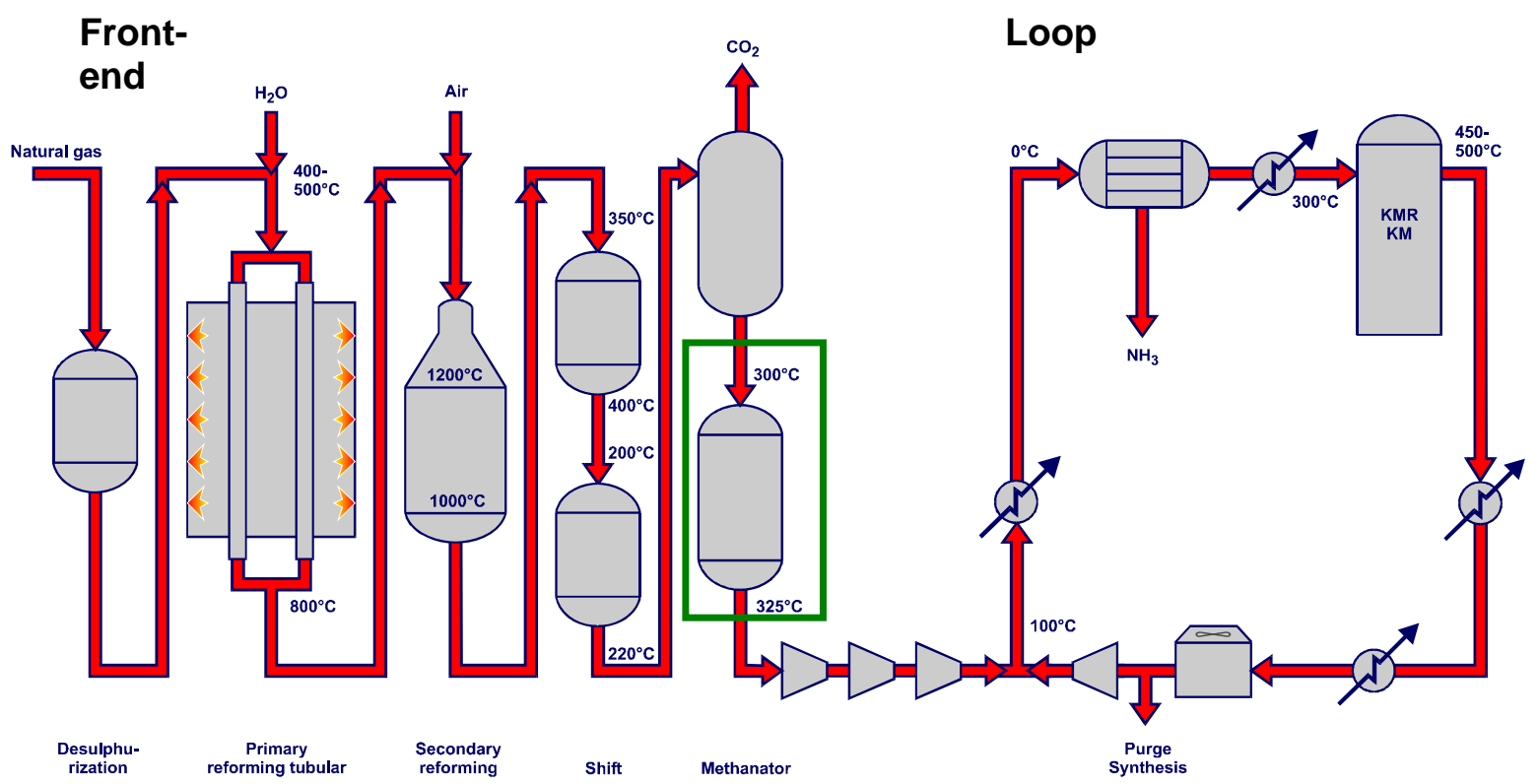

Figure 2.2 Sketch of an ammonia plant ${ }^{13}$ : In the front-end reforming and purification of the gases takes place. The methanator is indicated with a green box. The ammonia synthesis takes place in the loop.

The place where the methanation reaction takes place, the methanator, is marked with a green box in the figure. The methanation is the last step in the front-end of the system, just after the $\mathrm{CO}_{2}$ removal and before the loop where ammonia is formed. In the ammonia production it is not sufficient that the $\mathrm{CO}$ is hydrogenated in the methanator - the traces of $\mathrm{CO}_{2}$ need to be removed as well. Using a nickel catalyst in the methanator solves this problem by hydrogenating $\mathrm{CO}_{2}$ along with the $\mathrm{CO} . \mathrm{CO}_{2}$ can in principle be hydrogenated by two different routes, either directly:

$$
\mathrm{CO}_{2}+4 \mathrm{H}_{2} \rightarrow \mathrm{CH}_{4}+2 \mathrm{H}_{2} \mathrm{O}
$$

or alternative by hydrogenation of $\mathrm{CO}$ after the reverse water gas shift reaction has taken place: 


$$
\mathrm{CO}_{2}+\mathrm{H}_{2} \rightarrow \mathrm{CO}+\mathrm{H}_{2} \mathrm{O}
$$

The reverse water gas shift reaction has previously been shown to be the main route ${ }^{14}$. To get an impression of the effectiveness of a nickel catalyst in the methanator, the gas composition before and after the step must be examined. A typical composition in the inlet gas to the methanator in an ammonia plant is given by ${ }^{13,15}$ :

$$
\mathrm{H}_{2}=74.6 \%, \mathrm{CO}=0.4 \%, \mathrm{CO}_{2}=0.1 \%, \mathrm{CH}_{4}=0.3 \%, \mathrm{~N}_{2}=24.6 \% \text {. }
$$

After the methanation, using a nickel catalyst, the exit gas composition is changed to:

$$
\mathrm{H}_{2}=74.3 \%, \mathrm{CO}=1-2 \mathrm{ppm}, \mathrm{CO}_{2}=3 \mathrm{ppm}, \mathrm{CH}_{4}=0.8 \%, \mathrm{~N}_{2}=24.7 \% \text {. }
$$

Thus, the demands to a new developed catalyst are, that it is capable of hydrogenating both $\mathrm{CO}$ and $\mathrm{CO}_{2}$ and thereby reduce the levels of these contaminants to a few $\mathrm{ppm}^{16}$.

Other places, such as in plants where caprolactam is produced, the effectiveness of the purification is even more critical, and the methanation reaction is applied since it can lower the level to less than a few $\mathrm{ppm}^{11}$. In general the reaction can find application all places where purification of hydrogen is needed in refineries and hydrogen plants. The reaction might also find application in connection with fuel cells in the future, since the hydrogen used for these cells need to be pure as well ${ }^{17}$. The above mentioned examples show that the methanation reaction is highly important in the industry for gas purification.

\subsection{Substitute natural gas}

Not only has methanation attracted interest as a way of purification, it has also gained interest as a reaction in itself where methane is formed - in the 1970's the interest began, because of a period with insufficient natural gas supplying ${ }^{18,19}$. Using the reaction it is possible to produce substitute natural gas (SNG) from naphtha and coal or alternatively bio-mass ${ }^{20}$. The idea behind is derived from the fact, that there are large reserves of coals, meaning that this can be used as an energy source for hundreds of years still. The coal can be gasified, by heating it in water vapor:

$$
\mathrm{C}+\mathrm{H}_{2} \mathrm{O} \rightarrow \mathrm{CO}+\mathrm{H}_{2}
$$

The $\mathrm{H}_{2} / \mathrm{CO}$ ratio can be increased due to the water-gas-shift reaction:

$$
\mathrm{CO}+\mathrm{H}_{2} \mathrm{O} \rightarrow \mathrm{CO}_{2}+\mathrm{H}_{2}
$$

At high temperatures the coal can react with $\mathrm{CO}_{2}$, so the concentration of $\mathrm{CO}_{2}$ is decreased:

$$
\mathrm{C}+\mathrm{CO}_{2} \rightarrow 2 \mathrm{CO}
$$


This means that syn-gas can be obtained from coal, and a methanation catalyst can then convert this gas mixture to methane. This process may receive even more attention in the future. 


\section{Catalyst development}

\subsection{Introduction}

As mentioned in chapter 2 the industrially applied catalyst is based on nickel on alumina. It has been found that both cobalt and ruthenium on a support material act as more active catalysts than nickel ${ }^{21}, 22,23,24,25,26$, but due to the price of these materials they are rarely used. The methanation reaction is well described experimentally as well as theoretically ${ }^{27}, 28,29,30,31,32,33,34$ and a lot of effort has been put into developing new and better catalyst systems ${ }^{35}$. Recently an impressive experimental high-throughput screening ${ }^{14}$ was performed to identify new catalyst leads. In this screening a number of metals on zirconia and ceria were tested for $\mathrm{CO}$ and $\mathrm{CO}_{2}$ hydrogenation in order to discover new and improved catalysts. In this section a theoretical approach to find new catalysts using density functional theory (DFT) calculations will be described.

\subsection{Finding a descriptor}

An important factor when trying to find good catalysts is to use the principle of Sabatier. This principle states that the intermediates formed on the surface of the catalyst need to be stable enough to be formed, but on the other hand not more stable than they can react to form the products $^{28}$. This means that the surface properties are very important for the catalyst performance. Theoretical work investigating the methanation reaction has suggested that the activity of this reaction is dependent on two important properties both concerning the surface of the catalyst $\mathrm{t}^{28,33}$. These two factors are respectively the CO dissociation barrier and the stability of the main intermediates which are formed on the surface, namely atomic $\mathrm{C}$ and $\mathrm{O}$. The $\mathrm{CO}$ dissociation can be described by the following reaction scheme:

$$
\mathrm{CO}+2^{*} \rightarrow \mathrm{C}^{*}+\mathrm{O}^{*}
$$

where $*$ denotes the active sites on the catalyst.

DFT calculations of these two parameters for different metal surfaces have shown that there is a linear Brønsted-Evans-Polanyi (BEP) correlation between the activation energy for CO dissociation and the adsorped $\mathrm{CO}$ dissociation energy ${ }^{34}$ as shown in Figure 3.1. This linear correlation can be explained by the $\mathrm{C}-\mathrm{O}$ bond being so extended in the transitions state under the dissociation that it is very close to the final state. That means that the bonding properties of the transition state vary like the adsorbed atomic $\mathrm{C}$ and $\mathrm{O}$. 


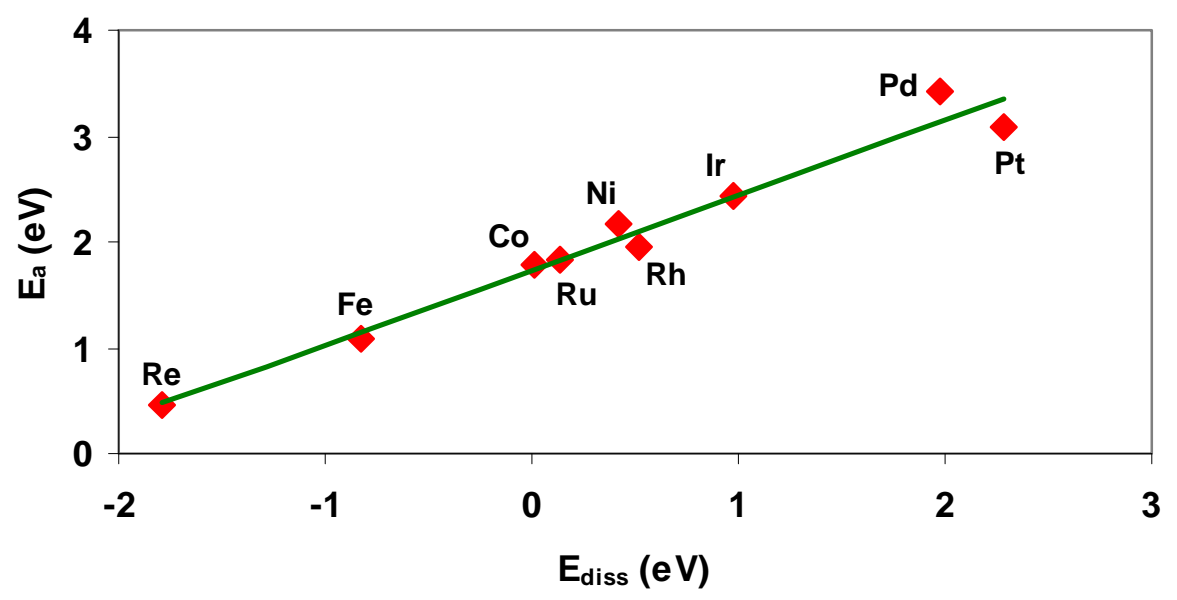

Figure 3.1 A linear correlation is observed between the activation energy $E_{a}$ of $\mathrm{CO}$ dissociation and the adsorbed $\mathrm{CO}$ dissociation energy $E_{\text {diss }}$ for different metals, meaning that a Brønsted-Evans-Polanyi relation exist between the parameters ${ }^{34}$.

Based on the established BEP relation it is meaningful to use the dissociation energy of $\mathrm{CO}$, $E_{\text {diss }}$, as a descriptor for the reactivity in the methanation reaction.

\subsection{Volcano plot}

Within the area of catalysis it is well known that it is often possible to correlate the catalytic activity with some kind of physical parameter to obtain a volcano $\operatorname{plot}^{28}$. Vulcano plots can be obtained for numerous reactions, such as the ammonia synthesis ${ }^{24,36}$, and in many different forms dependent on which parameters that have been chosen for the investigation.

The first time a volcano plot was made for the methanation reaction, the activity was plotted versus the heat of $\mathrm{CO}$ adsorption for a series of transition metals ${ }^{9}$. However, when a BEP relation is observed it is normal that a volcano plot can be obtained by plotting the catalytic activity versus the descriptor. For the methanation it means to plot the activity versus the $\mathrm{CO}$ dissociation energy. The volcano plot obtained this way is shown in Figure 3.2 where the experimentally measured activity is plotted for a series of elemental metal catalysts as a function of the dissociation energy on the most active sites of the metals ${ }^{34}$. 


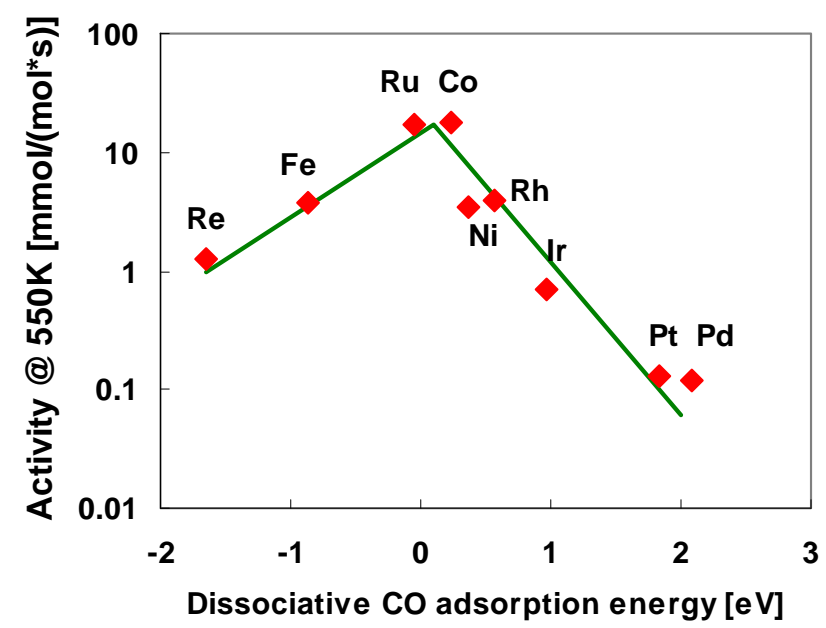

Figure 3.2 A volcano curve is found when plotting the activity in $\mathrm{CO}$ hydrogenation of different metals versus the dissociative $\mathrm{CO}$ adsorption energ $\mathrm{y}^{28}$.

For the elements on the left leg of the volcano plot, e.g. Fe, the desorption (removal of $\mathrm{C}$ and $\mathrm{O}$ from the surface to form products) is the rate determining step. The adsorption is strong for these elements. For the elements on the right leg, such as Ni, the dissociation of CO is the rate determining step (weak adsorption). At the top of the volcano optimal conditions for both desorption and adsorption are found. From the plot it is clear that cobalt and ruthenium are very active catalysts, since they are both located close to the optimum (top point) of the volcano. Furthermore it can be seen that the optimal value of the $\mathrm{CO}$ dissociation energy is close to $0.06 \mathrm{eV}$. A simple intuitive approach to find an optimized catalyst is to take one element from the left leg and combine it with one element from the right leg of the volcano. This way it could in theory be possible to obtain a bimetallic catalyst which has an overall better activity than the two monometallic catalysts. It has previously been shown by calculations, that the adsorption energy of such a mixed site, to a first order approximation, is a simple interpolation between the dissociation energy of the individual components ${ }^{34,37}$. This approach has previously been used to discover bimetallic catalysts for e.g. the ammonia synthesis reaction ${ }^{38,39}$. In order for the interpolation to work well, it is important that the two metals are in a close proximity at the surface ${ }^{40}$. 


\subsection{Pareto plot}

Recently a computational screening based on DFT calculations was performed for the methanation system using a quantitative approach to find new catalysts. The results are shown in Figure 3.3 in a so-called Pareto plot $^{34}$.

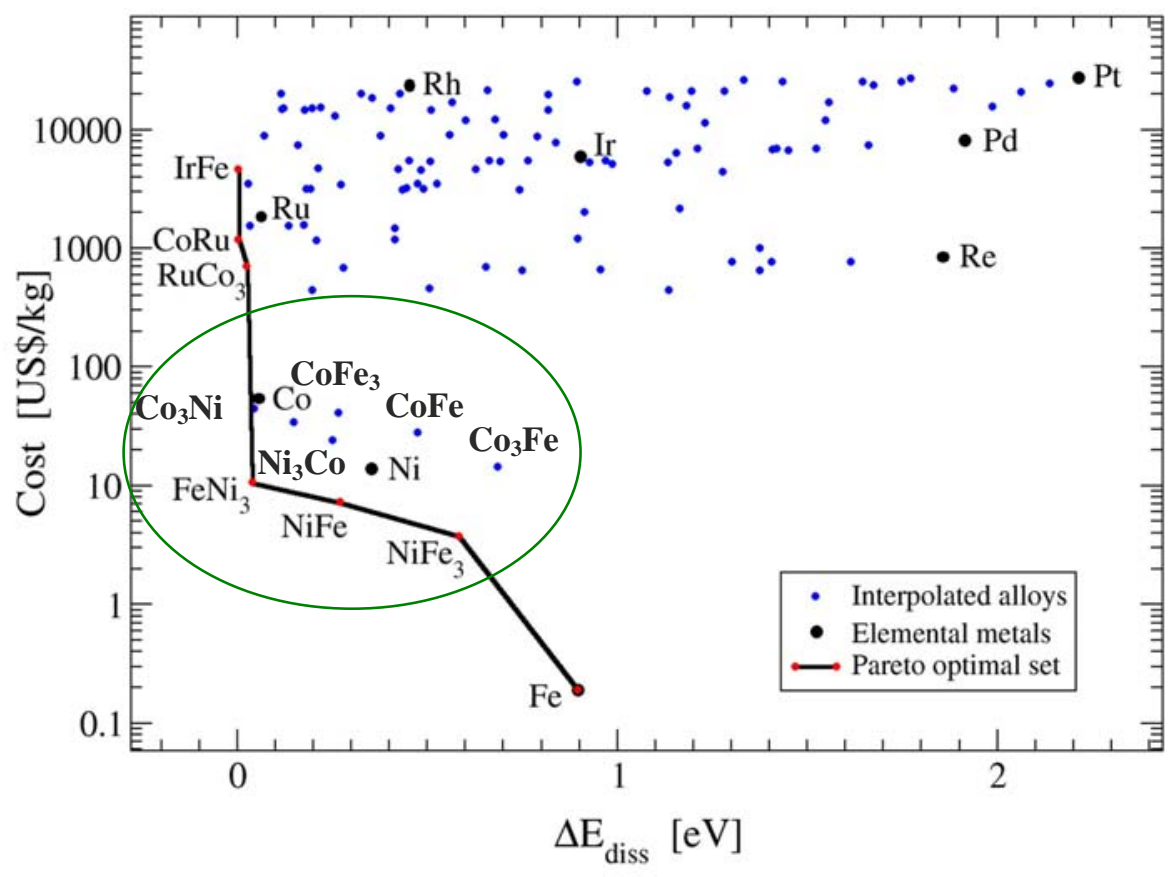

Figure 3.3 A Pareto plot ${ }^{34}$ : The cost of 117 different metals and alloys are plotted versus the catalytic activity expressed as the difference in dissociation energy for the catalytic material and the optimal dissociation energy (the optimum on the volcano plot). The green circle indicates the catalysts investigated experimentally in this thesis.

The method leading to such a plot was developed by the Italian economist Vilfredo Pareto ${ }^{41}$, and is often used within economy to show multifunctional optimizations. For the methanation reaction two parameters are optimized: the cost of the catalyst and the catalytic activity in the methanation reaction.

In Figure 3.3 the constitute cost and the interpolated descriptor for the methanation activity, $E_{\text {diss, }}$, is shown for 117 different catalytic materials. The dissociation energy is expressed as the difference between the dissociation energy of the metal/alloy investigated and the optimum found based on the volcano plot (Figure 3.2), meaning that

$$
\Delta E_{\text {diss }}(\mathrm{M})=\mid\left(E_{\text {diss }}(\mathrm{M})-E_{\text {diss }}(\text { optimal }) \mid,\right.
$$

was calculated. This means that the closer to zero $\Delta E_{\text {diss }}$ is, the better the catalyst. In the Pareto plot the electronic structure calculations on the metals were carried out using DFT calculations $^{42,43,44,45,46,47}$ on stepped metal surfaces, which are described in details 
elsewhere ${ }^{34}$. All the values for the alloys in the Pareto plot were obtained by a linear interpolation of the energies according to the concentration of the constituent elements. In the study catalysts with the composition $\mathrm{A}_{\mathrm{x}} \mathrm{B}_{1-\mathrm{x}}, \mathrm{x}=0 ; 0.25 ; 0.50 ; 0.75,1$, where $\mathrm{A}, \mathrm{B}=\mathrm{Ni}, \mathrm{Pd}$, $\mathrm{Pt}, \mathrm{Co}, \mathrm{Rh}, \mathrm{Ir}, \mathrm{Fe}, \mathrm{Ru}$, and Re, were investigated.

Several things can be noted from the Pareto plot. If a highly active catalyst is needed and price is no concern, then catalytic materials such as ruthenium and cobalt are indeed very catalytically active, and therefore a good choice. If on the other hand price is the main concern, materials such as iron are very cheep, though significantly less active than the most active metals. The industrial used nickel catalyst lies somewhere in-between these two extremes, and with respect to that it is a compromise facilitating reasonable activity at a reasonable price.

Another thing in the plot, which is worthwhile to draw the attention to, is the curve, indicating what is called the Pareto-set. The catalysts on this curve are the most optimal catalysts of those investigated, regarding both parameters. This means that it is non-dominated in the sense that it is impossible to choose another solution set which improves one parameter without making the other property worse. It is seen that this Pareto-set forms a so-called "knee" for Ni-Fe alloys making the neighboring materials in the plot considerable worse with respect to one of the parameters. The green circle in the Pareto plot indicates these nickel-iron alloys along with two other potential interesting alloy systems with high activities and reasonable prices namely the cobalt-iron and cobalt-nickel alloys. The most important conclusion from the computational screening is that nickel-iron alloys are found to be both cheaper and more catalytically active for the methanation reaction than the monometallic nickel catalyst. In fact one of the alloys, $\mathrm{Ni}: \mathrm{Fe}=3: 1$ should even have activities close to those of cobalt and ruthenium. This confirms that the simple qualitative approach mentioned above by combining one element from the left leg (iron) with an element from the right leg (nickel) of the volcano plot can give suggestions for good bimetallic catalysts.

\subsection{Other catalytic applications for the alloy systems}

In order to put the results from the computational screening in perspective, it can be noted that the three bimetallic systems, $\mathrm{Ni}-\mathrm{Fe}, \mathrm{Co}-\mathrm{Ni}$, and $\mathrm{Co}-\mathrm{Fe}$, marked in the green circle in the Pareto plot, previously have been found experimentally to show higher catalytic activity for the Fischer-Tropsch process than the corresponding monometallic catalysts ${ }^{48}$. However, in 
that case the promotion of the cobalt catalyst with iron is known to change the product distribution towards small olefins, $\mathrm{C}_{2}-\mathrm{C}_{4}{ }^{49,50,51}$. Moreover, in connection with these studies it was found that the bimetallic systems often have completely different $\mathrm{CO}$ and hydrogen adsorption properties. It has also been reported that the reduction of the bimetallic $\mathrm{Ni}-\mathrm{Fe}$ and Co-Fe catalysts, takes place at significantly lower temperatures than for the pure metals ${ }^{48,52}$. Nickel-iron alloys are also known to have good catalytic properties for partial oxidation of methane to syn-gas ${ }^{53}$, and the alloys have been tested for other hydrogenation reactions with carbon-containing compounds, such as benzene hydrogenation ${ }^{54}$ and $\mathrm{CO}_{2}$ hydrogenation ${ }^{55}$ with varying success. Despite these previous investigations of the Ni-Fe alloy system for other catalytic reactions, its activity toward the methanation reaction has not been discovered prior to the recent computational screening. 


\section{$4 \mathrm{CO}$ hydrogenation using Ni-Fe catalysts}

\subsection{Introduction}

Based on the computational screening a preliminary series of experiments have been performed to experimentally verify that Ni-Fe alloys show higher catalytic activity than a monometallic nickel catalyst ${ }^{34}$. In this chapter a more detailed study of the Ni-Fe system will be given. Parameters investigated for the $\mathrm{CO}$ hydrogenation are the iron-nickel ratio, the influence of the total metal loading, the temperature, and the support material.

\subsection{Catalyst preparation}

Series of catalysts on two different support materials were prepared, namely on spinel, $\mathrm{MgAl}_{2} \mathrm{O}_{4}$, and alumina, $\mathrm{Al}_{2} \mathrm{O}_{3}$, with surface areas of respectively $70 \mathrm{~m}^{2} / \mathrm{g}$ and $194 \mathrm{~m}^{2} / \mathrm{g}$. Prior to use, the support material was fractionized to obtain a $250-500 \mu \mathrm{m}$ particle size and dried at $200{ }^{\circ} \mathrm{C}$ for $5 \mathrm{~h}$. The pore volume was determined by impregnation with water to be respectively $0.7 \mathrm{ml} / \mathrm{g}$ and $0.6 \mathrm{ml} / \mathrm{g}$. Ni, Fe, and $\mathrm{Ni}-\mathrm{Fe}$ alloy catalysts were prepared with incipient wetness impregnation with aqueous solutions of nickel(II) nitrate and/or iron(III) nitrate. Catalysts with different total metal loading ranging from $2.5-30 \mathrm{wt} \%$ were prepared and the main focus was put on catalysts with the following compositions: $\mathrm{Ni}, \mathrm{Ni}: \mathrm{Fe}=3: 1$, $\mathrm{Ni}: \mathrm{Fe}=1: 1, \mathrm{Ni}: \mathrm{Fe}=1: 3$, and $\mathrm{Fe}$. After the impregnation the materials were allowed to stand in a closed system for $4 \mathrm{~h}$ in order for the solution to homogenously fill the pores of the support. The catalysts were then dried at room temperature for $12 \mathrm{~h}$, followed by heating them at $120{ }^{\circ} \mathrm{C}$ for $1 \mathrm{~h}$. For the catalysts with high metal loadings repetitive impregnations were performed. Finally the catalysts were calcined in air at $450{ }^{\circ} \mathrm{C}$ for $4 \mathrm{~h}$ after heating with a ramp of $2.5^{\circ} \mathrm{C} / \mathrm{min}$. After the calcination the catalysts were cooled to room temperature.

\subsection{Activity tests}

A typical catalytic activity test was performed by placing $150 \mathrm{mg}$ of catalyst in a quartz Utube plug flow reactor between two layers of quartz wool. The catalyst was reduced in-situ prior to the activity test. The reduction took place by heating the catalyst for $4 \mathrm{~h}$ at $500{ }^{\circ} \mathrm{C}$ in a flow $(100 \mathrm{ml} / \mathrm{min})$ of $2 \% \mathrm{CO}$ in $\mathrm{H}_{2}$ at atmospheric pressure. After the reduction the temperature was lowered to the reaction temperature, typically between 200 and $300{ }^{\circ} \mathrm{C}$, at a pressure of 1 bar, in the same gas composition and with the same space velocity as during the 
reduction. At each temperature tested, the conversion and selectivity was monitored for at least $1 \mathrm{~h}$ to insure stable catalyst performance. All temperatures were measured using an internal thermocouple.
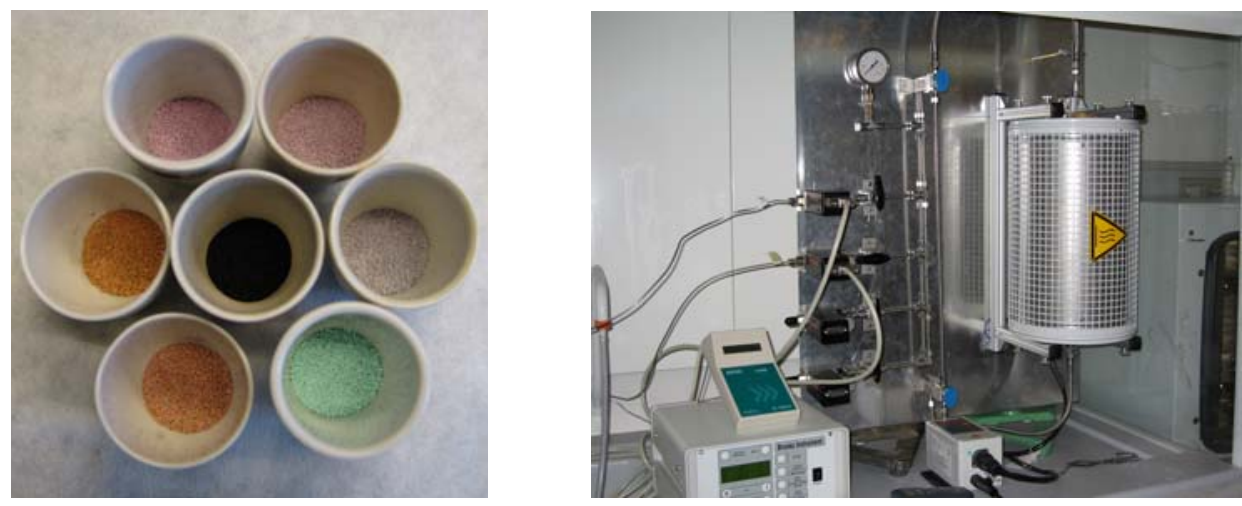

Figure 4.1 Nickel, iron, cobalt, and bimetallic catalysts before calcination are shown standing around one calcined sample (left). One of the three activity test set-up used for the methanation experiments in this study (right).

The exit gas was analyzed using a Shimadzu Gas Chromatograph (GC) equipped with a thermal conductivity detector (TCD) and a flame ionization detector (FID). To calculate the conversions of the catalysts the $\mathrm{CO}$ concentration was monitored at room temperature where the catalyst was inactive and no conversion took place.

\subsection{Characterization}

The catalysts were characterized using elemental analysis, $\mathrm{N}_{2}$ physisorption measurements, XRD, and TEM.

\subsubsection{Elemental analysis}

The elemental analyses were performed using atomic absorption spectroscopy (AAS). Solutions of the samples were made by dissolving a known amount of catalyst in concentrated $\mathrm{HNO}_{3}$ and diluting this with water in order to obtain metal concentrations of 1-7 mg/l. Standard solutions of nickel and iron in weakly acidic aqueous solutions were used for calibration. The AAS analyses were performed on a Perkin Elmer Analyst 100 atomic adsorption spectrophotometer.

\subsubsection{XRD}

X-ray powder diffraction (XRD) patterns were collected by a Philips powder diffractometer with Ni-filtered $\mathrm{Cu}-\mathrm{K}_{\alpha}$ radiation. The scans were performed in the region of $2 \theta=20-70^{\circ}$. 
Prior to the measurements all samples were reduced ex-situ in a flow of $50 \mathrm{ml} / \mathrm{min}$ hydrogen at $500{ }^{\circ} \mathrm{C}$ for $2 \mathrm{~h}$.

\subsection{3 $\quad \mathbf{N}_{2}$-physisorption}

$\mathrm{N}_{2}$-physisorption measurements were performed on a Micromeritics ASAP 2020 analyzer. All measurements were carried out at liquid nitrogen temperature after the samples were evacuated at $200{ }^{\circ} \mathrm{C}$ for $1 \mathrm{~h}$. The Brunauer, Emmet and Teller (BET) method was used to calculate the total surface areas.

\subsubsection{TEM}

Transmission electron microscopy (TEM) was performed on a JEOL 3000 transmission electron microscope with an energy of $300 \mathrm{keV}$. The samples were prepared in the same way as the samples used for XRD by an ex-situ reduction. The reduced samples were mixed with ethanol and mortared. The obtained suspension was placed on a carbon film (300 mesh copper grid) and dried prior to the measurement.

\subsection{Results and discussion}

\subsubsection{Characterization}

The results from the metal analysis by AAS are summarized in Table 4.1 along with the surface areas found by the $\mathrm{N}_{2}$ physisorption measurements. The first column shows the total amount of metal and the catalyst composition aimed for in the preparation.

From the table it is seen that the metal contents of iron, nickel, and in total in all cases are in accordance with the amount aimed for by the preparation.

The BET analysis was used to investigate the effect of different metal loadings on the surface areas. A significant decrease in the surface area is found for metal loadings of $25 \mathrm{wt} \%$ or more on spinel. This suggests that the formations of large oxide aggregates are limiting the access to the internal surface for these catalysts. For the catalysts prepared with $20 \mathrm{wt} \%$ metal or less no significant decrease is observed indicating that no physical blocking of the support surface with metal containing particles takes place. 
Table 4.1 The metal content and surface areas determined by $\mathrm{N}_{2}$ physisorption is shown for different Ni-Fe catalysts.

\begin{tabular}{|c|c|c|c|c|}
\hline \multirow{2}{*}{ Catalyst } & \multicolumn{3}{|c|}{ Metal content } & \multirow{2}{*}{$S_{\mathrm{BET}}, \mathrm{m}^{2} / \mathrm{g}$} \\
\hline & $\mathrm{Ni}[\%]$ & $\mathrm{Fe}[\%]$ & Total $[\%]$ & \\
\hline $2.5 \mathrm{wt} \% 100 \mathrm{Fe} / \mathrm{MgAl}_{2} \mathrm{O}_{4}$ & $\begin{array}{l}--- \\
\end{array}$ & 2.51 & 2.51 & 69 \\
\hline $2.5 \mathrm{wt} \% 25 \mathrm{Ni} 75 \mathrm{Fe} / \mathrm{MgAl}_{2} \mathrm{O}_{4}$ & 0.65 & 1.87 & 2.52 & 68 \\
\hline $2.5 \mathrm{wt} \% 50 \mathrm{Ni} 50 \mathrm{Fe} / \mathrm{MgAl}_{2} \mathrm{O}_{4}$ & 1.39 & 1.41 & 2.79 & 71 \\
\hline $2.5 \mathrm{wt} \% 75 \mathrm{Ni} 25 \mathrm{Fe} / \mathrm{MgAl}_{2} \mathrm{O}_{4}$ & 1.88 & 0.53 & 2.41 & 69 \\
\hline $2.5 \mathrm{wt} \% 100 \mathrm{Ni} / \mathrm{MgAl}_{2} \mathrm{O}_{4}$ & 2.86 & --- & 2.86 & 69 \\
\hline $10 \mathrm{wt} \% 100 \mathrm{Fe} / \mathrm{MgAl}_{2} \mathrm{O}_{4}$ & --- & 9.79 & 9.79 & 69 \\
\hline $10 \mathrm{wt} \% 25 \mathrm{Ni} 75 \mathrm{Fe} / \mathrm{MgAl}_{2} \mathrm{O}_{4}$ & 2.59 & 7.97 & 10.56 & 67 \\
\hline $10 \mathrm{wt} \% 50 \mathrm{Ni} 50 \mathrm{Fe} / \mathrm{MgAl}_{2} \mathrm{O}_{4}$ & 4.96 & 4.94 & 9.9 & 67 \\
\hline $10 \mathrm{wt} \% 75 \mathrm{Ni} 25 \mathrm{Fe} / \mathrm{MgAl}_{2} \mathrm{O}_{4}$ & 7.65 & 2.15 & 9.79 & 62 \\
\hline $10 \mathrm{wt} \% 100 \mathrm{Ni} / \mathrm{MgAl}_{2} \mathrm{O}_{4}$ & 9.98 & --- & 9.98 & 63 \\
\hline $5 \mathrm{wt} \% 75 \mathrm{Ni} 25 \mathrm{Fe} / \mathrm{MgAl}_{2} \mathrm{O}_{4}$ & 3.66 & 1.18 & 4.84 & 69 \\
\hline $15 \mathrm{wt} \% 75 \mathrm{Ni} 25 \mathrm{Fe} / \mathrm{MgAl}_{2} \mathrm{O}_{4}$ & 11.58 & 3.76 & 15.34 & 65 \\
\hline $20 \mathrm{wt} \% 75 \mathrm{Ni} 25 \mathrm{Fe} / \mathrm{MgAl}_{2} \mathrm{O}_{4}$ & 14.93 & 4.90 & 19.83 & 67 \\
\hline $25 \mathrm{wt} \% 75 \mathrm{Ni} 25 \mathrm{Fe} / \mathrm{MgAl}_{2} \mathrm{O}_{4}$ & 17.89 & 6.12 & 24.01 & 57 \\
\hline $30 \mathrm{wt} \% 75 \mathrm{Ni} 25 \mathrm{Fe} / \mathrm{MgAl}_{2} \mathrm{O}_{4}$ & 22.63 & 8.04 & 30.67 & 53 \\
\hline $10 \mathrm{wt} \% 100 \mathrm{Fe} / \mathrm{Al}_{2} \mathrm{O}_{3}$ & --- & 10.18 & 10.18 & 185 \\
\hline $10 \mathrm{wt} \% 25 \mathrm{Ni} 75 \mathrm{Fe} / \mathrm{Al}_{2} \mathrm{O}_{3}$ & 2.52 & 7.65 & 10.17 & 182 \\
\hline $10 \mathrm{wt} \% 50 \mathrm{Ni} 50 \mathrm{Fe} / \mathrm{Al}_{2} \mathrm{O}_{3}$ & 5.14 & 4.93 & 10.07 & 172 \\
\hline $10 \mathrm{wt} \% 75 \mathrm{Ni} 25 \mathrm{Fe} / \mathrm{Al}_{2} \mathrm{O}_{3}$ & 7.77 & 2.30 & 10.07 & 177 \\
\hline $10 \mathrm{wt} \% 100 \mathrm{Ni} / \mathrm{Al}_{2} \mathrm{O}_{3}$ & 9.95 & --- & 9.95 & 176 \\
\hline
\end{tabular}


Examination of the XRD analysis shows that samples which contain less than or equal to $5 \mathrm{wt} \%$ have no observable diffraction peaks from the metals and all peaks are attributed to the support material. The XRD patterns for samples containing $10 \mathrm{wt} \%$ metals have been studied in more detail. Diffractograms showing a sample containing monometallic nickel and iron as well as an alloy catalyst with the ratio of the two metals given by $\mathrm{Ni}: \mathrm{Fe}=1: 1$ on spinel are shown in Figure 4.2.

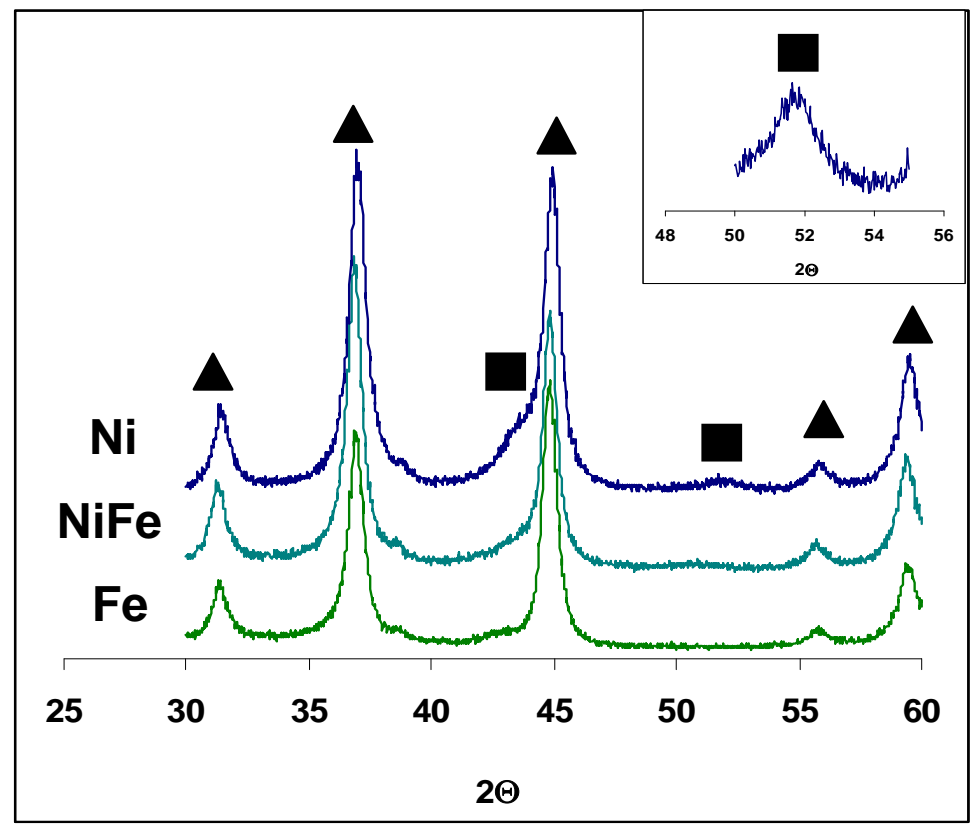

Figure 4.2 XRD patterns of Ni/spinel, $\mathrm{Fe} /$ spinel and $\mathrm{Ni}: \mathrm{Fe}=1: 1 /$ spinel. The triangles indicate the peaks from the support materials, while the squares indicate the peaks from nickel.

The diffraction peaks originating from spinel are indicated with black triangles. The pattern for monometallic nickel is indicated by black squares over the peaks and this clearly shows the diffraction peaks expected for the bulk nickel phase. The Scherrer equation ${ }^{6}$ can be used to determine the crystal size, $l$ :

$$
l=k^{*} \lambda /\left(\beta^{*} \cos \theta\right),
$$

where $k$ is a constant, $\lambda$ is the wavelength of the $\mathrm{X}$-ray, $\beta$ is the width of the peak and $\theta$ is the angel between the beam and the normal to the plane of the reflecting light.

By using the Scherrer equation for the peak at $2 \theta \sim 51^{\circ}$ it is possible to determine the particle size of nickel to $13-15 \mathrm{~nm}$. The XRD pattern for monometallic iron is strongly complicated by the fact that the support material and the bulk iron phase are reflecting at similar angels (at $2 \theta$ $\sim 38^{\circ}$ ). From the XRD diffractogram for the $\mathrm{Ni}: \mathrm{Fe}=1: 1$ alloy, this sample is found to have peaks at the same angles as for nickel but with much lower intensities, making it impossible to determine the particle size. 
TEM images of catalysts with different nickel-iron ratios on spinel were studied. In Figure 4.3 three representative images are shown - one of nickel, one of iron, and one alloy with the composition $\mathrm{Ni}: \mathrm{Fe}=3: 1$.
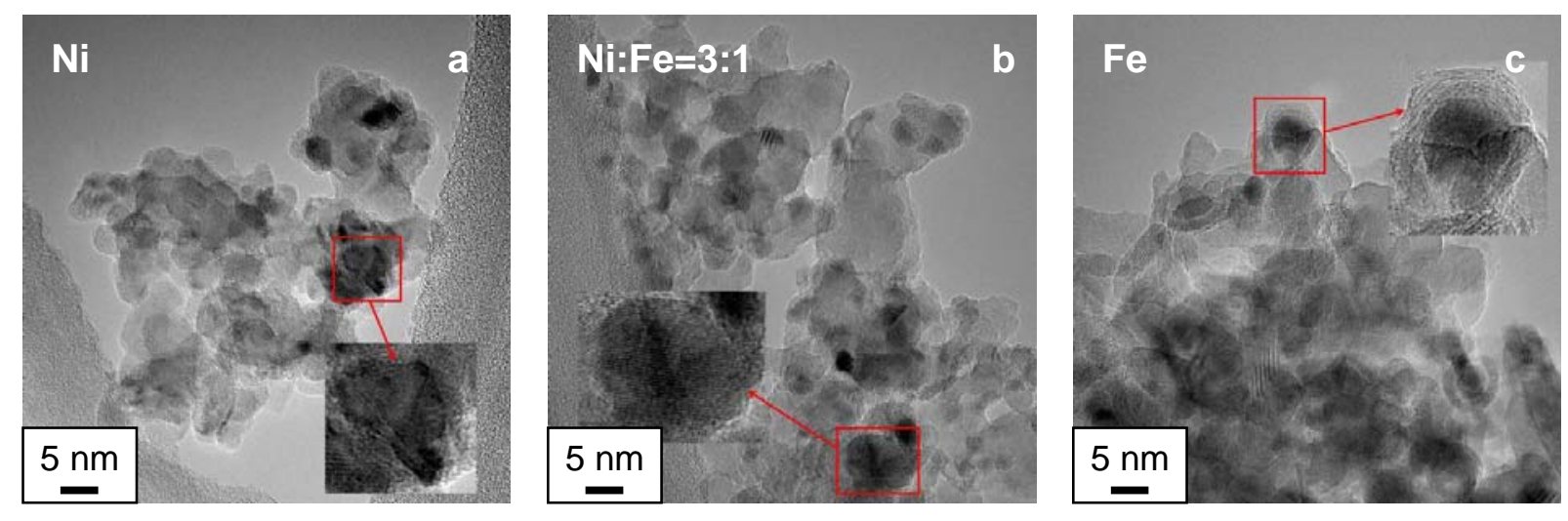

Figure 4.3 TEM images of a) Ni/spinel b) Ni:Fe=3:1/spinel c) Fe/spinel.

From these pictures it can be concluded that the particle sizes are quite similar for the monometallic nickel, iron, and the alloys. The particle sizes seem to be around 8-12 nm, which is in good agreement with the size found using XRD and the Scherrer equation for the nickel sample. The TEM image of iron on spinel is a bit different than the other images due to the formation of a thin oxide layer on top of the bulk metal. This is expected since iron is known to re-oxidize easily when exposed to air, which take place to some extend since the TEM images was recorded on an ex-situ reduced sample. However, the catalysts seem to exhibit rather similar dispersions which makes it fair to compare the catalytic activities, by normalizing the reaction rate to the metal content without having to take particle size effects into account.

\subsubsection{Alloy formation}

As mentioned in chapter 3 it is critical that the two metals are in close proximity at the surface, in order to obtain a catalyst with improved catalytic activity compared to the monometallic catalysts. One way to see if it is possible to get the metals in close proximity of each other, is to determine whether an alloy can be formed between the different metals or not. A phase diagram ${ }^{56}$ for nickel and iron indicates that nickel and iron at least forms one alloy, namely the alloy with the composition $\mathrm{Ni}: \mathrm{Fe}=3: 1$. Other irregular bulk alloys such as $\mathrm{Ni}: \mathrm{Fe}=1: 1, \mathrm{Ni}: \mathrm{Fe}=3: 2$, and $\mathrm{Ni}: \mathrm{Fe}=2: 1$ has been reported in the literature as well ${ }^{57}$. 
It is not possible to demonstrate whether an alloy is formed or not using XRD nor TEM, since these two analysis methods show only partial particle morphology. Previously a Mössbauer spectroscopy study has been reported in literature ${ }^{58}$, showing that nickel and iron actually form alloys under conditions similar to those used in this experimental work. Based on this it is reasonable to assume that the bimetallic Ni-Fe systems prepared in this study most likely contain a range of metal particles with different nickel-iron ratios. Furthermore it was concluded from the Mössbauer spectroscopy study, that the formation of the alloys is closely connected with the reducibility of the initial metal oxide in the system.

The melting points for iron, nickel, and the alloys are very similar $\left(1440-1538{ }^{\circ} \mathrm{C}\right)^{56}$, which implies that the Tamman temperatures (defined as the half of the melting temperature) are the same. This means that the surface migration and aggregation phenomenon for the catalysts can be considered to be within the same range. Therefore the catalyst activities can be compared without taking these parameters into account, assuming that alloys are formed.

\subsubsection{Activity data}

\subsubsection{Comparison of support materials}

Experiments were performed with pure support materials, both alumina and spinel, to insure that the catalytic activity for CO hydrogenation of these were negligible.

Based on the activity measurements of the metal containing catalysts the activity rate, $r$, was calculated as moles of $\mathrm{CO}$ converted per moles of metal per second:

$$
r=X_{c o} * F_{c o} / n_{\text {cat }},
$$

where $X_{C O}$ is the fractional conversion of $\mathrm{CO}, F_{C O}$ is the molar feed rate of $\mathrm{CO}(\mathrm{mol} / \mathrm{s})$, and $n_{\text {cat }}$ is the total molar amount of metal in the catalyst.

Different parameters were investigated with respect to catalytic activity. In Figure 4.4 a plot is shown where two different support materials (alumina and spinel) are compared along with two different metal loadings ( 2.5 and $10 \mathrm{wt} \%$ ) on spinel at $225{ }^{\circ} \mathrm{C}$. In the case of alumina only the data for $10 \mathrm{wt} \%$ metal are shown, since the $\mathrm{CO}$ conversion on the catalysts containing $2.5 \mathrm{wt} \%$ metal on alumina is almost negligible (more than a factor 10 smaller than for the corresponding spinel-based catalyst). This can be explained by the difference in the reduction profiles of the metals on the different supports ${ }^{57}$. In these plots the activity is plotted as a function of the catalyst composition expressed as the percentage of $\mathrm{Ni}$ out of the total amount of impregnated metal on the support material. 


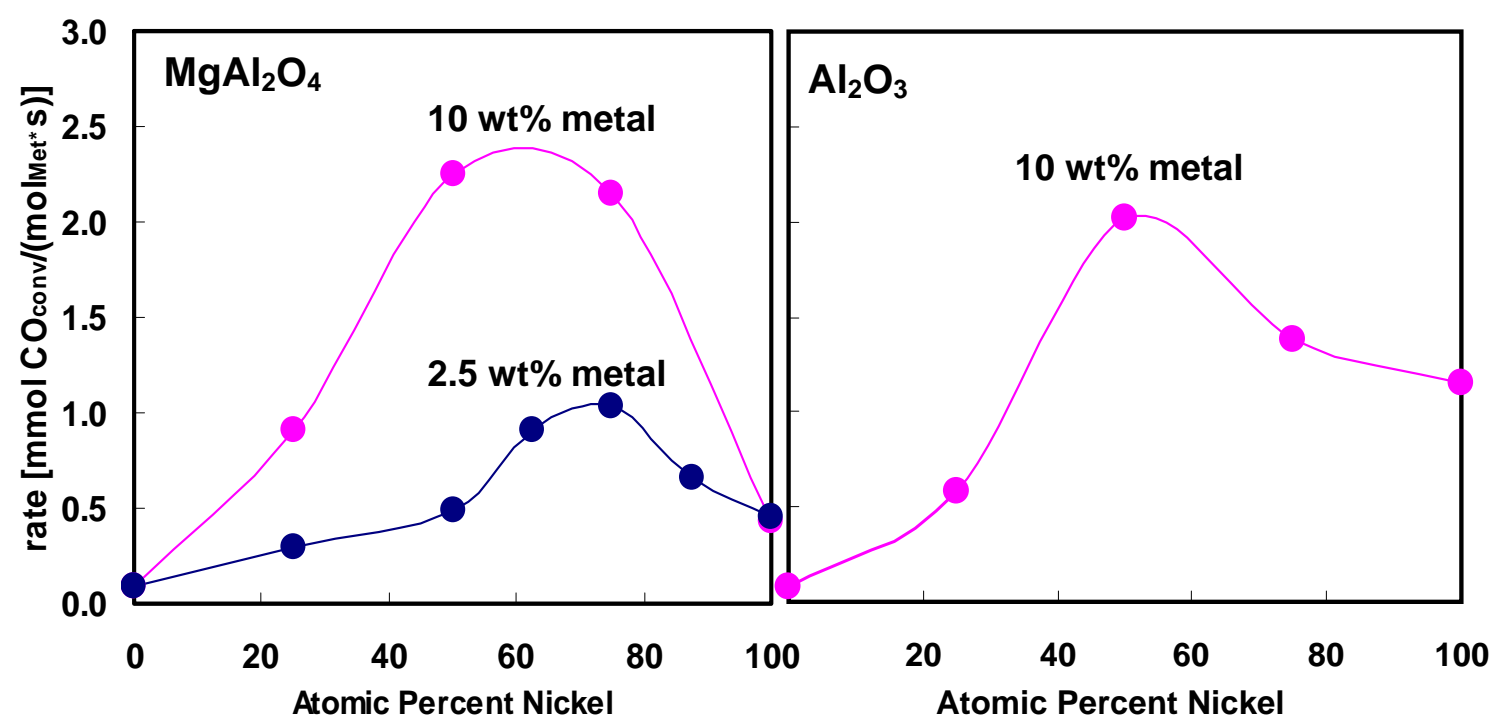

Figure 4.4 Catalytic conversion for the Ni-Fe system at $225{ }^{\circ} \mathrm{C}$. The left figure shows catalysts with 2.5 and $10 \mathrm{wt} \%$ metal loadings on spinel, while the right figure shows catalysts with $10 \mathrm{wt} \%$ metal on alumina. For the series with $2.5 \mathrm{wt} \%$ metal a few extra nickel-iron ratios has been included. In all cases, the rate is plotted versus the atomic percent nickel out of the total metal content in the catalyst.

In all cases a maximum in catalytic activity is obtained with an alloy catalyst. The position of the maximum is slightly dependent on the support and total metal loading, and is changing between $\mathrm{Ni}: \mathrm{Fe}=3: 1$ and $\mathrm{Ni}: \mathrm{Fe}=1: 1$. When the catalysts are prepared on spinel and has a low metal content, the optimum is found for $\mathrm{Ni}: \mathrm{Fe}=3: 1$, while the $\mathrm{Ni}: \mathrm{Fe}=1: 1$ is the optimum for higher metal loadings on both spinel and alumina. It should of course be noted that both of these catalysts are close in metal-to-metal ratio to the stoichiometry of the regular well-known alloy, $\mathrm{Ni}: \mathrm{Fe}=3: 1$, mentioned earlier. The same trend is noticed at all other examined temperatures in the interval from $200-300{ }^{\circ} \mathrm{C}$. These results show that the interpolation concept and computational screening works in general with different metal concentrations and support materials for the Ni-Fe system.

The monometallic nickel catalyst is found to be more active than the monometallic iron catalyst in these experiments. This is somewhat surprising when comparing to the volcano plot (Figure 3.2), where nickel and iron seem to be equally good. This might be explained with a different $\mathrm{CO} / \mathrm{H}_{2}$ ratio in the two series of experiments (those described here, and those shown in the volcano plot). Alternatively it can be due to a difference in the degree of reduction, sintering or other physical reasons.

Finally, it should be mentioned that by increasing the temperature all catalysts will reach $100 \%$ CO conversion (within the uncertainty in the GC measurements), as needed in order 
for the catalysts to be attractive for gas purifications. However, the temperature needed to achieve $100 \%$ conversion varies for the catalysts dependent on the metal composition. In order to compare the catalyst activity temperatures have been chosen in an interval where most of the catalysts exhibit activity but without achieving full conversion.

In Table 4.2 a number of selected $\mathrm{CO}$ conversions along with selectivity data are summarized at two different temperatures, 225 and $250^{\circ} \mathrm{C}$.

Table 4.2 CO conversions and methane selectivities at 225 and $250{ }^{\circ} \mathrm{C}$ for the Ni-Fe catalysts with 2.5 and $10 \mathrm{wt} \%$ metal on spinel and alumina.

\begin{tabular}{|c|c|c|c|c|}
\hline \multirow{2}{*}{ Catalyst } & \multicolumn{2}{|c|}{ CO Conversion, \% } & \multicolumn{2}{|c|}{ Selectivity to $\mathrm{CH}_{4}, \%$} \\
\hline & $225^{\circ} \mathrm{C}$ & $250^{\circ} \mathrm{C}$ & $225^{\circ} \mathrm{C}$ & $250{ }^{\circ} \mathrm{C}$ \\
\hline $2.5 \mathrm{wt} \% 100 \mathrm{Fe} / \mathrm{MgAl}_{2} \mathrm{O}_{4}$ & $<0.1$ & 0.23 & --- & 58.5 \\
\hline $2.5 \mathrm{wt} \% 25 \mathrm{Ni} 75 \mathrm{Fe} / \mathrm{MgAl}_{2} \mathrm{O}_{4}$ & $<0.1$ & 3.7 & --- & 76 \\
\hline $2.5 \mathrm{wt} \% 50 \mathrm{Ni} 50 \mathrm{Fe} / \mathrm{MgAl}_{2} \mathrm{O}_{4}$ & 2.3 & 7.2 & 82.1 & 91.2 \\
\hline $2.5 \mathrm{wt} \% 75 \mathrm{Ni} 25 \mathrm{Fe} / \mathrm{MgAl}_{2} \mathrm{O}_{4}$ & 5.6 & 14.3 & 86.6 & 92.4 \\
\hline $2.5 \mathrm{wt} \% 100 \mathrm{Ni} / \mathrm{MgAl}_{2} \mathrm{O}_{4}$ & 0.9 & 7.2 & 85.3 & 97.6 \\
\hline $10 \mathrm{wt} \% 100 \mathrm{Fe} / \mathrm{MgAl}_{2} \mathrm{O}_{4}$ & 1.6 & 4.4 & 55.7 & 68.1 \\
\hline $10 \mathrm{wt} \% 25 \mathrm{Ni} 75 \mathrm{Fe} / \mathrm{MgAl}_{2} \mathrm{O}_{4}$ & 16.3 & 39.0 & 75.7 & 85.3 \\
\hline $10 \mathrm{wt} \% 50 \mathrm{Ni} 50 \mathrm{Fe} / \mathrm{MgAl}_{2} \mathrm{O}_{4}$ & 40.5 & 95.4 & 85.5 & 92.9 \\
\hline $10 \mathrm{wt} \% 75 \mathrm{Ni} 25 \mathrm{Fe} / \mathrm{MgAl}_{2} \mathrm{O}_{4}$ & 38.6 & 99.5 & 90.7 & 96.4 \\
\hline $10 \mathrm{wt} \% 100 \mathrm{Ni} / \mathrm{MgAl}_{2} \mathrm{O}_{4}$ & 8.0 & 34.6 & 84.8 & 94.2 \\
\hline $10 \mathrm{wt} \% 100 \mathrm{Fe} / \mathrm{Al}_{2} \mathrm{O}_{3}$ & 1.4 & 4.3 & 85.5 & 88.6 \\
\hline $10 \mathrm{wt} \% 25 \mathrm{Ni} 75 \mathrm{Fe} / \mathrm{Al}_{2} \mathrm{O}_{3}$ & 11.1 & 27.4 & 88.9 & 90.2 \\
\hline $10 \mathrm{wt} \% 50 \mathrm{Ni} 50 \mathrm{Fe} / \mathrm{Al}_{2} \mathrm{O}_{3}$ & 38.2 & 99.5 & 96.1 & 98.6 \\
\hline $10 \mathrm{wt} \% 75 \mathrm{Ni} 25 \mathrm{Fe} / \mathrm{Al}_{2} \mathrm{O}_{3}$ & 25.6 & 85.8 & 97.5 & 98.8 \\
\hline $10 \mathrm{wt} \% 100 \mathrm{Ni} / \mathrm{Al}_{2} \mathrm{O}_{3}$ & 21.1 & 72.5 & 96.0 & 98.9 \\
\hline
\end{tabular}


The methane selectivity for the nickel catalyst and the alloy catalysts are found to be as high as $90-99 \%$ when the conversion is above $50 \%$. The iron catalyst shows significant lower methane selectivity. Furthermore, the selectivity increases as the percentage of nickel in the catalyst is increased.

Except from methane the only products observed are small hydrocarbons, $\mathrm{C}_{2}-\mathrm{C}_{4}$. From the data comparison it can be noticed that the selectivity towards methane increases as the $\mathrm{CO}$ conversion increases. This fact indicates that methane is the primary stable reaction product under the reaction conditions used.

\subsubsection{Dependence on the metal loading}

A systematic study of the effect of the metal loading was performed on a series of catalysts on spinel, with a ratio of nickel and iron given by $\mathrm{Ni}: \mathrm{Fe}=3: 1$. This was done in order to optimize the metal loading. The activity and selectivity data for these experiments at $275{ }^{\circ} \mathrm{C}$ are summarized in Table 4.3.

Table 4.3 CO conversion and methane selectivity at $275^{\circ} \mathrm{C}$ for $\mathrm{Ni}: \mathrm{Fe}=3: 1$ catalysts with different total metal loading.

\begin{tabular}{|c|c|c|c|c|}
\hline \multirow{2}{*}{$\begin{array}{l}\text { Total metal } \\
\text { loading, wt } \%\end{array}$} & \multicolumn{2}{|c|}{$\begin{array}{l}\text { Metal content in the } \\
\text { catalyst, wt } \%\end{array}$} & \multirow{2}{*}{$\begin{array}{c}\mathrm{CO} \\
\text { conversion, \% }\end{array}$} & \multirow{2}{*}{$\begin{array}{l}\text { Selectivity to } \\
\qquad \mathrm{CH}_{4}, \%\end{array}$} \\
\hline & $\mathrm{Ni}$ & $\mathrm{Fe}$ & & \\
\hline 2.41 & 1.88 & 0.53 & 24.3 & 92.8 \\
\hline 4.84 & 3.66 & 1.18 & 37.6 & 93.6 \\
\hline 9.79 & 7.65 & 2.15 & 95.8 & 97.4 \\
\hline 15.34 & 11.58 & 3.76 & 98.7 & 98.3 \\
\hline 19.83 & 14.93 & 4.90 & 100.0 & 99.1 \\
\hline 24.01 & 17.89 & 6.12 & 96.3 & 98.7 \\
\hline 30.67 & 22.63 & 8.04 & 2.9 & 83.0 \\
\hline
\end{tabular}


The Ni:Fe $=3: 1$ catalysts were studied at different temperatures, and in all cases it was found that the activity of the methanation increases with increasing metal loading up to a total loading of $20 \mathrm{wt} \%$ metal. At metal loadings higher than that ( $25 \mathrm{wt} \%$ and $30 \mathrm{wt} \%$ ) the activity decreased as seen in Table 4.3 at $275{ }^{\circ} \mathrm{C}$. This can be explained by blocking of the external surface. This explanation is supported by the BET data, which showed a significant decrease in the surface area for the two catalysts with the loadings of $25 \mathrm{wt} \%$ and $30 \mathrm{wt} \%$ (approximately $55 \mathrm{~m}^{2} / \mathrm{g}$ ) compared to the other catalysts (approximately $67 \mathrm{~m}^{2} / \mathrm{g}$ ) as it was shown in Table 4.1.

In connection to the role of the metal content, it is worthwhile to consider the influence of this parameter on the reducibility of the metal oxides as well as the possibilities for unwanted incorporation of the metal into the support material. It has been reported in the literature ${ }^{59}$ for nickel on alumina (prepared by impregnation), that no nickel was incorporated into the support material framework at reduction temperatures below $700{ }^{\circ} \mathrm{C}$. For all nickel loadings examined in this literature study, the reduction was found to begin at $250{ }^{\circ} \mathrm{C}$ and to be finished below $700{ }^{\circ} \mathrm{C}$. In another study ${ }^{57}$ nickel catalysts with different loadings on spinel were examined. It was reported that the reduction temperature was shifted $100{ }^{\circ} \mathrm{C}$ towards lower temperatures as the metal loading was increased from $1 \mathrm{wt} \%$ to $15 \mathrm{wt} \%$. This might be explained by difference in particle size dependent on the loading - small particles (e.g. formed when the metal loading is low) are more difficult to reduce than larger particles and thereby requiring higher reduction temperature ${ }^{60,61}$. The same could be an issue in the series of catalysts studied in this thesis: since none of the $2.5 \mathrm{wt} \%$ metal containing catalysts show peaks in XRD, it can be assumed that these particles are too small to be observed due to broad peaks of low intensity. It should be noted, that the reason for these metals not to be detected by XRD alternatively can be ascribed to the small amount of the metal species being below the detectable level. However, it is likely that the degree of reduction at $500{ }^{\circ} \mathrm{C}$ is highest for the sample with higher loading ${ }^{58,62}$. At the same time the amount of potential active sites are increased as the loading is increased. This leads to higher activities of these catalysts, until the loading is so high that physical blocking takes place. In the literature study of nickel on spinel ${ }^{57}$ it was also found that no significant amount of $\mathrm{NiAl}_{2} \mathrm{O}_{4}$ was formed. These results from the literature indicate that incorporation of nickel in the structure of the support material is most likely not a problem for the catalyst systems on alumina and spinel examined in this study. 
Finally it should be mentioned that the same trend in selectivity, as in the other experiments is seen: when the conversion of CO increases, the selectivity towards methane increases as well.

\subsubsection{Activation energy and Arrhenius plot}

Arrhenius plots for catalysts with different Ni:Fe ratio and a total metal loading of $2.5 \mathrm{wt} \%$ on spinel are drawn using the Arrhenius equation:

$$
\ln (r)=\ln \left(r_{0}\right)-E_{A} / R * 1 / T
$$

where $r$ is the rate $\left(\mathrm{mmol} /\left(\mathrm{s}^{*} \mathrm{~mol}_{\mathrm{met}}\right)\right), r_{0}$ is the initial rate $\left(\mathrm{mmol} /\left(\mathrm{s}^{*} \mathrm{~mol}_{\mathrm{met}}\right)\right), E_{A}$ is the activation energy $(\mathrm{kJ} / \mathrm{mol}), R$ is the gas constant $\left(\mathrm{J} /\left(\mathrm{K}^{*} \mathrm{~mol}\right)\right)$, and $T$ is the absolute temperature $(\mathrm{K})$.

Arrhenius plots are made by plotting the natural logarithm to the rate as a function of the inverse absolute temperature, which results in a straight line with a slope of $-E_{A} / R$ and a yintercept of $\ln \left(r_{0}\right)$. These plots are shown in Figure 4.5.

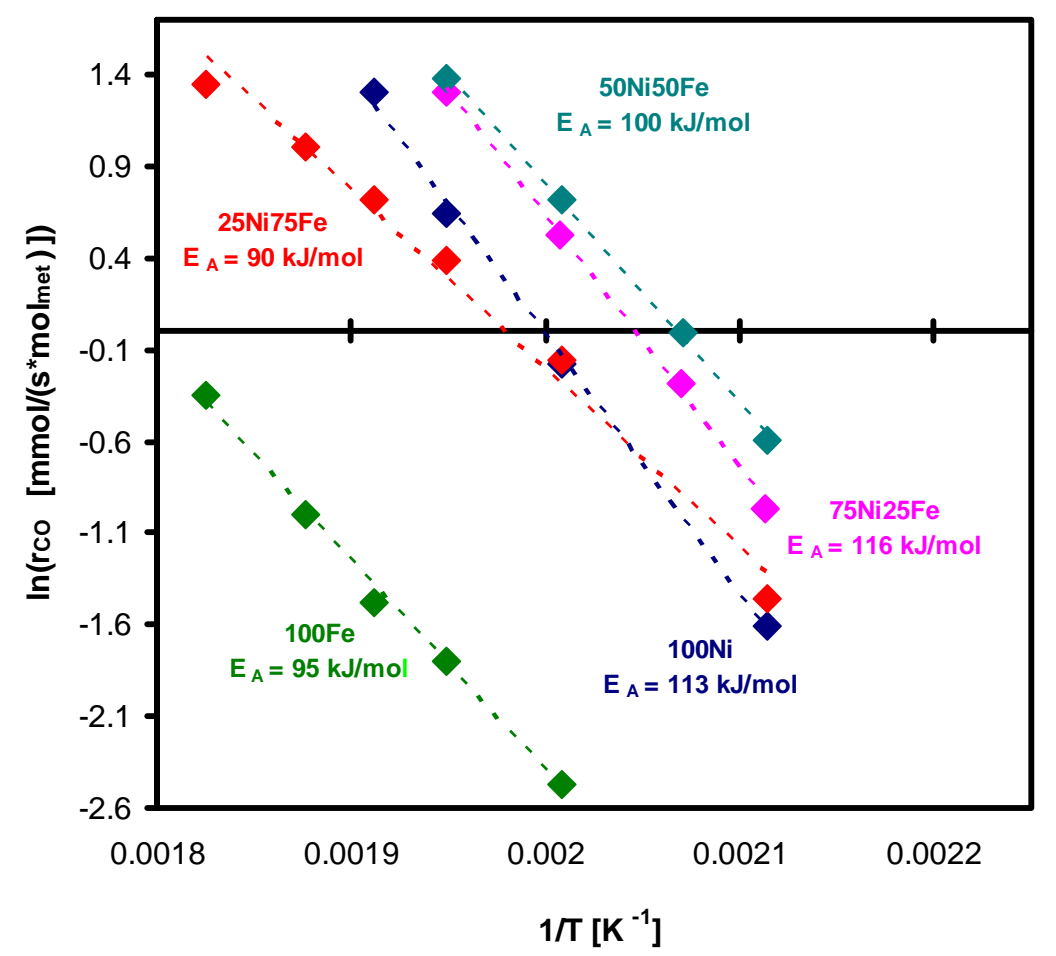

Figure 4.5 Arrhenius plots of $10 \mathrm{wt} \% \mathrm{Ni}-\mathrm{Fe}$ catalysts on spinel. The logarithm of the rate for $\mathrm{CO}$ conversion is plotted versus the reciprocal absolute temperature.

In all cases only data points for CO conversions at lower than $50 \%$ or in some cases preferable $40 \%$ were used for the plots. It should, however, be noted that the experiments were not performed under differential conditions, but here it is assumed that it is possible to use the data for qualitative estimates. Figure 4.5 shows that the activities of all the catalysts follow an Arrhenius-like behavior leading to straight lines. An estimate of the activation 
energy can be evaluated by the slope of these lines. These values are found to be close to each other, namely $90-116 \mathrm{~kJ} / \mathrm{mol}$. These values are in good agreement with comparable data found in the literature ${ }^{30,63}$. However, precaution should, as mentioned before, be taken by using these values quantitatively. The result of this is that it is impossible to compare them directly with activation energies calculated for the elementary reactions.

\subsection{Conclusions}

Series of mono- and bimetallic nickel and iron catalysts on different support materials, alumina and spinel, were investigated in CO hydrogenation. For low metal loadings $(2.5 \mathrm{wt} \%)$ the alumina catalysts were found to be significantly less active than the spinel based catalysts. This is explained by the difference in the reduction profile for the metals on the two different support materials. For all the investigated series of catalysts it was found that some of the nickel-iron alloys were considerably better than the monometallic catalysts as expected from the Pareto plot. This means, that it is indeed possible to obtain cheaper and more active catalysts for CO hydrogenation using Ni-Fe alloys as suggested by the DFT study instead of using the currently commercially used nickel catalysts. Of the catalysts studied experimentally the alloys with composition $\mathrm{Ni}: \mathrm{Fe}=3: 1$ and $\mathrm{Ni}: \mathrm{Fe}=1: 1$ were the most active the absolute maximum varies dependent on the metal loading and the support material. The improved activities for the bimetallic alloy catalysts provide indirect evidence for the proposed alloy formation. Regarding metal loading a maximum in activity was found for a total of $20 \mathrm{wt} \%$ metal - at higher loadings a blocking of the external surface took place. The selectivity for methane was found to increase with increasing CO conversion. Moreover, the selectivity was found to increase with increasing nickel content in the sample. 


\section{$5 \mathrm{CO}_{2}$ hydrogenation}

\subsection{Introduction}

In the previous section it was shown that bimetallic Ni-Fe catalysts indeed have superior catalytic activity for the $\mathrm{CO}$ hydrogenation compared to a monometallic nickel catalyst. However, in order to be useful in industrial applications, such as in the ammonia synthesis, it is important that the improved activity also accounts $\mathrm{CO}_{2}$ hydrogenation. In this section this aspect will be covered, by investigating the activity of Ni-Fe alloys for this reaction.

\subsection{Catalyst preparation}

The catalysts were prepared by incipient wetness impregnation with aqueous solutions of nickel(II) nitrate and iron(III) nitrate on $\eta$-alumina. The aim was to obtain a metal loading around $23 \mathrm{wt} \%$ for both the monometallic nickel catalyst and the bimetallic catalysts. A fraction of the alumina with particle size between 250-500 $\mu \mathrm{m}$ and a surface area of $194 \mathrm{~m}^{2} / \mathrm{g}$ was used. Before impregnation, the support material was dried carefully at $200^{\circ} \mathrm{C}$ for $2 \mathrm{~h}$ to remove all water. After the impregnation, the samples were left at room temperature for $4 \mathrm{~h}$ in a closed vial in order to assure a proper filling of the pores and thereby a proper distribution of the metal ions. The catalysts were then dried at room temperature followed by a calcination step, by heating the catalysts to $450{ }^{\circ} \mathrm{C}$ in air with a ramp of $3.5^{\circ} \mathrm{C} / \mathrm{min}$ and keeping the calcination temperature for $4 \mathrm{~h}$.

\section{3 $\mathrm{CO}_{2}$ hydrogenation experiments}

In a standard activity test $40 \mathrm{mg}$ of the catalyst was mixed with $260 \mathrm{mg}$ of an inert material, spinel $(250-500 \mu \mathrm{m})$, and placed in a steel reactor with a diameter of $7 \mathrm{~mm}$. The catalyst was reduced for $4 \mathrm{~h}$ at $550{ }^{\circ} \mathrm{C}$ in $9 \% \mathrm{CO}_{2}$ in $\mathrm{H}_{2}$. After the reduction the catalytic performance of the $\mathrm{CO}_{2}$ hydrogenation was tested at $250{ }^{\circ} \mathrm{C}$ measured with an internal thermocouple using a total flow of $16.5 \mathrm{Nl} / \mathrm{h}$ of a gas mixture of $9 \% \mathrm{CO}_{2}$ in $\mathrm{H}_{2}$ at standard pressure. The exit gas was analyzed using a Hewlett Packard Gas Chromatograph equipped with a TCD detector. 


\subsection{Results and discussion}

\subsubsection{Characterization}

The metal content was determined using atomic absorption spectroscopy. The measured metal percentages are shown in Table 5.1, along with the total metal content.

Table 5.1 Measured metal content in Ni-Fe catalysts on alumina used for $\mathrm{CO}_{2}$ hydrogenation.

\begin{tabular}{|c|c|c|c|}
\hline \multirow{2}{*}{ Composition } & \multicolumn{3}{|c|}{ Metal Content [wt\%] } \\
\hline & $\mathrm{Ni}$ & $\mathrm{Fe}$ & Total \\
\hline $66 \mathrm{Ni3} 3 \mathrm{Fe} / \mathrm{Al}_{2} \mathrm{O}_{3}$ & 14.8 & 7.24 & 22.04 \\
\hline $75 \mathrm{Ni25Fe} / \mathrm{Al}_{2} \mathrm{O}_{3}$ & 17.5 & 5.85 & 23.35 \\
\hline $85 \mathrm{Ni15Fe} / \mathrm{Al}_{2} \mathrm{O}_{3}$ & 20.2 & 3.47 & 23.67 \\
\hline $\mathrm{Ni} / \mathrm{Al}_{2} \mathrm{O}_{3}$ & 23.9 & 0.14 & 24.04 \\
\hline
\end{tabular}

From the table it can be noted that the metal content vary slightly between 22 and $24 \mathrm{wt} \%$.

\subsubsection{Activity}

The activity of $\mathrm{CO}_{2}$ hydrogenation is shown in Figure 5.1 expressed as the rate of the $\mathrm{CO}_{2}$ conversion versus the nickel content in the catalyst as percent of the nickel out of the total metal loading. The reaction rate, $r$, is calculated as

$$
r=X_{\mathrm{CO}_{2}} * \mathrm{~F} / n_{\text {cat }}
$$

where $\mathrm{X}_{\mathrm{CO}_{2}}$ is the fractional conversion of $\mathrm{CO}_{2}, \mathrm{~F}$ is the molar feed rate of $\mathrm{CO}_{2}(\mathrm{~mole} / \mathrm{s})$, and $n_{\text {cat }}$ is the total amount of metal (mol). 


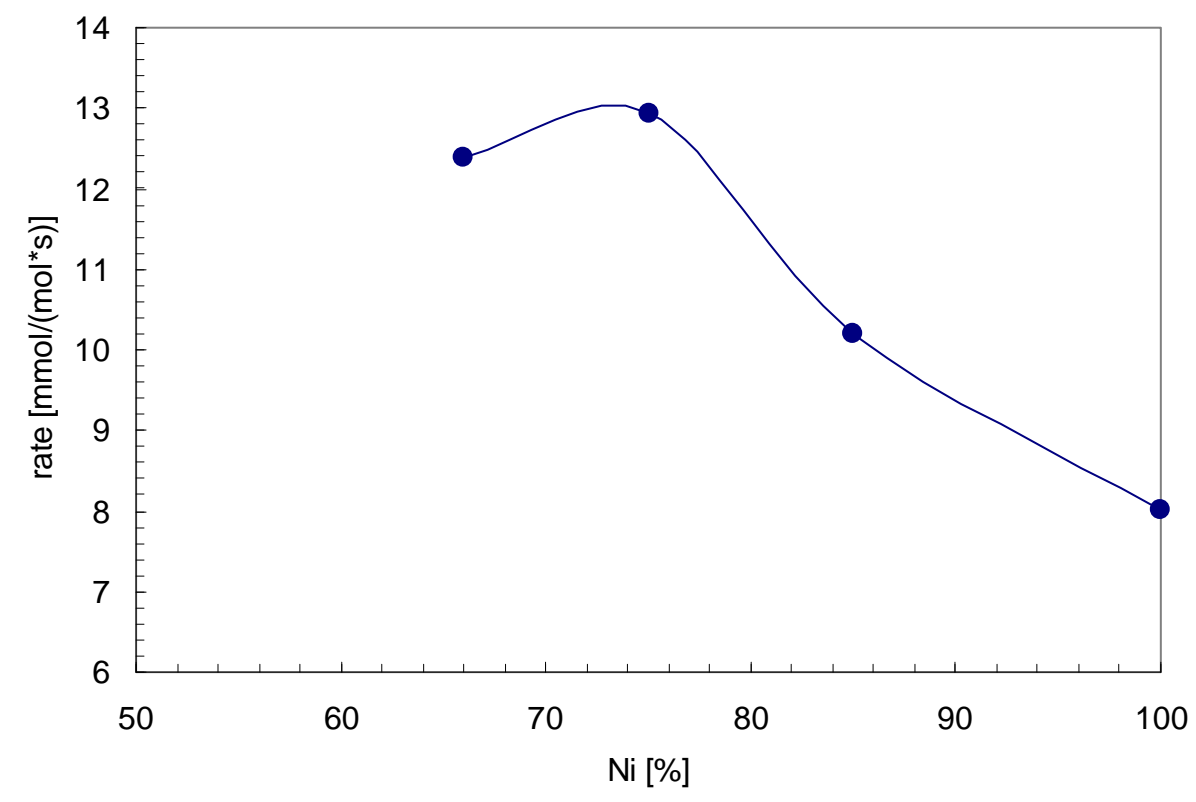

Figure 5.1 The rate for $\mathrm{CO}_{2}$ hydrogenation at $250{ }^{\circ} \mathrm{C}$ is plotted versus the nickel content in the catalysts out of the total metal loading.

Figure 5.1 shows that the bimetallic nickel-iron catalysts examined indeed are better than the monometallic nickel catalyst for $\mathrm{CO}_{2}$ conversion.

\subsection{Conclusion}

The bimetallic Ni-Fe alloys are found to show higher activity in the $\mathrm{CO}_{2}$ hydrogenation than the monometallic nickel catalyst, meaning that these catalysts can handle the $\mathrm{CO}_{2}$ hydrogenation. 


\section{Simultaneous $\mathrm{CO}$ and $\mathrm{CO}_{2}$ hydrogenation}

\subsection{Introduction}

A simultaneous $\mathrm{CO}$ and $\mathrm{CO}_{2}$ hydrogenation study with iron, nickel, and bimetallic nickel-iron alloys was performed in order to ensure that the co-existence of carbon monoxide and carbon dioxide in the gas feed does not change the overall activity pattern seen for the $\mathrm{CO}$ hydrogenation and $\mathrm{CO}_{2}$ hydrogenation experiments described in chapter 4 and 5 .

\subsection{Catalyst preparation and characterization}

The catalysts used for simultaneous $\mathrm{CO}$ and $\mathrm{CO}_{2}$ hydrogenation were the same catalysts as the $10 \mathrm{wt} \%$ metal on alumina series prepared for $\mathrm{CO}$ hydrogenation, described in section 4.2. The nickel and iron contents in the catalysts were determined using atomic absorption spectroscopy (AAS) and the $\mathrm{N}_{2}$ physisorption measurements as explained previously and the metal content and the surface areas for the catalysts are found in Table 4.1.

\subsection{Simultaneous $\mathrm{CO}$ and $\mathrm{CO}_{2}$ hydrogenation experiments}

In a standard activity test $150 \mathrm{mg}$ of the catalyst was placed in a quartz plug-flow reactor between two layers of quartz wool. Prior to the activity test, the catalyst was reduced at $500{ }^{\circ} \mathrm{C}$ for $4 \mathrm{~h}$ in $2 \% \mathrm{CO}$ and $2 \% \mathrm{CO}_{2}$ in $\mathrm{H}_{2}$. The activity of the catalyst was tested at temperatures from $220-330{ }^{\circ} \mathrm{C}$ with a total flow of $6 \mathrm{Nl} / \mathrm{h}$ of the gas mixture used for the reduction under an absolute pressure of 1.0-1.1 bar. At each temperature the conversion and selectivity was monitored for at least one hour to ensure stable catalyst performance. The exit gas was examined using a Shimadzu Gas Chromatograph equipped with TCD and FID detectors. In this way the concentrations of $\mathrm{CO}, \mathrm{CO}_{2}, \mathrm{CH}_{4}$, and the small amount of organic compounds were determined.

\subsection{Results and discussion}

In the simultaneous $\mathrm{CO}$ and $\mathrm{CO}_{2}$ hydrogenation experiments, the expected trend (based on the experiments with $\mathrm{CO}$ hydrogenation and $\mathrm{CO}_{2}$ hydrogenation) is seen for hydrogenation of both species. The bimetallic nickel-iron catalysts with high nickel content exhibit higher activities than the monometallic nickel catalysts, even if both carbon oxides are present. If 
comparing the two monometallic catalysts, it is found that the nickel catalyst shows significantly higher catalytic activity in both hydrogenation processes than the iron catalyst. In Figure 6.1 this is shown for the $\mathrm{CO}_{2}$ conversion at $330{ }^{\circ} \mathrm{C}$.

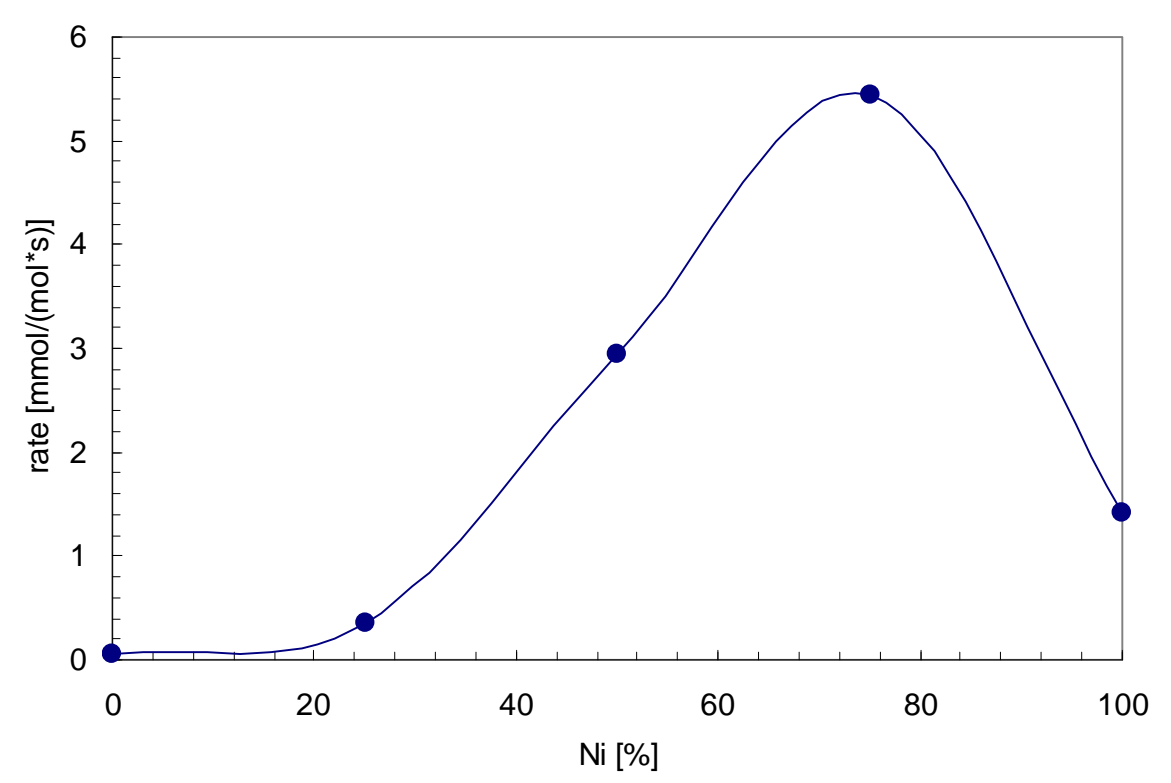

Figure 6.1 The rate of the $\mathrm{CO}_{2}$ conversion at $330{ }^{\circ} \mathrm{C}$ is plotted versus the percentage of nickel out of the total metal content present in the catalysts.

Figure 6.1 is plotted in the same way as in the previous hydrogenation activity plot, thus the rate for the conversion of $\mathrm{CO}_{2}$ is shown as a function of the nickel content in the catalyst relative to the total metal loading. The catalyst which shows the highest activity is found to be $\mathrm{Ni}: \mathrm{Fe}=3: 1$ independently of the examined temperature in the temperature range explored $\left(220-330{ }^{\circ} \mathrm{C}\right)$. This is in accordance with the experiments performed with the pure $\mathrm{CO}_{2}$ hydrogenation. Activity data for $\mathrm{CO}$ and $\mathrm{CO}_{2}$ conversions versus the temperature are shown in Figure 6.2 for catalysts with different nickel-iron ratios. 


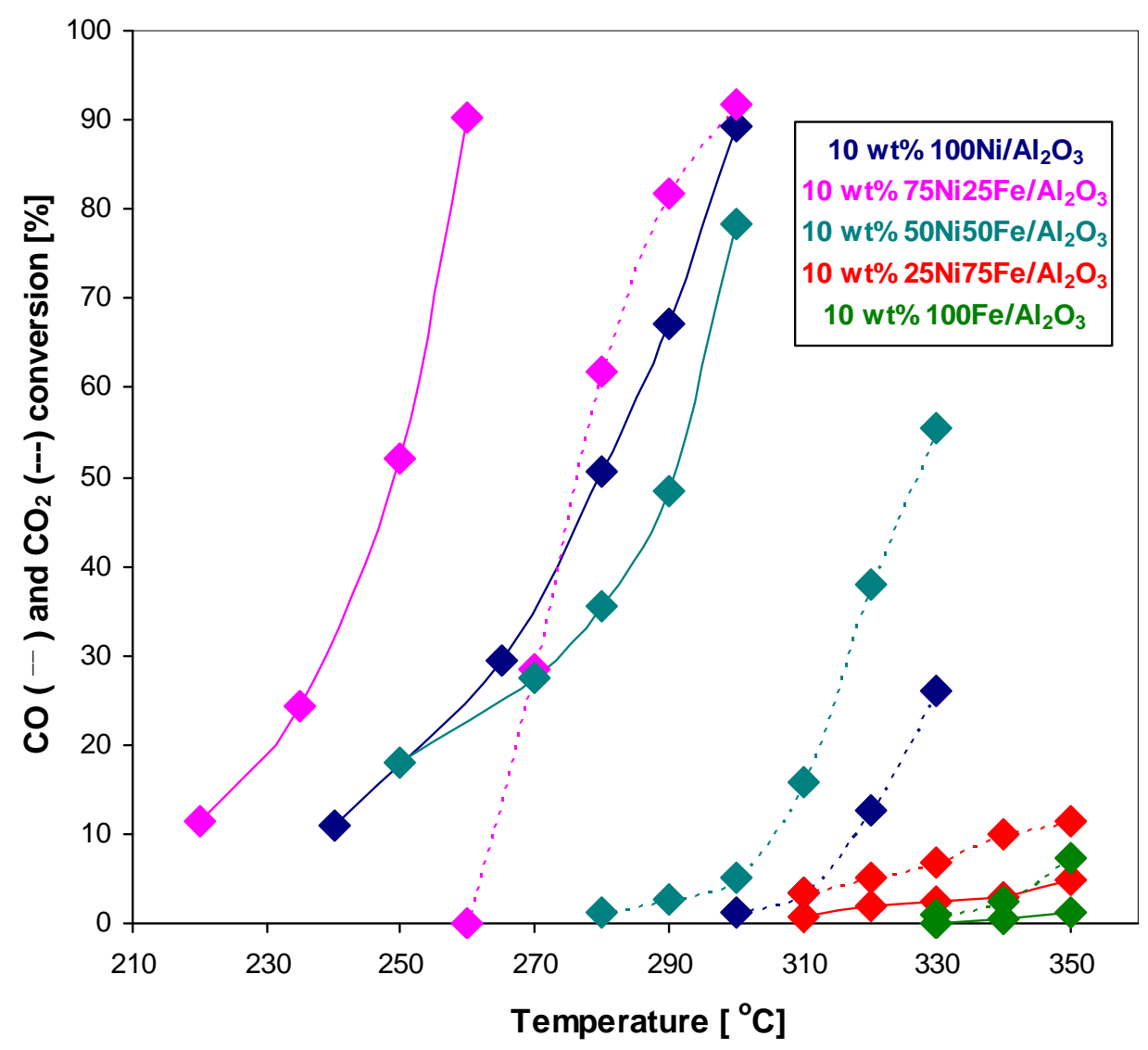

Figure 6.2 The $\mathrm{CO}$ and $\mathrm{CO}_{2}$ conversions are plotted versus the temperature for $\mathrm{Ni}, \mathrm{Fe}$, and $\mathrm{Ni}-\mathrm{Fe}$ alloys on alumina.

It should be noted that the $\mathrm{CO}$ and $\mathrm{CO}_{2}$ hydrogenation reactions take place in different temperature intervals - higher temperatures are needed in order to hydrogenate the $\mathrm{CO}_{2}$ than $\mathrm{CO}$. The Ni:Fe=3:1 alloy catalyst is seen to be the most active catalyst for both $\mathrm{CO}$ and $\mathrm{CO}_{2}$ hydrogenation when both carbon oxides are present in the gas.

The methane selectivities of the catalysts are found to be very high for the catalysts where $50 \%$ or more of the metal on the catalyst is nickel. The selectivities are found to be considerable lower for catalysts containing more iron than nickel. In Figure 6.3 a plot of the selectivity as a function of the amount of nickel present in the catalyst is shown at $330{ }^{\circ} \mathrm{C}$. 


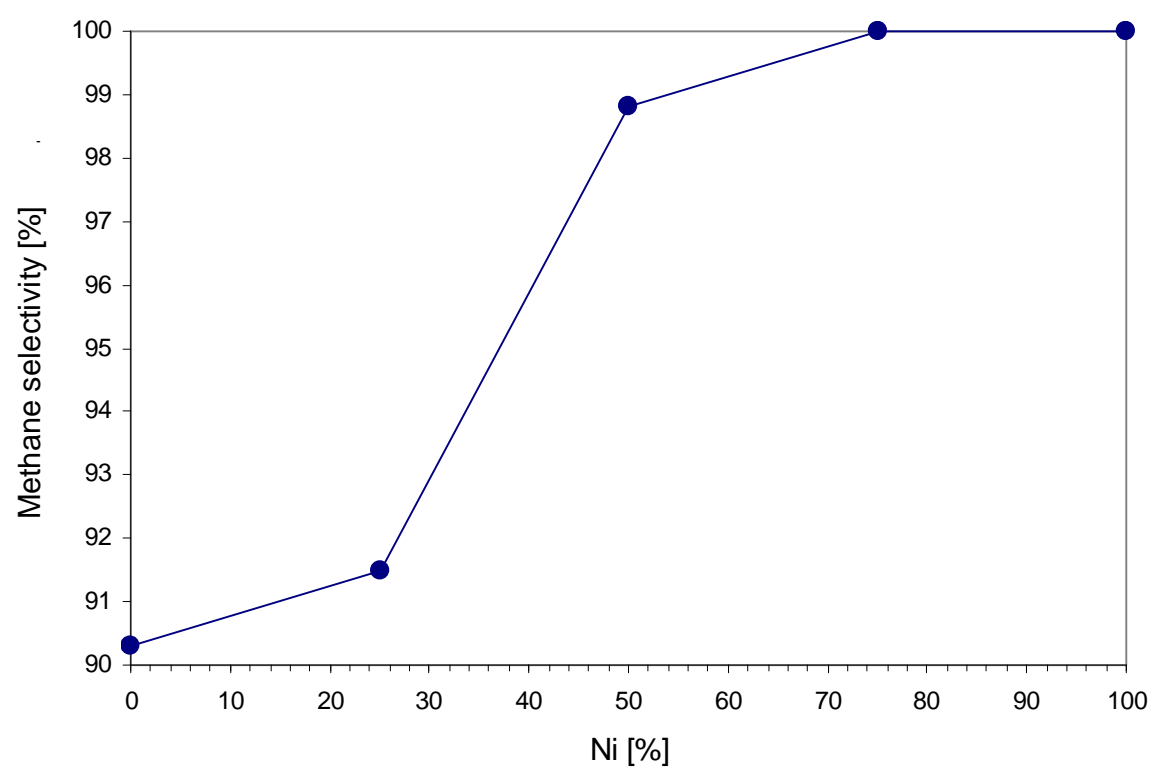

Figure 6.3 Methane selectivity versus nickel content in catalysts with a total loading of $10 \mathrm{wt} \%$ metal at $330{ }^{\circ} \mathrm{C}$.

At all examined temperatures above $220^{\circ} \mathrm{C}$ the selectivities toward methane are found to be between $95-100 \%$ for the catalysts with high nickel content (50\% or more). In connection with selectivity it should be noted that the only byproducts observed using the GC are the short hydrocarbon chains $\mathrm{C}_{2}-\mathrm{C}_{4}$.

\subsection{Conclusion}

It was found that the bimetallic nickel-iron catalysts exhibit significantly higher catalytic activity in the simultaneous hydrogenation of $\mathrm{CO}$ and $\mathrm{CO}_{2}$ than the monometallic nickel catalyst. The monometallic nickel catalyst shows higher activity than the monometallic iron catalyst for both $\mathrm{CO}$ and $\mathrm{CO}_{2}$ hydrogenation. Thus the activity pattern can be represented as a volcano plot for both the $\mathrm{CO}$ and the $\mathrm{CO}_{2}$ hydrogenation. The experiments show that the $\mathrm{Ni}: \mathrm{Fe}=3: 1$ alloy catalyst has the highest activity for the hydrogenation reactions under the examined experimental conditions. 


\section{Bimetallic Co-Fe and Co-Ni catalysts for CO hydrogenation}

\subsection{Other bimetallic systems: Co-Fe and Co-Ni}

If returning to the Pareto plot shown in Figure 3.3 it is worth noticing that a couple of other bimetallic systems than Ni-Fe could be of interest, since they are expected to exhibit high catalytic activity and at the same time not to be highly expensive. These are the bimetallic $\mathrm{Co}: \mathrm{Ni}$ and the $\mathrm{Co}: \mathrm{Fe}$ catalysts. However, the prices of these materials are considerable higher than those of the Ni-Fe system, due to the high cobalt price. This means that these systems are not expected to be of huge commercial interest, but due to their academic interest and as examples of the computational screening as a way to find new catalysts, these series of catalysts have been examined and are included in following. The Co-Ni and Co-Fe systems were only examined for the CO hydrogenation, meaning that they have not been studied as detailed as the Ni-Fe system.

\subsection{Catalyst preparation}

A series of $10 \mathrm{wt} \%$ monometallic and bimetallic cobalt-iron and cobalt-nickel catalysts on alumina were prepared with the following compositions: $100 \mathrm{Fe}, 25 \mathrm{Co} 75 \mathrm{Fe}, 50 \mathrm{Co} 50 \mathrm{Fe}$, $75 \mathrm{Co} 25 \mathrm{Fe}$, $85 \mathrm{Co} 15 \mathrm{Fe}$, 90Co10Fe, 95Co5Fe, 99Co1Fe, $100 \mathrm{Co}, 99 \mathrm{Co} 1 \mathrm{Ni}, 95 \mathrm{Co} 5 \mathrm{Ni}$, $90 \mathrm{Co} 10 \mathrm{Ni}, 75 \mathrm{Co} 25 \mathrm{Ni}, 50 \mathrm{Co} 50 \mathrm{Ni}, 40 \mathrm{Co} 60 \mathrm{Ni}, 25 \mathrm{Co} 75 \mathrm{Ni}, 15 \mathrm{Co} 85 \mathrm{Ni}, 5 \mathrm{Co} 95 \mathrm{Ni}, 1 \mathrm{Co} 99 \mathrm{Ni}$, and $100 \mathrm{Ni}$. The numbers indicate the percentage of the metal out of the $10 \mathrm{wt} \%$ total metal in the catalyst. The alumina had a pore volume of $0.5 \mathrm{ml} / \mathrm{g}$ and was dried at $120{ }^{\circ} \mathrm{C}$ before it was impregnated. The catalysts were prepared with incipient wetness impregnation of alumina with aqueous solutions of iron(III) nitrate, cobalt(II) nitrate, and/or nickel(II) nitrate. The resulting product was left in closed vials over night in order to get the pores filled and the metal evenly distributed. The catalyst was subsequently dried for $4 \mathrm{~h}$ at $120{ }^{\circ} \mathrm{C}$. The dried precursor was heated to $500{ }^{\circ} \mathrm{C}$ in air for $4 \mathrm{~h}$, in order to decompose the nitrates and obtain metal oxide particles on the surface of the support material. 


\subsection{Catalytic testing}

In all activity tests $150 \mathrm{mg}$ of the given catalyst was placed in a fixed bed quartz reactor between two layers of quarts wool. Several different reduction conditions were applied for the cobalt-nickel system in order to see how this influenced the catalyst performance in the activity tests. The composition of the reduction gas, the reduction time, and the reduction temperature were varied. The composition of the reducing mixture was varied in a range from pure hydrogen to $5 \% \mathrm{CO}$ in $\mathrm{H}_{2}$; the time was in changed from 2-12 h, and the temperature in the interval $400-600{ }^{\circ} \mathrm{C}$. As a standard procedure for comparison the catalysts were reduced in-situ for $4 \mathrm{~h}$ in a flow on $6 \mathrm{Nl} / \mathrm{h}$ of $2 \% \mathrm{CO}$ in $\mathrm{H}_{2}$ at $500{ }^{\circ} \mathrm{C}$ and 1 bar. After the reduction the temperature was decreased to $200{ }^{\circ} \mathrm{C}$ and the first measurement was performed. The catalyst was tested at different temperatures, by increasing the temperature in intervals of 10$15^{\circ} \mathrm{C}$ and waiting for steady state to adjust before the catalytic performance was measured. The exit gas was examined using a gas chromatograph equipped with an FID detector.

\subsection{Results and discussion}

\subsubsection{Co-Fe catalysts}

The activities of the Co-Fe catalysts are plotted versus the cobalt content at two different temperatures, namely $225^{\circ} \mathrm{C}$ and $240{ }^{\circ} \mathrm{C}$ as shown in Figure 7.1 .

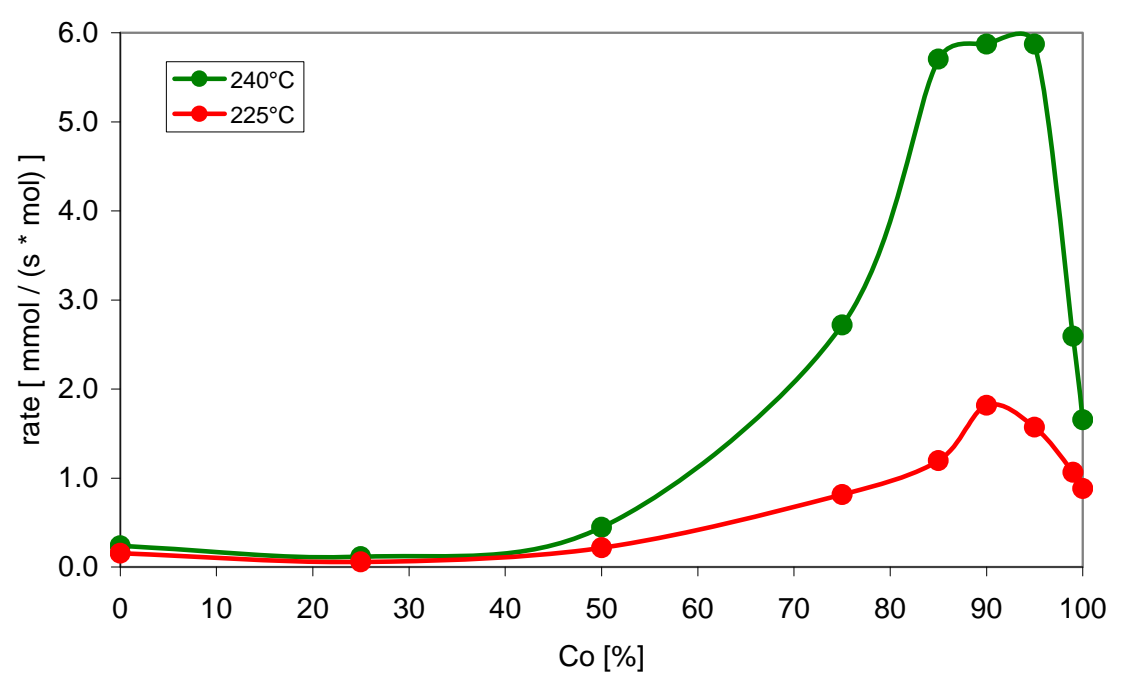

Figure 7.1 The rate for the $\mathrm{CO}$ conversion is plotted versus the cobalt content in $10 \mathrm{wt} \% \mathrm{Co}-\mathrm{Fe} / \mathrm{Al}_{2} \mathrm{O}_{3}$ catalysts at $225^{\circ} \mathrm{C}$ and $240{ }^{\circ} \mathrm{C}$, respectively.

The activity pattern is a volcano, where the maximum of activity is located between 85 and $95 \%$ cobalt of the total metal loading. The maximum in activity is shifted much towards high 
cobalt content (and thereby low iron content) compared to what was seen in the case of the nickel-iron system (Figure 4.4). This can be explained by cobalt's position on the volcano plot for monometallic catalysts (Figure 3.2) close to the maximum of activity. Furthermore, the experimental results indicate that cobalt is located on the opposite leg (right leg) on the volcano plot compared to iron (left leg). For a metal positioned at the right leg close to the maximum of the volcano, the CO-dissociation energy is slightly low. Although the rate determining step is $\mathrm{CO}$ dissociation, only a small amount of an element from the left leg of the volcano with desorption as the rate limiting step (such as iron) needs to be added in order to obtain improved activity. Adding too much of such an element might overrule the synergic effect and lead to a catalyst which adsorbs CO strongly and thereby lower the activity.

The shift in the maximum of activity towards one of the metals can be caused by other effects, influencing the catalyst performance. It could e.g. be explained by iron functioning as a promoter, by difference in particle sizes among the different catalysts, or by other physical effects. Finally, it should be noted that the DFT calculations in the Pareto plot (Figure 3.3) indicates that the Co-Fe alloys, such as $75 \mathrm{Co} 25 \mathrm{Fe}$, should exhibit activities between those of the monometallic catalysts. The reason this is not observed experimentally for $75 \mathrm{Co} 25 \mathrm{Fe}$ might be due to uncertainty in the DFT calculation e.g. relating to cobalt's exact position on the volcano relative to iron.

The methane selectivities for the cobalt-iron catalysts were investigated as well, and these are shown at two temperatures in Table 7.1.

Table 7.1 Methane selectivity at 225 and $240{ }^{\circ} \mathrm{C}$ for $10 \mathrm{wt} \% \mathrm{Co}-\mathrm{Fe} / \mathrm{Al}_{2} \mathrm{O}_{3}$ catalysts with different cobalt content.

\begin{tabular}{|c|c|c|}
\hline \multirow[b]{2}{*}{$\%$ Co } & \multicolumn{2}{|c|}{$\% \mathrm{CH}_{4}$ selectivity } \\
\hline & $225^{\circ} \mathrm{C}$ & $240^{\circ} \mathrm{C}$ \\
\hline 0 & 89 & 94 \\
\hline 1 & 86 & 91 \\
\hline 5 & 87 & 93 \\
\hline 10 & 88 & 94 \\
\hline 25 & 87 & 95 \\
\hline 50 & 95 & 96 \\
\hline 60 & 92 & 95 \\
\hline 75 & 93 & 96 \\
\hline 85 & 92 & 95 \\
\hline 95 & 91 & 94 \\
\hline 99 & 91 & 94 \\
\hline 100 & 92 & 95 \\
\hline
\end{tabular}


The methane selectivities are in general high - especially for the catalysts with low iron content.

\subsubsection{Co-Ni catalysts}

Based on the DFT calculations for the CO-dissociation energies shown in the Pareto plot (Figure 3.3) it was expected that one of the Co-Ni alloys, $\mathrm{Co}: \mathrm{Ni}=3: 1$, should exhibit improved activity compared to the two monometallic catalysts. Thus from the theoretical study it was expected to see a volcano shaped curve like in Figure 4.4 for the nickel-iron system, when plotting the methanation activity as a function of the nickel content for the Co-Ni catalysts. However, as explained in connection with the cobalt-iron system, the experiments indicate that the cobalt is located at the opposite leg of the volcano compared to iron. Thus it is likely that cobalt is located on the same leg as nickel. Based on this experimental result it is expected that the activities of the Co: $\mathrm{Ni}$ intermetallic compounds would be in the range between those of cobalt and nickel. This turned out to be different and more complicated than expected, as seen in Figure 7.2 where the rates for $\mathrm{CO}$ conversion at two different temperatures are plotted versus the nickel content of the total metal concentration for the CoNi system.

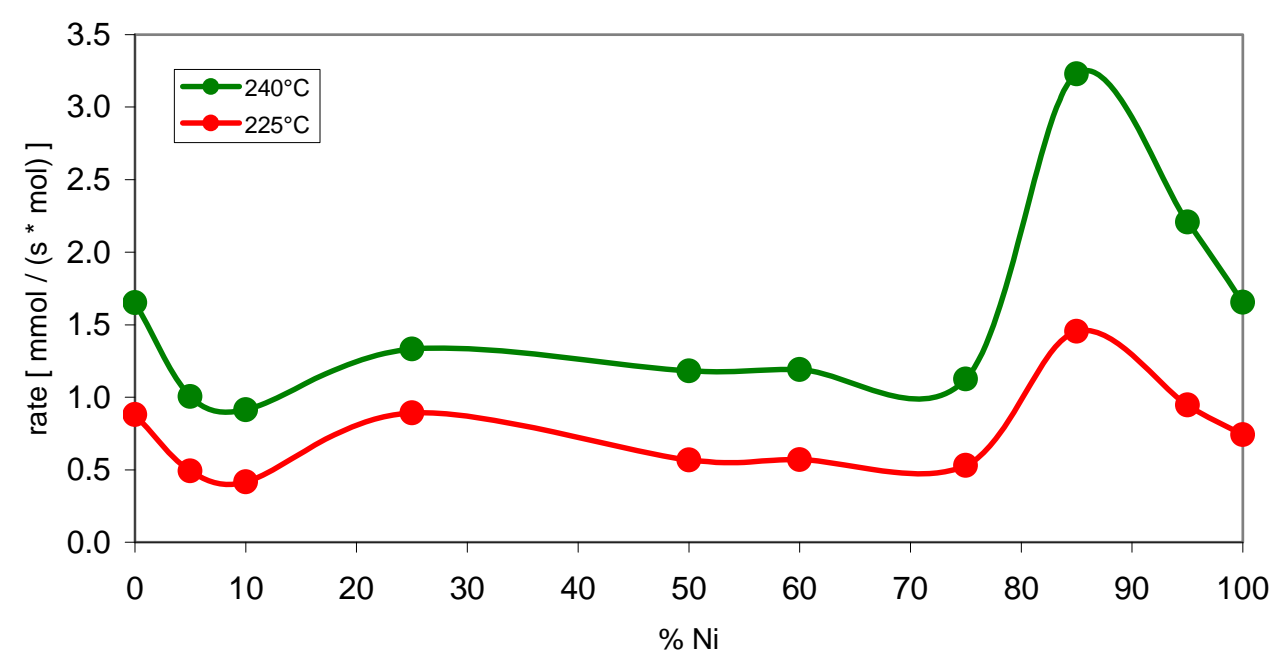

Figure 7.2 The rate for $\mathrm{CO}$ conversion at 225 and $240{ }^{\circ} \mathrm{C}$ is plotted versus the nickel content in a series of $10 \mathrm{wt} \%$ Co-Ni catalysts on alumina.

For high Ni:Co ratios a volcano-like shape of the curve is observed with a maximum for $\mathrm{Ni}: \mathrm{Co}=85: 15$. However, an "inverse" volcano-like curve for high cobalt:nickel ratios $(0-25 \%$ $\mathrm{Ni}$ ) is seen in the same plot with a minimum in activity at $\mathrm{Ni}: \mathrm{Co}=10: 90$. This is a rather surprising result. Some possible explanations will be discussed here. One explanation could 
be related to the formation of a mixture of the two metals that might result in a surface that is unfavorable for the reaction. The alloy of the two metals might be different than assumed in the DFT calculations or might not even be formed for the nanoparticles on the surface of the support material.

Another possible explanation is that the standard reduction condition leads to different degrees of reduction of the monometallic and the bimetallic catalysts in this system. The influence of the reduction conditions on the activity of $\mathrm{CO}$ hydrogenation was studied for one bimetallic catalyst namely the $\mathrm{Ni}: \mathrm{Co}=1: 1$ catalyst and the monometallic nickel catalyst. The gas composition was varied in a series: $\mathrm{H}_{2}, 0.5 \% \mathrm{CO}$ in $\mathrm{H}_{2}, 2 \% \mathrm{CO}$ in $\mathrm{H}_{2}$, and $5 \% \mathrm{CO}$ in $\mathrm{H}_{2}$ and experiments with different reduction times and temperatures were performed as well. None of these parameters seemed to change the internal relation in activity pattern between the bimetallic catalysts and the nickel catalyst - thus it is not likely to assume that the standard reduction procedure is considerably worse for the bimetallic catalyst than for the nickel catalysts. However, the surprisingly small difference between the activity of the monometallic cobalt catalyst and the monometallic nickel catalyst might be an indication that these two catalysts are not reduced to the same degree or that the particle size of the metals differs in the two cases. A preliminary temperature programmed reduction (TPR) study has not revealed an answer to the question. The investigation of the reduction conditions do, however, not rule out that the problems might be due to different particle sizes and thereby difference in dispersion of the different catalyst.

If returning to the activity tests of the entire Co:Ni catalyst series, the methane selectivity was examined after the standard reduction conditions. The selectivities for selected catalysts are shown in Table 7.2 at the two temperatures for which the activity data were plotted in Figure 7.2 .

Table 7.2 Methane selectivities of $\mathrm{Co}-\mathrm{Ni} / \mathrm{Al}_{2} \mathrm{O}_{3}$ at 225 and $240{ }^{\circ} \mathrm{C}$.

\begin{tabular}{|c|c|c|}
\hline \multirow[b]{2}{*}{$\% \mathrm{Ni}$} & \multicolumn{2}{|c|}{$\% \mathrm{CH}_{4}$ Selectivity } \\
\hline & $225^{\circ} \mathrm{C}$ & $240^{\circ} \mathrm{C}$ \\
\hline 0 & 92 & 95 \\
\hline 10 & 88 & 94 \\
\hline 25 & 87 & 95 \\
\hline 50 & 95 & 96 \\
\hline 75 & 93 & 96 \\
\hline 85 & 92 & 95 \\
\hline 100 & 89 & 94 \\
\hline
\end{tabular}


The selectivities are, in general, higher at $240{ }^{\circ} \mathrm{C}$ than at $225{ }^{\circ} \mathrm{C}$. At $240{ }^{\circ} \mathrm{C}$ the methane selectivity is $94-96 \%$ for all the catalysts. At $225{ }^{\circ} \mathrm{C}$ there are small derivations between the values changing from 87 to $95 \%$. No clear correlation between activity and selectivity is found nor is a direct correlation between the metal ratio and the selectivity found. It can, however, be concluded that all catalysts show high methane selectivities of the same magnitude.

\subsection{Conclusion}

The cobalt-iron system shows a volcano curve when plotting the activity versus the fraction of cobalt out of the total metal loading. The maximum in activity for the $\mathrm{CO}$ hydrogenation is located around $90 \%$ Co. This result indicates that cobalt is located on the opposite site of the volcano plot compared to iron.

The cobalt-nickel catalysts show an interesting activity pattern with both a local minimum and a local maximum for the bimetallic catalysts between the two monometallic catalysts. A reasonable explanation can be found in the difference in reducibility of the monometallic and bimetallic catalysts under the standard procedure or by differences in particle size - a phenomenon that could be interesting to investigate further in the future e.g. by pulse chemisorption. Since the activity data cannot be fully explained, it leaves room for further experimental as well as theoretical work.

The selectivities towards methane are found to be high in all cases for both the Co-Fe and CoNi catalysts. 


\section{Overall conclusions on the methanation part}

In this study it has been shown, that a computational screening can provide suggestions for new catalysts even for a reaction which has been known for more than a century. This makes computational screenings an attractive method and a nice alternative (or supplement) to highthroughput experimental screenings.

The experimental results for $\mathrm{CO}$ hydrogenation, $\mathrm{CO}_{2}$ hydrogenation, and simultaneous $\mathrm{CO}$ and $\mathrm{CO}_{2}$ hydrogenation with nickel-iron alloys show that it, indeed, is possible to increase the catalytic activity significantly, by using alloy catalysts compared to the currently industrially used monometallic nickel catalyst as suggested by the computational screening.

The CO hydrogenation experiments with $\mathrm{Co}-\mathrm{Fe}$ and $\mathrm{Co}-\mathrm{Ni}$ seem to result in volcano plots $-\mathrm{a}$ formation of an optimum in activity is seen for some of the bimetallic catalysts. However, these optima are shifted towards respectively high content of cobalt and low content of iron in the cobalt-iron system, and high nickel content and low cobalt content in the cobalt-nickel system. For the latter, a minimum in activity is observed in the situation where the Co:Ni ratio is high. This is unexpected from the DFT calculations, and the final explanation is still to be found, but is left for future investigations. 
Design of heterogeneous catalysts 


\section{Part II}

\section{The Fischer-Tropsch Process}


Design of heterogeneous catalysts 


\section{The Fischer-Tropsch process}

\subsection{History}

In 1923 the two German scientists Frans Fischer and Hans Tropsch made the discovery that $\mathrm{CO}$ and $\mathrm{H}_{2}$ can react over a catalyst and form hydrocarbons and water ${ }^{64,65,66}$. This means that the process is a possible path to produce synthetic fuel for transportation purposes. The reaction is now known as the Fischer-Tropsch (FT) process. One of the first catalysts Fischer and Tropsch worked with was based on approximately $30 \mathrm{wt} \%$ cobalt on kiselguhr (impure $\mathrm{SiO}_{2}$ from the nature). It was found that the selectivity could be shifted towards heavier hydrocarbons by adding thoria and magnesia as promoters ${ }^{67}$.

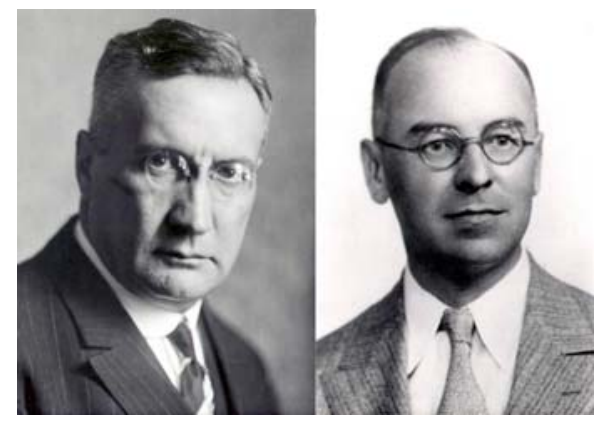

Figure 9.1 F. Fischer (left) and H. Tropsch (right).

The discovery was important to Germany already few years after the time where it was made, since the country was cut of from oil supply due to World War II ${ }^{67,68,69}$. The first FT plant was established by Ruhrchemi in 1935 as the first out of nine. The production of synthetic fuel on these plants peaked in 1944 with an annual production of 4.1 million barrels ${ }^{68}$. After the war the economy of the plants was not viable anymore and the plants were closed down ${ }^{69}$. In the following years low to moderate interest in the FT process was seen on a worldwide basis $^{70,71}$ with South Africa being an exception. In South Africa huge amounts of cheap coal was available and a great effort was put into optimizing the process to make the country energy independent of other countries. The SASOL company opened the first plant there in $1955^{72,73}$.

In the 1970s the oil crises occurred and the interest in the FT process increased significantly due to this. The global interest resulted in many research programs from several industrial companies such as Statoil, Shell, Gulf/Chevron, and ExxonMobil as well as in the academic scientific environments in many countries ${ }^{74}$. 
Nowadays there are several reasons to keep being interested in the FT process. The high oil prices make the FT process worth to consider. Furthermore, the changes in the reserves of fossil resources make it necessary to find new and improved methods to meet the amount of fuels needed in our world today. Moreover the FT process can help make parts of the world more independent of the oil exporting countries. Environmental concerns must of course also be taken into consideration ${ }^{71}$. Hydrocarbons produced by the FT process have the advantage that they do not contain any nitrogen or sulfur. This means that the FT products do not contribute to fuel related pollution by oxides formed of these compounds when burnt, which is seen when normal fuel is used in e.g. automotive applications.

It can be mentioned that a series of smaller plants are currently being constructed in China, Australia, Africa and a big plant is expected to be opened in Qatar in 2011 with a capacity of 0.8 million barrels per day ${ }^{71,75}$.

\subsection{The FT process}

In the FT process alkenes, alkanes, and oxygenated products are formed ${ }^{20}$ as indicated in the reaction schemes below, where de oxygenated products are represented by alcohols.

$$
\begin{gathered}
\mathrm{nCO}+2 \mathrm{nH}_{2} \rightarrow \mathrm{C}_{\mathrm{n}} \mathrm{H}_{2 \mathrm{n}}+\mathrm{nH}_{2} \mathrm{O}(\mathrm{n}=2,3, \ldots) \\
\mathrm{mCO}+(2 \mathrm{~m}+1) \mathrm{H}_{2} \rightarrow \mathrm{C}_{\mathrm{m}} \mathrm{H}_{2 \mathrm{~m}+2}+\mathrm{mH}_{2} \mathrm{O}(\mathrm{m}=1,2,3, \ldots) \\
\mathrm{pCO}+2 \mathrm{pH}_{2} \rightarrow \mathrm{C}_{\mathrm{p}-1} \mathrm{H}_{2 \mathrm{p}-1} \mathrm{CH}_{2} \mathrm{OH}+(\mathrm{p}-1) \mathrm{H}_{2} \mathrm{O}(\mathrm{p}=1,2,3, \ldots)
\end{gathered}
$$

The most active catalyst for the FT process is found to be ruthenium, but since this platinum group metal is rare and expensive, commercial applications are not feasible. The two metals commonly used for industrial applications are iron and cobalt. Iron has a rather limited activity, but since it is relatively cheap and since it can catalyze the water gas shift reaction, it is interesting for coal-based FT applications. Cobalt catalysts are very active and stable, but a disadvantage is that the price is higher than for the iron catalyst. Cobalt catalysts are, however, the mainly used catalyst for natural gas based FT plants.

Many other monometallic catalysts and promotion of these with different metals have been investigated as well as bimetallic alloy catalysts. In the experimental work in this thesis cobalt catalysts with manganese (and platinum) promotion have been investigated, and from now on the focus will be on cobalt catalysts.

The mechanism for Co-based catalysts is believed to consist of dissociative adsorbtion of $\mathrm{CO}$ followed by hydrogenation from dissociated hydrogen. The oxygen is then removed as water 
is formed, while the carbon is partly hydrogenated, followed by a polymerization process leading to carbon chains of different lengths ${ }^{76}$. The process is terminated either by hydrogen adsorption or abstraction leading to paraffins and olefins, respectively.

The chain lengths of the hydrocarbons formed during the process obey a statistical distribution, called the Anderson-Schulz-Flory distribution ${ }^{20}$

$$
W_{i}=i(1-\alpha)^{2} \alpha^{(i-1)}
$$

where $i$ is the number of carbon atoms, $W_{i}$ is the weight fraction of chains with length $i, \alpha$ is the chain growth propagation probability and 1- $\alpha$ is the probability that a chain terminates.

The $\alpha$ parameter is very important, and the aim is to get it as high as possible to avoid too small carbon chains. For practical applications carbon chains with a length higher or equal to $\mathrm{C}_{5}$ are desirable. Therefore the selectivity towards $\mathrm{C}_{5+}$ products is a key parameter. The selectivity towards methane $C_{1}$ is often examined in FT studies as well - the lower $C_{1}$ selectivity the better, since the methane normally has to be recycled in order to reduce waste to the highest possible extend. Another crucial parameter, when describing the system, is the activity of the catalyst. This can be described by the cobalt time yield (CTY). The CTY value is defined as the mole CO converted per g of Co per s. In order to compare catalysts relative to each other, both with respect to $\mathrm{C}_{5+}$ selectivity and activity, a $\mathrm{C}_{5+}$ yield is used in this thesis. The $\mathrm{C}_{5+}$ yield is defined as the product of the CTY value and the fraction expressing the $\mathrm{C}_{5+}$ selectivity.

\subsection{Dispersion and particle size effect}

Since the discovery of the FT process a lot of research has been carried out in order to improve the catalytic system. A possible way to improve the cobalt based catalyst could be by improving the dispersion of the cobalt. An improvement of the metal dispersion can be achieved by decreasing the particle size of metal. Most cobalt catalysts are not sufficiently well dispersed, and a typical catalyst has a particle size of approximately $20 \mathrm{~nm}^{74}$. If the particle size is decreased to e.g. $5 \mathrm{~nm}$, the catalyst is expected to be much more active since the amount of cobalt on the surface is increased significantly. This would be very attractive due to the cobalt price. Attempts to prepare small particles have been successfully carried out and are described in the literature; however the influence on the activity is not as pronounced as expected: For cobalt particles between 10-200 $\mathrm{nm}$ no effect of the size has been observed $^{77,78,79,80,81,82}$. For particles smaller than $10 \mathrm{~nm}$ the picture is unclear. Some research 
group report to have observed higher activities for these small particles ${ }^{83,84,85}$, while other groups claim the opposite $86,87,88,89$. This can be explained by the difficulties in reducing these small metal oxides particles prior to the activity test - possibly in combination with interaction between the metals and support materials such as $\mathrm{TiO}_{2}, \mathrm{SiO}_{2}$, and $\mathrm{Al}_{2} \mathrm{O}_{3}$, which decreases the degree of reducibility even further ${ }^{90,91}$. In order to reduce these problems studies have been carried out on carbon nanofibers ${ }^{83,84,92}$. This showed a very clear particle size dependence and the optimal particle size of cobalt on this support material was found to be $6 \mathrm{~nm}{ }^{93}$. The experience from this study was later implemented on oxide containing supports such as titania and silica ${ }^{94}$, since oxide support materials are more interesting for industrial applications. In a recent study it was found that an optimal way to prepare cobalt catalysts with small particle sizes was by using calcination in NO instead of calcination in air ${ }^{95}$. In Figure 9.2 TEM images of cobalt catalysts on silica are shown after a calcination in air and a calcination in NO, respectively.
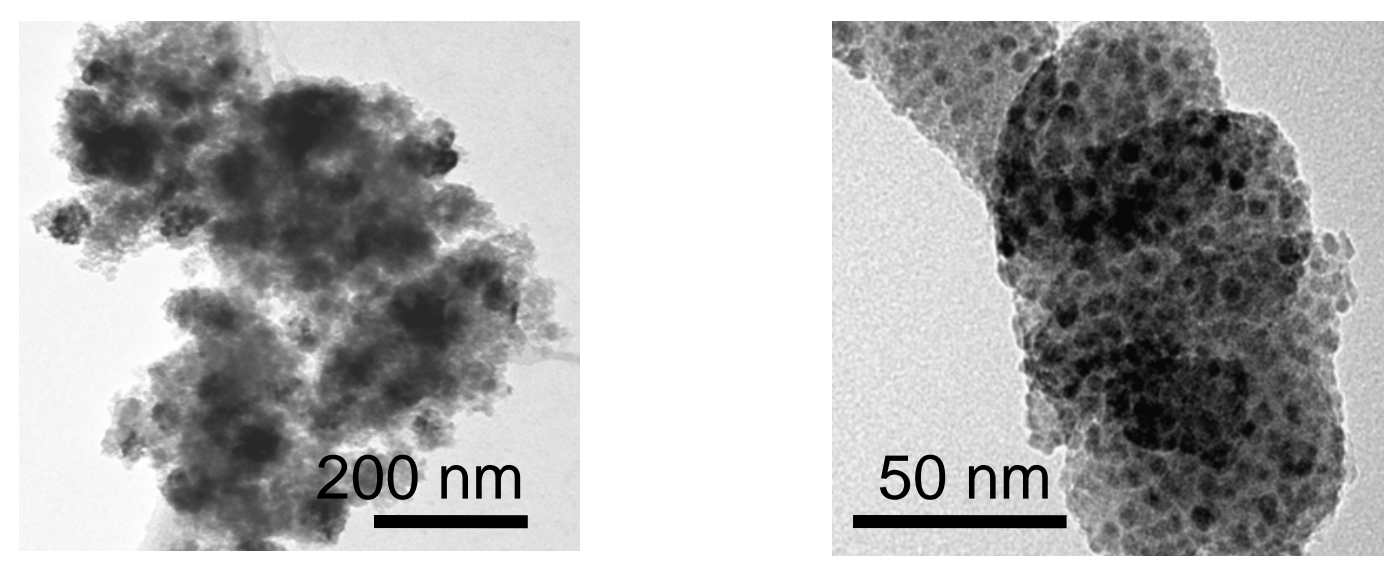

Figure 9.2 TEM images of an air calcined cobalt sample (left) and an NO calcined cobalt sample (right) prepared by incipient wetness impregnation on silica.

From the TEM images it is clearly seen that the particles prepared by air calcination are very large, differs in size, and results in an inhomogeneous sample. On the other hand in the case where NO calcination has been applied, the sample seems very homogeneous. The particles are well dispersed and have particle sizes around $6 \mathrm{~nm}$. The results showing the effect of this on the catalytic activity in the FT process is summarized in Table 9.1. 
Table 9.1 Activity and selectivity data for a cobalt catalyst prepared by air calcination and an NO calcination, respectively.

\begin{tabular}{|c|c|c|c|}
\hline Catalyst & $\begin{array}{c}\text { Activity } \\
\left(10^{-5} \mathrm{~mol} \mathrm{CO} \mathrm{go}^{-1} \mathrm{~s}^{-1}\right)\end{array}$ & $\begin{array}{c}\text { Selectivity } \mathrm{C}_{5+} \\
(\%)\end{array}$ & $\begin{array}{c}\mathrm{C}_{5+} \text { yield } \\
\left(10^{-5} \mathrm{~mol} \mathrm{CO} \mathrm{go}_{\left.\mathrm{Co}^{-1} \mathrm{~s}^{-1}\right)}\right.\end{array}$ \\
\hline $\begin{array}{c}\mathrm{Co} / \mathrm{SiO}_{2} \\
\text { Air calcination }\end{array}$ & 2.6 & 56 & 1.45 \\
\hline $\begin{array}{c}\mathrm{Co} / \mathrm{SiO}_{2} \\
\mathrm{NO} \text { calcination }\end{array}$ & 4.7 & 35 & 1.65 \\
\hline
\end{tabular}

From this table it can be seen, that it is possible to improve the activity significantly by performing an NO calcination instead of an air calcination. On the other hand the $\mathrm{C}_{5+}$ selectivity is found to decrease. This results in a higher $\mathrm{C}_{5+}$ yield of $1.65^{*} 10^{-5} \mathrm{~mol} \mathrm{CO} \mathrm{g}_{\mathrm{Co}}{ }^{-1} \mathrm{~s}^{-1}$ for the NO calcined sample versus $1.45^{*} 10^{-5} \mathrm{~mol} \mathrm{CO} \mathrm{g}_{\mathrm{Co}}{ }^{-1} \mathrm{~s}^{-1}$ for the air calcined sample. However, it would be appreciable to increase this even further, for example by adding a promoter which is known to improve the $\mathrm{C}_{5+}$ selectivity. This experimental study in this work has been related to this aspect. 


\section{Manganese promoted cobalt catalysts}

\subsection{Introduction}

The aim of this part of the project was to obtain a more active and selective Fischer-Tropsch catalyst by combining the knowledge regarding the positive effect of $\mathrm{NO}$ calcination on the activity of cobalt catalysts with the addition of a $\mathrm{C}_{5_{+}}$selectivity promoter.

Manganese has been reported in the literature to be a promoter for cobalt based catalyst in the FT process ${ }^{96,97}$. The addition of manganese is known to increase the $\mathrm{C}_{5+}$ selectivity of the catalyst; on behalf of the activity, though ${ }^{98}$. Several research groups have been working with the Co-Mn system on different supports and their results vary quite a lot ${ }^{97,98,99}$. The effect of manganese might be due to an influence on the degree of reducibility of the cobalt, but is far from being fully understood ${ }^{100,101}$. The manganese is expected to be present in a mixed cobalt-manganese spinel structure $\left(\mathrm{Co}_{1-\mathrm{x}} \mathrm{Mn}_{\mathrm{x}}\right)_{3} \mathrm{O}_{4}{ }^{102}$.

In this study series of cobalt-manganese on silica oxide supported catalysts (in some cases promoted with platinum as well) have been examined. All catalysts were prepared by incipient wetness impregnation.

In the first phase of the experimental work a series of cobalt-manganese catalysts with a small amount of platinum was prepared with different Co:Mn ratios. The platinum was added since it was believed to improve the degree of reducibility. The activity and selectivity for these catalysts were compared to investigate the dependence of the manganese content. Furthermore each catalyst was calcined in two different ways: air calcination at $240{ }^{\circ} \mathrm{C}$ and NO calcination at $240{ }^{\circ} \mathrm{C}$, and for all catalysts the influence of the calcination method was compared as well. A series of catalysts with different Co:Mn ratios without platinum was prepared and their activity and selectivities were compared to each other and to the platinum containing series of catalysts after treatment with air calcination as well as NO calcination. Finally the influence of the reduction temperature was investigated for selected catalysts.

\subsection{Experimental}

\subsubsection{Catalyst preparation}

Before impregnation the silica (Grace-Davison silica gel, $500 \mathrm{~m}^{2} / \mathrm{g}$ ) was dried over night at $120{ }^{\circ} \mathrm{C}$ followed by treating $1.00 \mathrm{~g}$ of the support material in dynamic vacuum for $2 \mathrm{~h}$ at room temperature. 
Aqueous solutions containing cobalt(II) nitrate, manganese(II) nitrate and tetraammoniumplatinum(II) nitrate were prepared, in such a way that impregnation of $1 \mathrm{~g}$ of silica would lead to catalysts with the composition $17 \mathrm{wt} \% \mathrm{Co}$, x wt $\%$ Mn (where $\mathrm{x}=0-4.25$ $w t \%$ ) and $y w t \% P t$ (where $y=0$ or 0.5 ). In order to prepare these very concentrated metal containing solutions, they were exposed to treatment on an ultra sound bath for 30 minutes. Five different catalyst composition were prepared: Co, Co:Mn=4:1, Co:Mn=8:1, $\mathrm{Co}: \mathrm{Mn}=12: 1$, and $\mathrm{Co}: \mathrm{Mn}=16: 1$. One series of these catalysts was made with $0.05 \mathrm{wt} \%$ platinum and one series was made without.

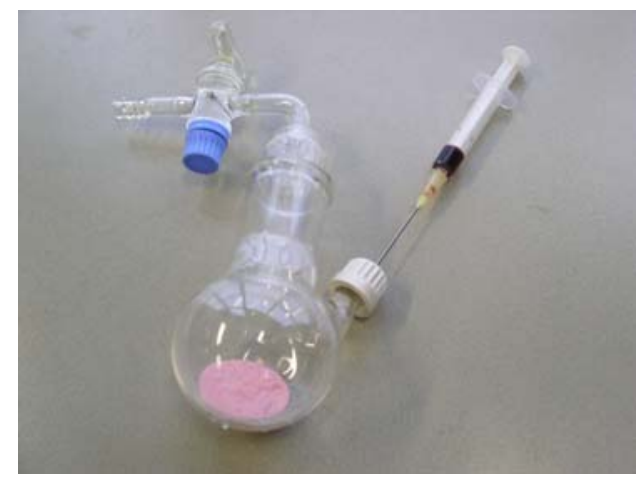

Figure 10.1 Catalyst preparation, incipient wetness impregnation of silica with a cobalt-manganese containing solution under vacuum.

The vacuum impregnation was performed, as shown in Figure 10.1 using a syringe containing the volume of the metal nitrate solution needed to make an incipient wetness impregnation. The pore volume was determined by $\mathrm{N}_{2}$-BET and checked with water impregnation in a test prior to the real impregnation. Half of the solution was added drop wise during stirring. The syringe was removed and the flask was placed in an ultra sound bath for 5-10 seconds. The procedure was repeated with the last part of the solution. After the impregnation the sample was left under vacuum for 30 minutes to let the solution, and thereby the metal ions, distribute evenly. Thereafter the vacuum was removed and the sample was dried.

\subsubsection{Drying procedure}

To establish whether or not the drying conditions had an influence, three different drying temperatures were investigated for a cobalt catalyst: $55^{\circ} \mathrm{C}, 70{ }^{\circ} \mathrm{C}$, and $85{ }^{\circ} \mathrm{C}$. Furthermore, the heating ramp was investigated: $1{ }^{\circ} \mathrm{C} / \mathrm{min}, 0.3{ }^{\circ} \mathrm{C} / \mathrm{min}$, and a preheated oven were used. The final temperature was kept for $12 \mathrm{~h}$ in all cases. One sample was dried at room temperature in an exicator over silica gel. It was also examined if waiting $24 \mathrm{~h}$ after the impregnation before the drying step was performed had an influence compared to just waiting for 30 minutes. The drying conditions examined here were found not to have impact on the 
catalysts performance. Therefore the same standard procedure was applied for all catalysts: The sample was heated from room temperature to $70{ }^{\circ} \mathrm{C}$ with $1{ }^{\circ} \mathrm{C} / \mathrm{min}$ and left at $70{ }^{\circ} \mathrm{C}$ for $12 \mathrm{~h}$ followed by cooling to room temperature.

\subsubsection{Calcinations}

\subsubsection{Air calcination}

When performing air calcination $100 \mathrm{mg}$ of sample was placed in a reactor (see Figure 10.2). It was heated in a gas flow (up-flow) of $20 \mathrm{ml} / \mathrm{min} \mathrm{O}_{2}$ and $80 \mathrm{ml} / \mathrm{min} \mathrm{N}_{2}$ with a ramp of $1{ }^{\circ} \mathrm{C} /$ min to $240{ }^{\circ} \mathrm{C}$. The sample was kept at $240{ }^{\circ} \mathrm{C}$ for $1 \mathrm{~h}$ in the same gas flow and then cooled to room temperature as fast as possible.
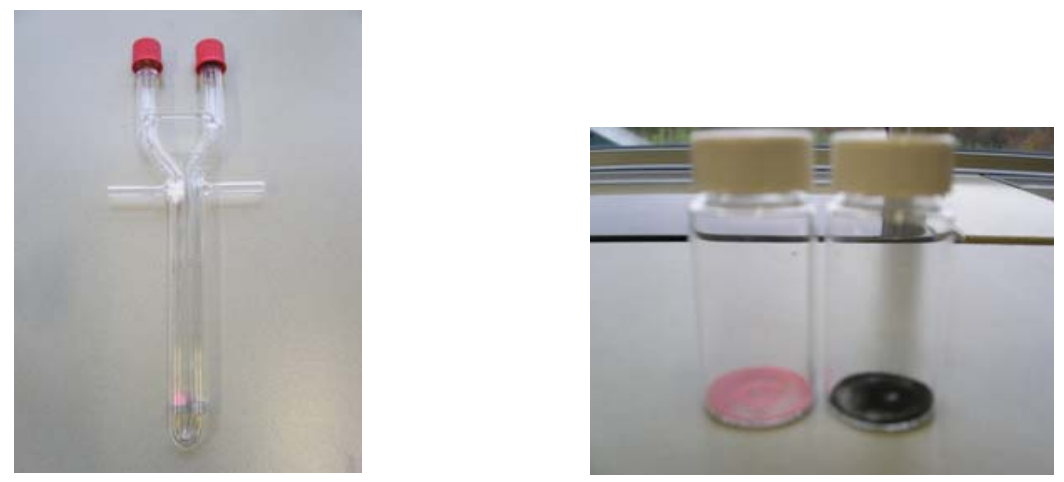

Figure 10.2 Reactor type used for both air and NO calcinations (left). Photo of a sample before and after calcination (right).

\subsubsection{NO calcination}

$100 \mathrm{mg}$ of catalyst was placed in a reactor, and the system was flushed with helium for 10 minutes before the gas was changed to $100 \mathrm{ml} / \mathrm{min} 1 \% \mathrm{NO}$ in $\mathrm{Ar}$ (up-flow). The sample was heated with $1{ }^{\circ} \mathrm{C} / \mathrm{min}$ to $240{ }^{\circ} \mathrm{C}$ and left at that temperature for $1 \mathrm{~h}$. Then the sample was cooled to room temperature in a flow of $40 \mathrm{ml} / \mathrm{min} \mathrm{He}$.

\subsubsection{Ex-situ reduction}

When reduced samples were needed for characterization purposes $25 \mathrm{mg}$ of the sample was placed in a reactor with down-flow. The system was flushed with $\mathrm{N}_{2}$ for 10 minutes before the experiments. The flows were then changed to $60 \mathrm{ml} / \mathrm{min} \mathrm{N}_{2}$ and $30 \mathrm{ml} / \mathrm{min} \mathrm{H}_{2}$ and the samples were heated to $550{ }^{\circ} \mathrm{C}$ with a rate of $5{ }^{\circ} \mathrm{C} / \mathrm{min}$. The treatment at $550{ }^{\circ} \mathrm{C}$ lasted for $2 \mathrm{~h}$ and the sample was then cooled to room temperature in the same gas composition. Then the sample was flushed with $\mathrm{N}_{2}$ for $1 \mathrm{~h}$. Finally the sample was passivated by treating it with a 
mixture of $100 \mathrm{ml} / \mathrm{min} \mathrm{N}_{2}$ and $2 \mathrm{ml} / \mathrm{min} \mathrm{O}_{2}$ for 15 minutes before removing it from the reactor.

\subsection{FT activity test}

In a traditional activity test $20 \mathrm{mg}$ of the catalyst, which was mixed carefully with $200 \mathrm{mg}$ of $\mathrm{SiC}(0.2 \mathrm{~mm})$ to obtain isothermal plug flow conditions under the experiments, was placed in a reactor (see Figure 10.3).
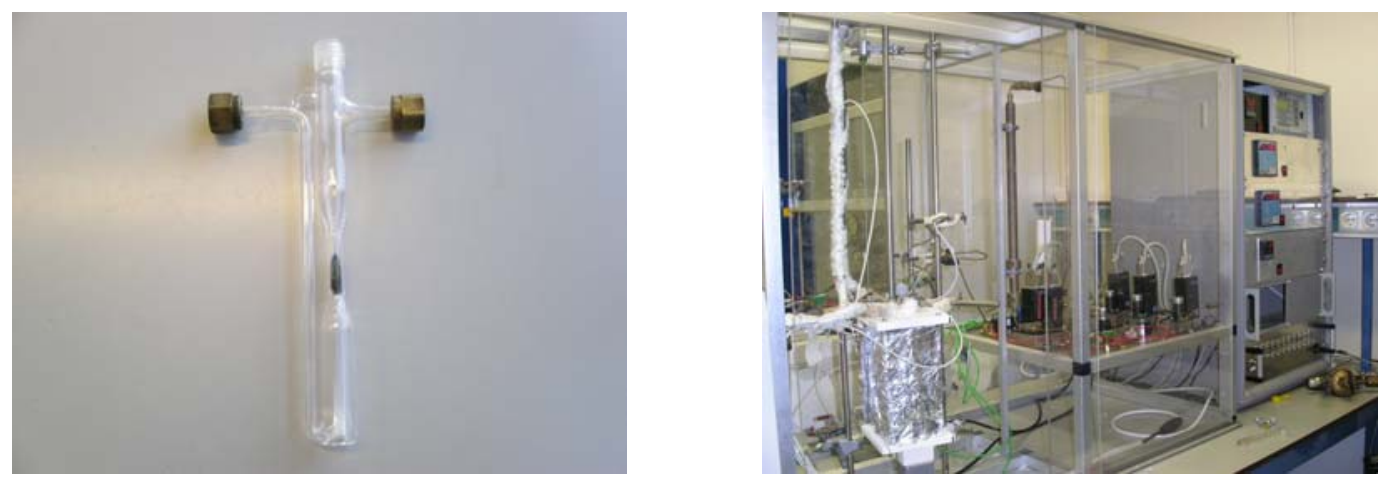

Figure 10.3 FT tests were carried out in a reactor with a mixture of catalyst and silicon carbide (left). FT test set-up (right).

The sample was reduced in-situ prior to the activity test by heating it in $20 \mathrm{ml} / \mathrm{min} \mathrm{H}_{2}$ mixed with $40 \mathrm{ml} / \mathrm{min} \operatorname{Ar}$ (down-flow) with a heating rate of $5{ }^{\circ} \mathrm{C} / \mathrm{min}$ to the desired reduction temperature $\left(400-550^{\circ} \mathrm{C}\right)$. The sample was kept at the reduction temperature for $2 \mathrm{~h}$, and then it was cooled to $220^{\circ} \mathrm{C}$ with a rate of $10^{\circ} \mathrm{C} / \mathrm{min}$.

The Fischer-Tropsch synthesis was carried out at 1 bar at $220{ }^{\circ} \mathrm{C}$. The flow was changed to $1.5 \mathrm{ml} / \mathrm{min} \mathrm{CO}$ mixed with $3.0 \mathrm{ml} / \mathrm{min} \mathrm{H}_{2}$. The products formed by the process were detected with a GC equipped with an FID detector over night. The next day, when steady state was obtained, the flows were adjusted as needed to obtain a $2 \% \mathrm{CO}$ conversion and a $\mathrm{CO}: \mathrm{H}_{2}$ ratio of 1:2. A couple of GC measurements were performed under these conditions to assure reproducibility.

\subsection{Characterization}

\subsection{1 $\mathrm{N}_{2}$ adsorption-desorption measurements}

The silica was investigated with $\mathrm{N}_{2}$-BET in order to determine pore volume and surface area. The $\mathrm{N}_{2}$-physisorption experiments were performed on a Micrometrics Tristar Surface Area and Porosity analyzer. 


\subsubsection{XRD}

As a standard procedure all calcined samples were investigated with powder X-ray diffraction (XRD) in order to estimate the particle size. The XRD patterns were recorded using an EnrafNonius CPS 120 powder diffraction apparatus with Co K $\alpha$ radiation (1.789 $\AA$ ).

\subsubsection{TEM and EDX}

Ex-situ reduced and passivated samples were examined with transmission electron microscopy (TEM) in a FEI Tecnai 12 or in a FEI Technai 20F. The samples were crushed and suspended in buthanol under ultrasonic vibration. One drop of this solution was placed on a holey carbon film on a copper TEM grid. Energy dispersive X-ray spectroscopy (EDX) was investigated too.

\subsubsection{XANES}

$\mathrm{X}$-ray absorption spectroscopy (XAS) data were measured in transmission at beam-line $\mathrm{C}$ of the HASYLAB synchrotron in Hamburg. The beam-line was equipped with a Si(111) double crystal monochromator, which was detuned to $60 \%$ of the maximum intensity to avoid higher harmonics. A cobalt foil was simultaneously measured as a reference with a third ionization chamber. Samples were reduced in-situ in $\mathrm{He} / \mathrm{H}_{2}=2 / 1$ in a dedicated cell and in order to measure EXAFS it was cooled down to liquid-nitrogen temperature.

Spectra of cobalt foil and $\mathrm{CoO}$ were measured as references. Extraction of the EXAFS data from the measured absorption spectra was performed with the XDAP code using standard procedures, averaging over three scans. Normalization was done at $50 \mathrm{eV}$ after the absorption edge using cubic spline routines for the background subtraction. To obtain information on the extend of the reduction focus has only been put on the X-ray absorption near edge structure (XANES) part of the XAS data.

\subsection{Results and discussion}

\subsubsection{Activity of manganese promoted cobalt catalysts}

The activity of catalysts containing $17 \mathrm{wt} \% \mathrm{Co}, 0.05 \mathrm{wt} \% \mathrm{Pt}$, and different manganese contents were tested in the Fischer-Tropsch process. These catalysts were calcined using either an NO calcination or an air calcination. All the catalysts were reduced at $550{ }^{\circ} \mathrm{C}$. In the following their steady state performance at 1 bar and $220{ }^{\circ} \mathrm{C}$ will be compared. The flows were adjusted to obtain $2 \% \mathrm{CO}$ conversion. The activity was calculated as CTY-values: 


$$
\mathrm{CTY}=F_{C O} * X_{C O} / m_{C O}
$$

where $F_{C O}$ is the molar feed of $\mathrm{CO}$ (mole/s) after adjusting to $2 \% \mathrm{CO}$ conversion, $X_{C O}$ is the measured fraction of CO converted (close to $2 \%$ ), and $m_{C o}$ is the mass of cobalt (g).

Figure 10.4 shows the activity expressed as CTY values as a function of the manganese content in the sample, expressed as a cobalt manganese ratio.

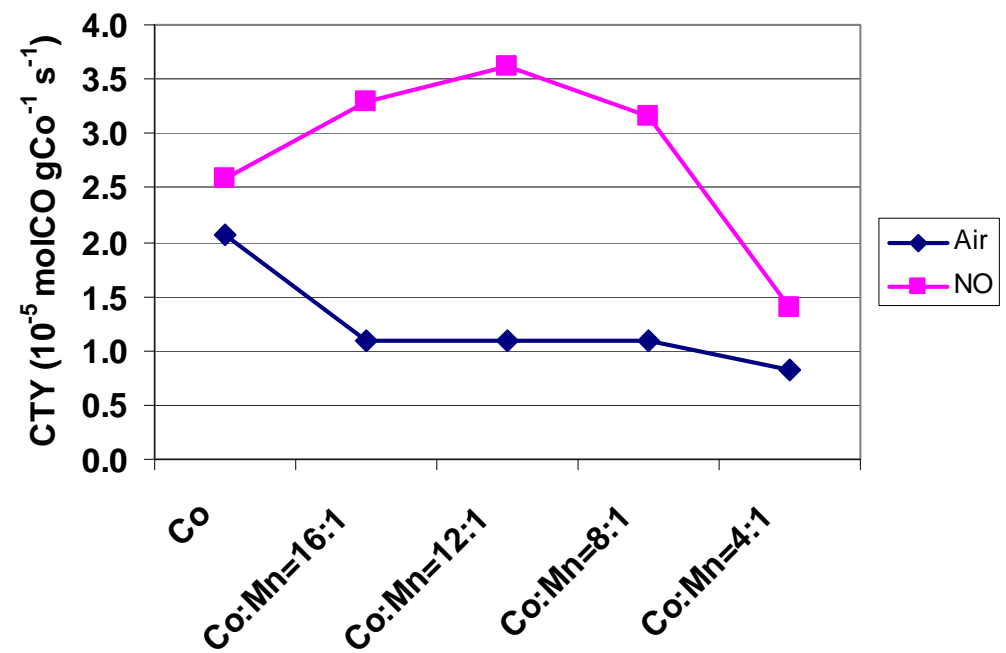

Figure 10.4 Catalytic activity plotted vs. Co:Mn ratio for an air calcined series and an NO calcined series of catalysts. All catalysts contain $0.05 \mathrm{wt} \% \mathrm{Pt}$ and they are all reduced at $550{ }^{\circ} \mathrm{C}$. The activity is measured at $220{ }^{\circ} \mathrm{C}$ at steady state after the flows has been adjusted to obtain $2 \% \mathrm{CO}$ conversion.

The first thing worth noticing is the tremendous impact the calcination method has on the activity. For some of these catalysts the activity is improved by more than a factor of 3 when using NO calcination instead of the standard air calcination. The increase in activity is in accordance with previous work $^{95}$ done with monometallic cobalt catalysts, but the influence has never previous been investigated for samples containing more than one metal. If looking at the two series individually, a few thing should be noted. For the air calcined samples the activities are in all cases lower for the manganese promoted samples than for the monometallic cobalt sample, as would be expected since manganese is a selectivity promoter, and expected to decrease the activity. Furthermore, it can be concluded that the influence of the amount of manganese is rather limited when studying samples with $\mathrm{Co}: \mathrm{Mn}=1: \mathrm{x}$, where $\mathrm{x}=8,12,16$. The sample with $\mathrm{Co}: \mathrm{Mn}=4: 1$ shows slightly lower activities indicating that with too much manganese present, the activity will drop further. If looking closer into the NO calcined samples it is seen that the activity of the Co:Mn=1:x, where $\mathrm{x}=8,12,16$, catalysts are actually higher than for the Co sample. This is a rather surprising result which later will be discussed further. Compared to the air calcined samples the NO calcined samples show an 
activity dependence of the amount of manganese present. The optimum activity is found for $\mathrm{Co}: \mathrm{Mn}=12: 1$, and for that reason this catalyst has been chosen to be the primary target for further studies where only one of the manganese promoted catalyst could be examined due to the time limitation of the project. When increasing the Co:Mn ratio even further the activity drops dramatically - the sample with $\mathrm{Co}: \mathrm{Mn}=4: 1$ shows rather poor activity. This means that the same trend is seen for both calcination series in that respect - too high manganese content is lowering the activity of the sample. As manganese is expected to be a $\mathrm{C}_{5+}$ selectivity promoter based on the literature ${ }^{96,97}$, this is investigated by plotting the values for the selectivity as a function of the manganese content, as shown in Figure 10.5.

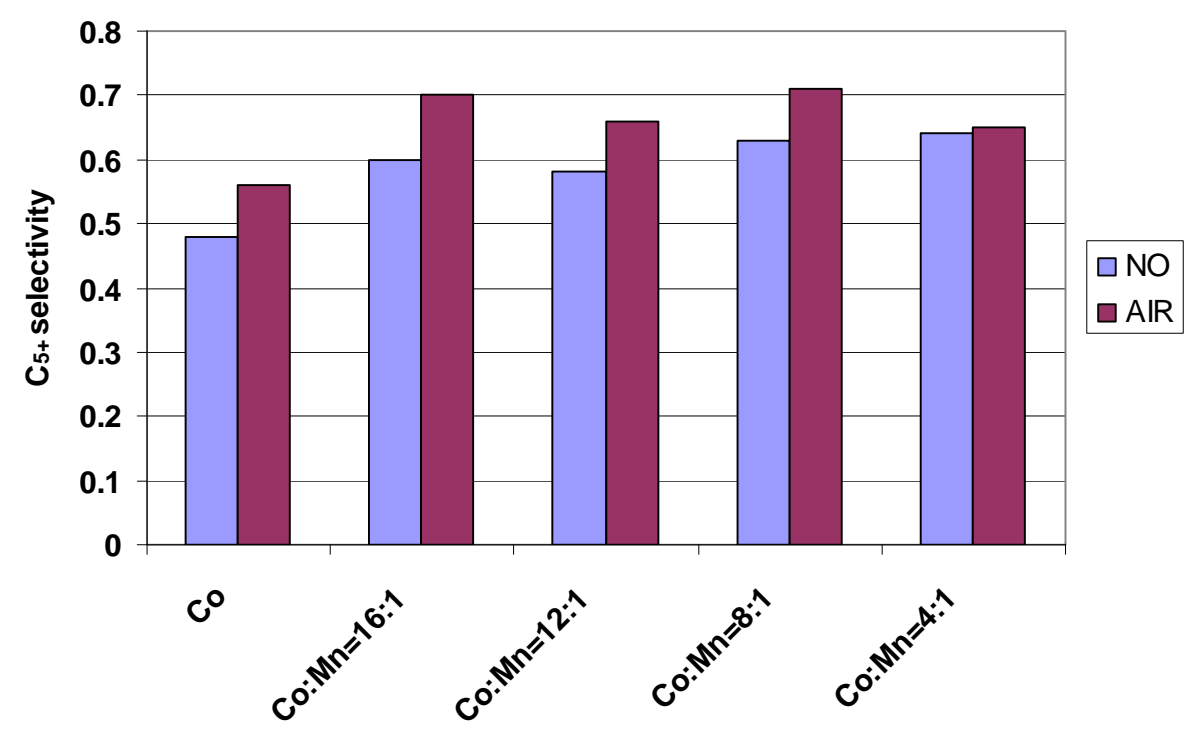

Figure 10.5 $\mathrm{C}_{5+}$ selectivities for air- and NO calcined samples containing $0.05 \mathrm{wt} \% \mathrm{Pt}$, reduced at $550^{\circ} \mathrm{C}$. The measurements are performed at $220^{\circ} \mathrm{C}$ at steady state and at $2 \% \mathrm{CO}$ conversion.

From Figure 10.5 it can be seen that air calcined samples have a higher $\mathrm{C}_{5+}$ selectivity than the NO calcined samples in all cases. This is exactly what was expected based on the preliminary experiments done on the monometallic cobalt system ${ }^{95}$. Furthermore, it is seen that the addition of manganese improves the $\mathrm{C}_{5+}$ selectivity compared to the cobalt catalyst in all cases. The $\mathrm{C}_{5+}$ selectivity is more or less constant for all the manganese containing samples within a calcination series, meaning that no clear correlation between the $\mathrm{C}_{5+}$ selectivity and the manganese content (as long as manganese is present) is observed.

\subsubsection{Influence of platinum}

A number of catalysts without platinum was prepared and compared to the corresponding samples with platinum, to investigate the effect on the activity of adding platinum. In Figure 
10.6 a comparison of activities at $220^{\circ} \mathrm{C}$ for catalysts with and without platinum are shown. All these catalysts were reduced at $550{ }^{\circ} \mathrm{C}$.

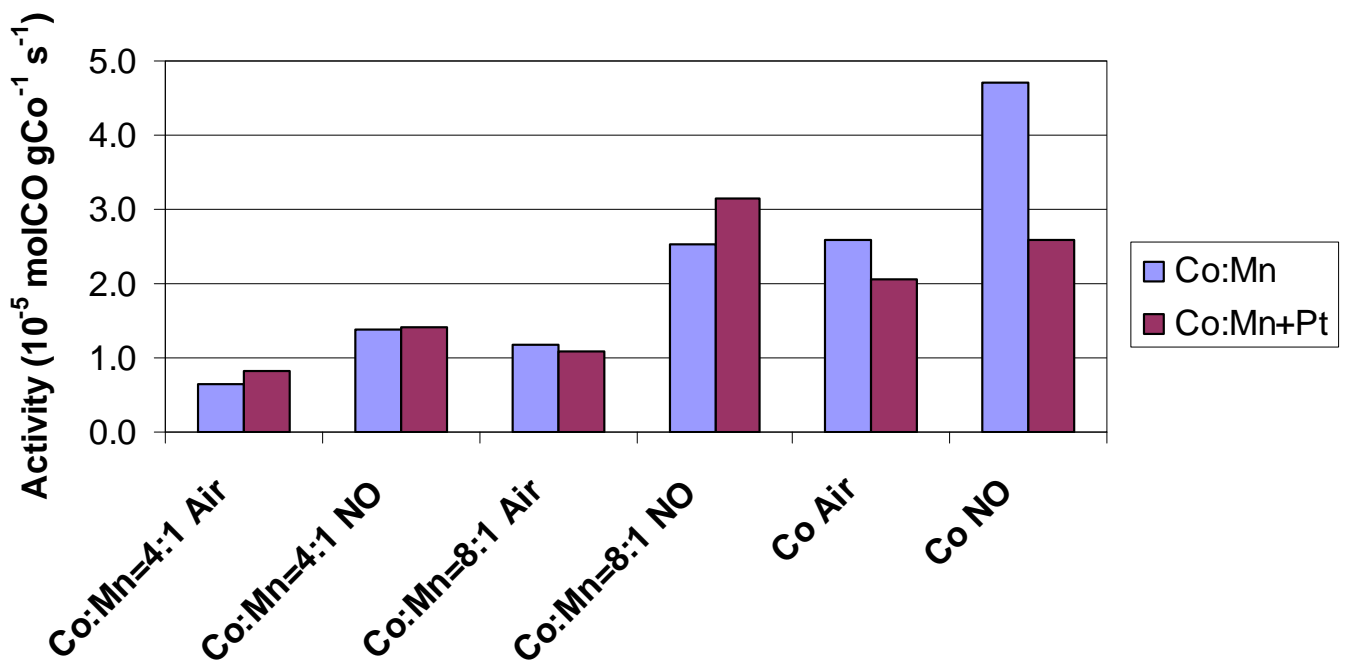

Figure 10.6 Comparison of catalytic activities for catalysts with and without platinum. All catalysts are reduced at $550{ }^{\circ} \mathrm{C}$. The activity is measured at $220{ }^{\circ} \mathrm{C}$ at steady state after the flows has been adjusted to obtain $2 \% \mathrm{CO}$ conversion.

Figure 10.6 shows that the addition of platinum leaves the activity almost unchanged in the samples where manganese is present. For the cobalt air calcined sample the difference in activity whether or not platinum is present is negligible too. However, for the NO calcined Co sample the situation is different. In this case the addition of platinum lowers the activity significantly. A possible explanation is that the platinum increases the degree of reduction, and enhances the possibility of sintering whereby the activity lowered. It is understandable that sintering might occur to a higher degree for the NO calcined cobalt sample than for the air calcined sample - in the NO calcined sample the particles are small and can easily migrate and sinter together, while for the air calcined samples the particles are already large and clustered together, as illustrated in the TEM images in Figure 9.2. Thus, it can be imagined that even small changes in the NO calcined sample will change the activity a lot. Since this is not a problem for the platinum containing manganese promoted samples, this might be the reason for these catalysts to be more active than the platinum containing cobalt catalyst in the NO calcined series in Figure 10.4.

In order to see if the addition of platinum has an effect it is not sufficient to investigate the activity - the $\mathrm{C}_{5+}$ selectivity for these two series of catalysts, with and without platinum, must be examined as well. The results of a selectivity comparison are shown in Figure 10.7. 


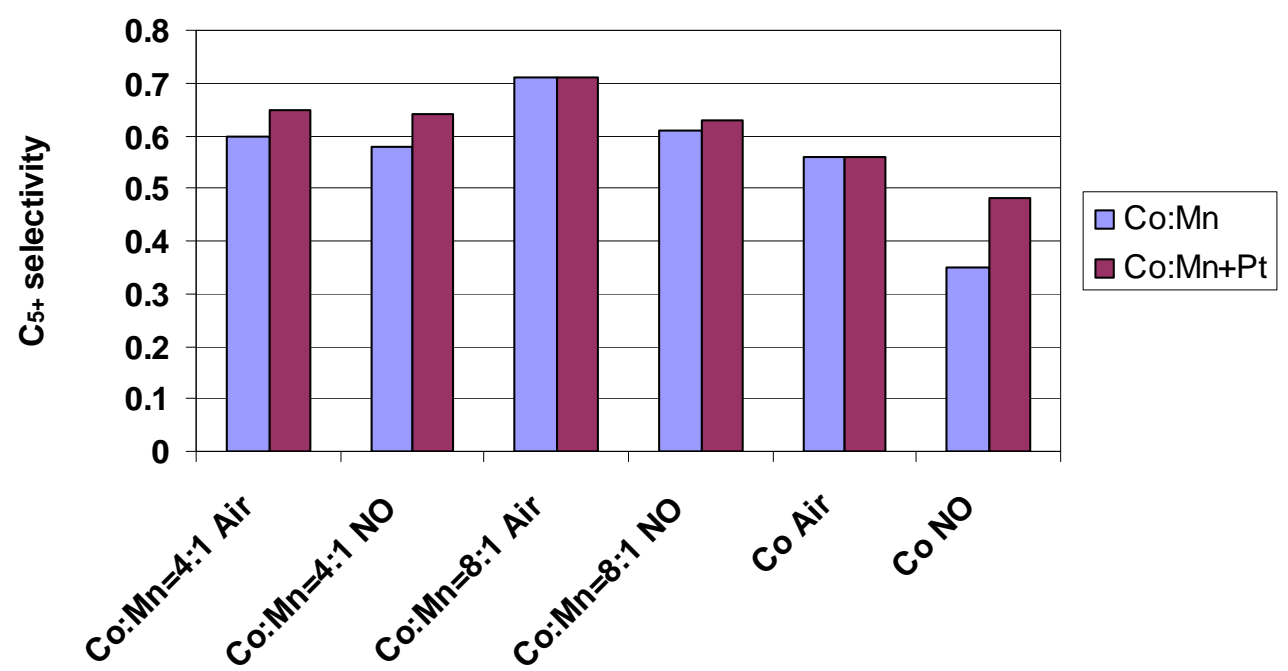

Figure 10.7 Comparison of $\mathrm{C}_{5+}$ selectivities for catalysts with and without platinum. All catalysts are reduced at $550{ }^{\circ} \mathrm{C}$. The selectivity is studied at $220{ }^{\circ} \mathrm{C}$ at steady state after the flows have been adjusted to $2 \% \mathrm{CO}$ conversion.

The selectivity is found to be rather independent of the presence of platinum in these samples where the activity was not affected either: the air calcined Co sample and all the manganese promoted samples. This means that the only sample where the $\mathrm{C}_{5+}$ selectivity is significantly affected is the NO calcined Co sample. In this case the $\mathrm{C}_{5+}$ selectivity is higher for the platinum containing sample. This is expected if the theory about sintering in the sample is correct, since it has previously observed that samples with large particles exhibit higher selectivities than samples with small particles (see Table 9.1). Based on the unchanged activities and selectivities for the manganese containing samples, it is expected that the manganese protect the samples from sintering.

\subsubsection{Reduction at different temperatures}

Since sintering is closely related to reducibility, it became interesting to look into the impact of the reduction, and hereby the reduction temperature. This was investigated for two

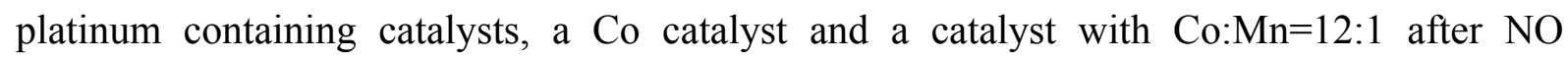
calcination. In Figure 10.8 the activity (expressed as CTY values), and the $\mathrm{C}_{1}$ and $\mathrm{C}_{5+}$ selectivity for the catalysts are plotted, showing their catalytic performance after having been reduced at different temperatures. 


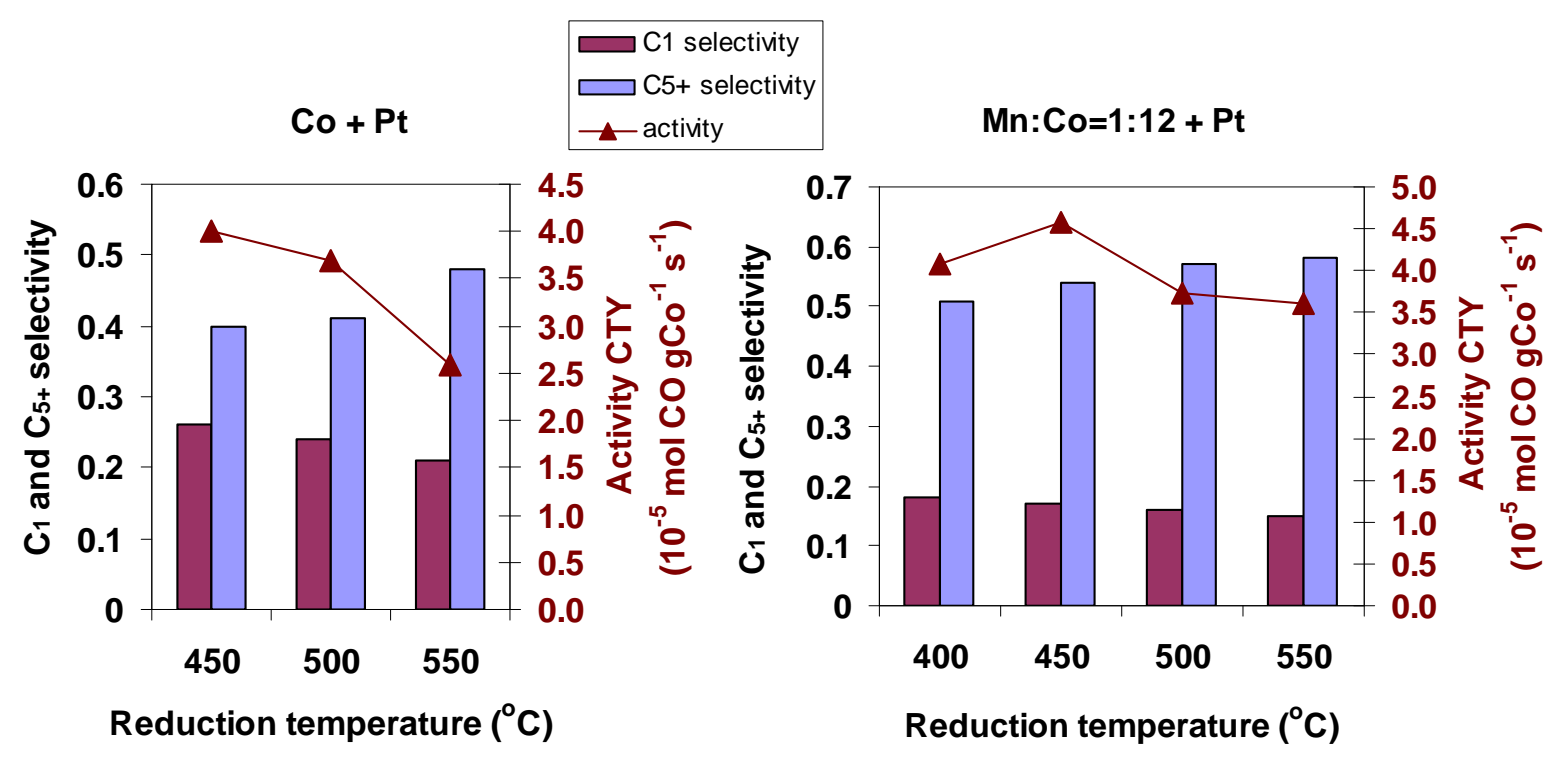

Figure 10.8 Catalytic performance of a Co catalyst and Co:Mn=1:12 (both containing $0.05 \mathrm{wt} \%$ platinum) after reduction at different temperatures. The activities and selectivities are measured at $220{ }^{\circ} \mathrm{C}$ at steady state after the flows have been adjusted to $2 \% \mathrm{CO}$ conversion.

For the cobalt catalyst the activity is seen to be very dependent on the reduction temperature. At $450{ }^{\circ} \mathrm{C}$ the activity is highest and it is decreasing with increasing reduction temperature. The $\mathrm{C}_{5+}$ selectivity is slightly higher the higher the reduction temperature gets. However, the difference in $\mathrm{C}_{5+}$ selectivity for the three experiments within this series is low. For the $\mathrm{Co:} \mathrm{Mn}=12: 1$ catalyst the activity is highest at $450{ }^{\circ} \mathrm{C}$. At higher reduction temperature the activity decreases, probably due to sintering. When performing the reduction at $400{ }^{\circ} \mathrm{C}$ the activity is lower than after a reduction at $450{ }^{\circ} \mathrm{C}$, which probably can be explained by the catalyst not being fully reduced at $400{ }^{\circ} \mathrm{C}$. The $\mathrm{C}_{5+}$ selectivity is also found to decrease slightly with increasing reduction temperatures as for the cobalt catalyst. However, the effect on the activity as a function of the reduction temperature is more pronounced than the difference in $\mathrm{C}_{5+}$ selectivity. The conclusion based on these two investigated catalysts is, that it is advantageous to use $450{ }^{\circ} \mathrm{C}$ as a standard reduction temperature for future experiments instead of the $500{ }^{\circ} \mathrm{C}$ used in most cases in this work.

\subsubsection{Anderson-Schultz-Flory distribution}

For all catalysts the product distribution was investigated by making an Anderson-SchultzFlory (ASF) plot. An example of such a plot is shown in Figure 10.9 where a logarithmic plot of the concentration (ppm) of carbon chains of length $n, C_{n}$, is shown as a function of $n$, for $\mathrm{n}=1, \ldots, 12$. The catalyst investigated here is the NO calcined $\mathrm{Co}: \mathrm{Mn}=12: 1+0.05 \mathrm{wt} \% \mathrm{Pt}$ sample after reduction at $450{ }^{\circ} \mathrm{C}$. The numbering of the curves indicates after how many 
hours from the beginning of the reaction (temperature $220{ }^{\circ} \mathrm{C}$, flows changed from the reduction gas to the syn-gas), the investigated gas sample was taken. Sample 1-6 (before steady state) and 12-13 (after steady state) were taken when the flows of $\mathrm{CO}$ and $\mathrm{H}_{2}$ were 1.5 and $3.0 \mathrm{ml} / \mathrm{min}$, respectively. Sample 14 and 15 were taken after the flows were adjusted to obtain $2 \%$ CO conversion at steady state.

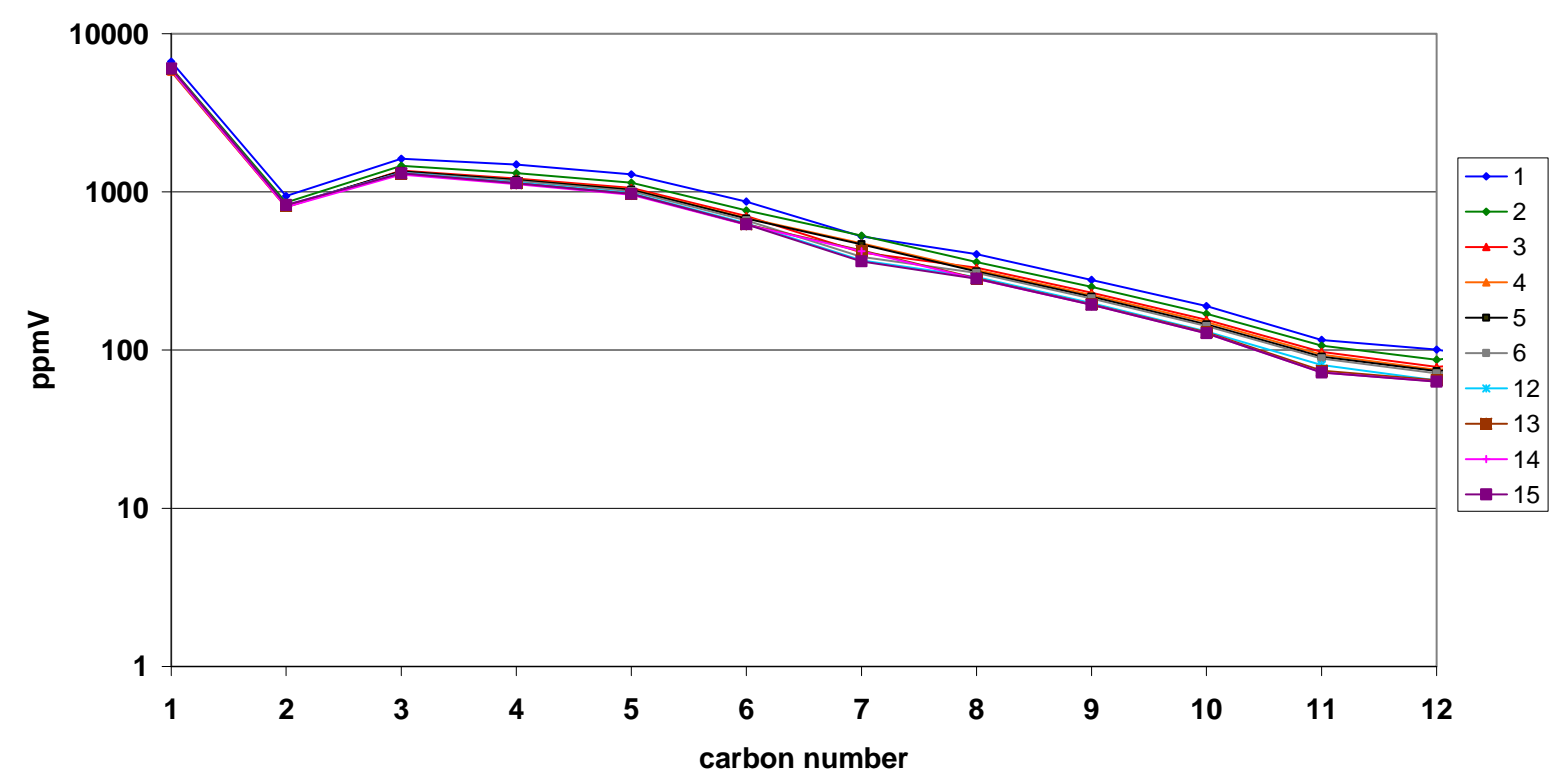

Figure 10.9 Anderson-Schulz-Flory plot for a catalyst with the composition $\mathrm{Co}: \mathrm{Mn}=12: 1+0.05 \mathrm{wt} \% \mathrm{Pt}$, calcined in $\mathrm{NO}$ and reduced at $450^{\circ} \mathrm{C}$.

The first thing that can be noticed is that the points for $\mathrm{C}_{3}-\mathrm{C}_{12}$ form a straight line, in accordance with the distribution. In this part of the curve the amounts of the different products decrease monotonously with increasing chain length. $\mathrm{C}_{1}$ and $\mathrm{C}_{2}$ are exceptions. This fact is well known from the literature ${ }^{103}$ and can be explained. More $C_{1}$ than predicted by extrapolation from the line is formed, since the $\mathrm{C}_{1}$ formation result in termination for polymer growth. On the other hand there seems to be too little $\mathrm{C}_{2}$ products. This can be explained by the fact that $\mathrm{C}_{2}$ can work as insertion unit in the chain growth, meaning that a part of the $\mathrm{C}_{2}$ will be used as building blocks for longer chains before the reaction is terminated and the $\mathrm{C}_{2}$ molecule is liberated from the catalytic active sites. It is seen that the trend in these curves are the same, independent on the time at which they are taken. The slight decrease in amount of product with time can be related to the loose of activity for the catalyst in the induction period and thereby decrease in CO conversion until steady state is reached. 


\subsubsection{Paraffins and olefins}

When investigating the product distribution it is also useful to investigate the paraffin/olefin $(\mathrm{P} / \mathrm{O})$ ratio. A logarithmic plot of $\mathrm{P} / \mathrm{O}$ is plotted versus the number of carbon atoms in the chain, as shown in Figure 10.10. This is done for the same catalyst, $\mathrm{Co:Mn}=12: 1+0.05 \mathrm{wt} \% \mathrm{Pt}$, for which the ASF distribution was illustrated. The data for both plots were obtained during the same experiment and at the same times.

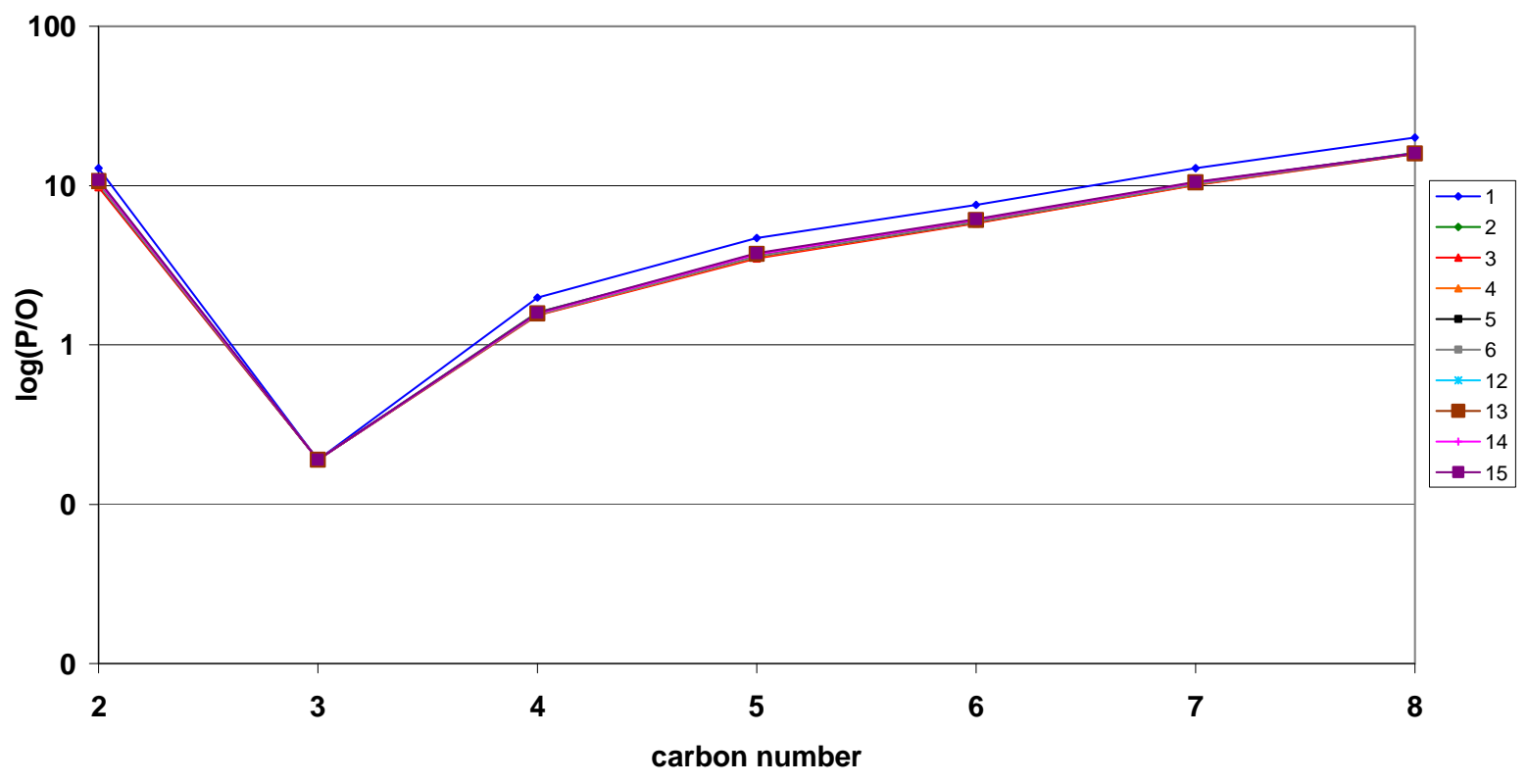

Figure 10.10 Logarithmic plot of the paraffin/olefin ratio versus the carbon number for a catalyst with the composition Co:Mn=12:1+0.05 wt $\% \mathrm{Pt}$, calcined in $\mathrm{NO}$ and reduced at $450^{\circ} \mathrm{C}$.

Again, it is seen that $\mathrm{C}_{2}$ is behaving different than the others; the paraffin/olefin ratio is higher for $\mathrm{C}_{2}$ than for the other carbon chains. The relatively low formation of olefins can again be explained by the fact that intermediates of this can act as a monomer in the polymer growth whereby the formed paraffin can not react further and terminates the process. From $\mathrm{C}_{3}$ and up a monotonous increase in the paraffin/olefin ratio is observed.

It should be mentioned that the trend in the ASF-plot and the P/O-plot is representative for all the investigated catalysts. Surely the values vary, as it would be expected, which can be seen in section 10.5.6.

\subsubsection{Comparison of the catalysts}

In Table 10.1 the $\alpha, \mathrm{C}_{1}, \mathrm{C}_{5+}$ values and the ratio between paraffin and olefins for $\mathrm{C}_{2}, \mathrm{C}_{4}$, and $\mathrm{C}_{8}$ are shown for the different catalyst systems discussed in this chapter along with particle size and reduction temperature, making it easier to see and compare all the data. 
Table 10.1 Comparison of important parameters for the FT catalysts.

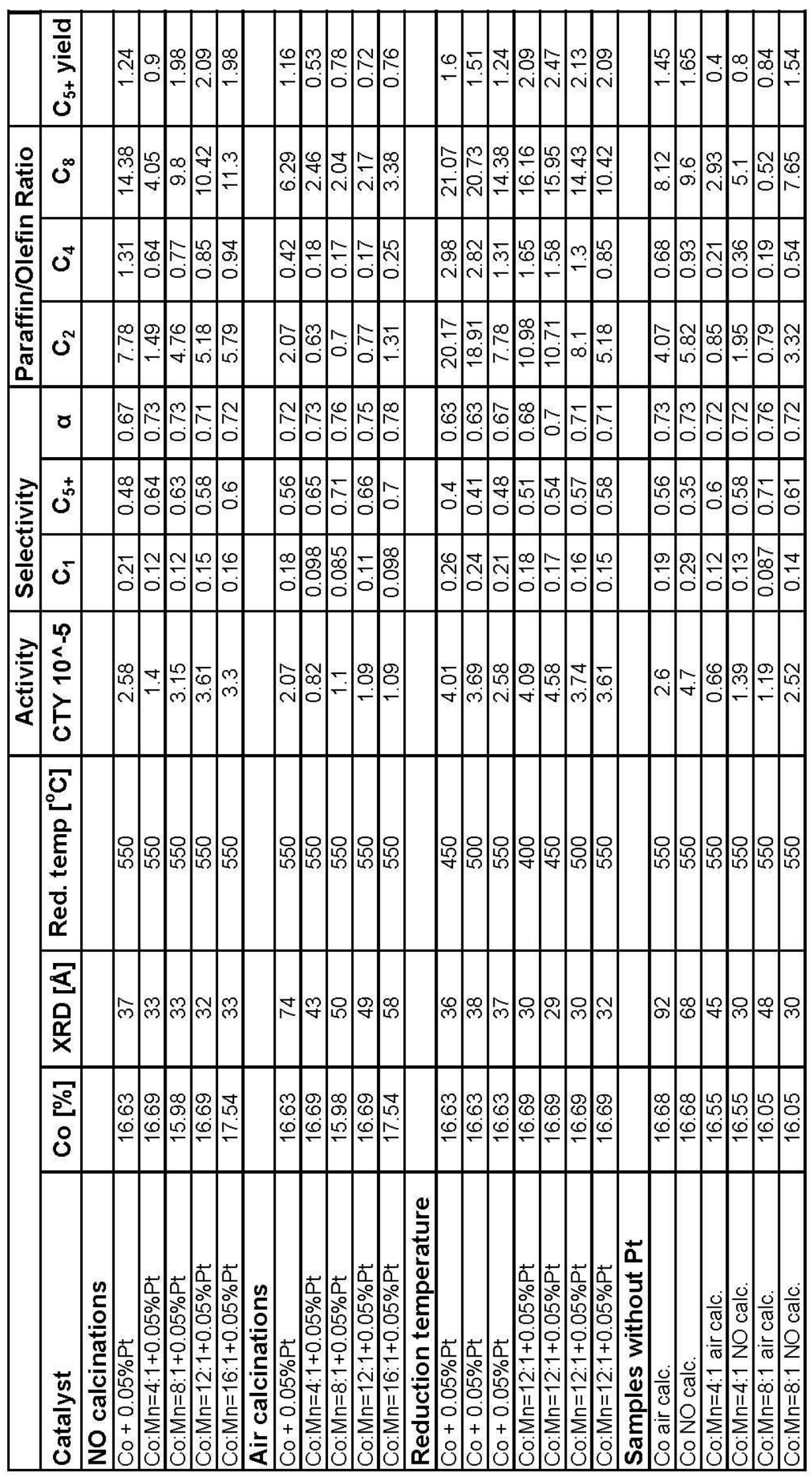




\subsubsection{Induction period}

Another interesting parameter to examine is the induction period of the catalysts. It was investigated how the catalytic behavior changed from the time where the gases were shifted to $\mathrm{CO} / \mathrm{H}_{2}$ and until the next day when steady state was obtained. The over-all decreases in activity for the air calcined series of catalysts as well as the NO calcined series are shown in Figure 10.11 .

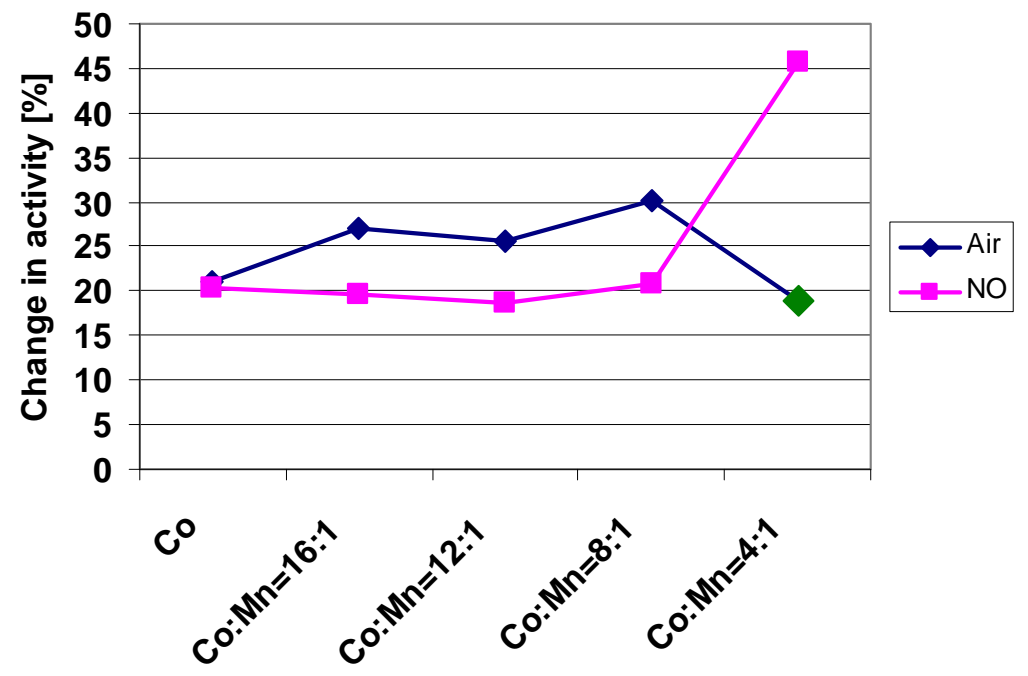

Figure 10.11 Decrease in activity for platinum containing catalyst (in percentage) from the time where the experiments were started (shift from gas used for reduction to syn-gas) and until steady state was reached. The green point is connected with great uncertainty. All catalysts are reduced at $550{ }^{\circ} \mathrm{C}$ for $2 \mathrm{~h}$ before the tests.

There is in general a clear relation between the decrease in activity during the induction period and the final activities at steady state - the less percentage decrease the higher final activity. The NO calcined catalyst with $\mathrm{Co}: \mathrm{Mn}=12: 1$, which is found to have the highest CTY at steady state, has the lowest decrease in activity during the induction period. In the NO calcined series a huge decrease in activity is found for the catalyst containing most manganese, Co:Mn=4:1, which is indeed the least active catalyst within that series. For the air calcined series, it should be mentioned that the catalyst with $\mathrm{Co}: \mathrm{Mn}=4: 1$ has very low initial activity, making it difficult to determine the decrease in activity and compare it fair with the other data. Therefore care should be taken when using the value for this data point (green) too quantitatively. Except for this data point, the other data in the air calcined series follow the same tendency regarding final activity and decrease in activiy during the induction period as the NO calcined samples. Furthermore the air calcined samples seem to loose more activity before steady state is reached than the NO calcined samples. Again this trend is in accordance 
with the activity found after steady state - the NO calcined samples are more catalytically active than the air calcined series.

\subsection{Characterization}

\subsubsection{XANES}

The catalysts were characterized in different ways. In order to look into the reducibility aspect as described previously, XANES analysis were performed on selected samples. This technique allowed determination of the degree of the reduction. The degree of reduction was established from the whiteline intensities using an extrapolation between a Co foil sample and a cobalt(II) oxide sample. The spectra are shown in Figure 10.12.

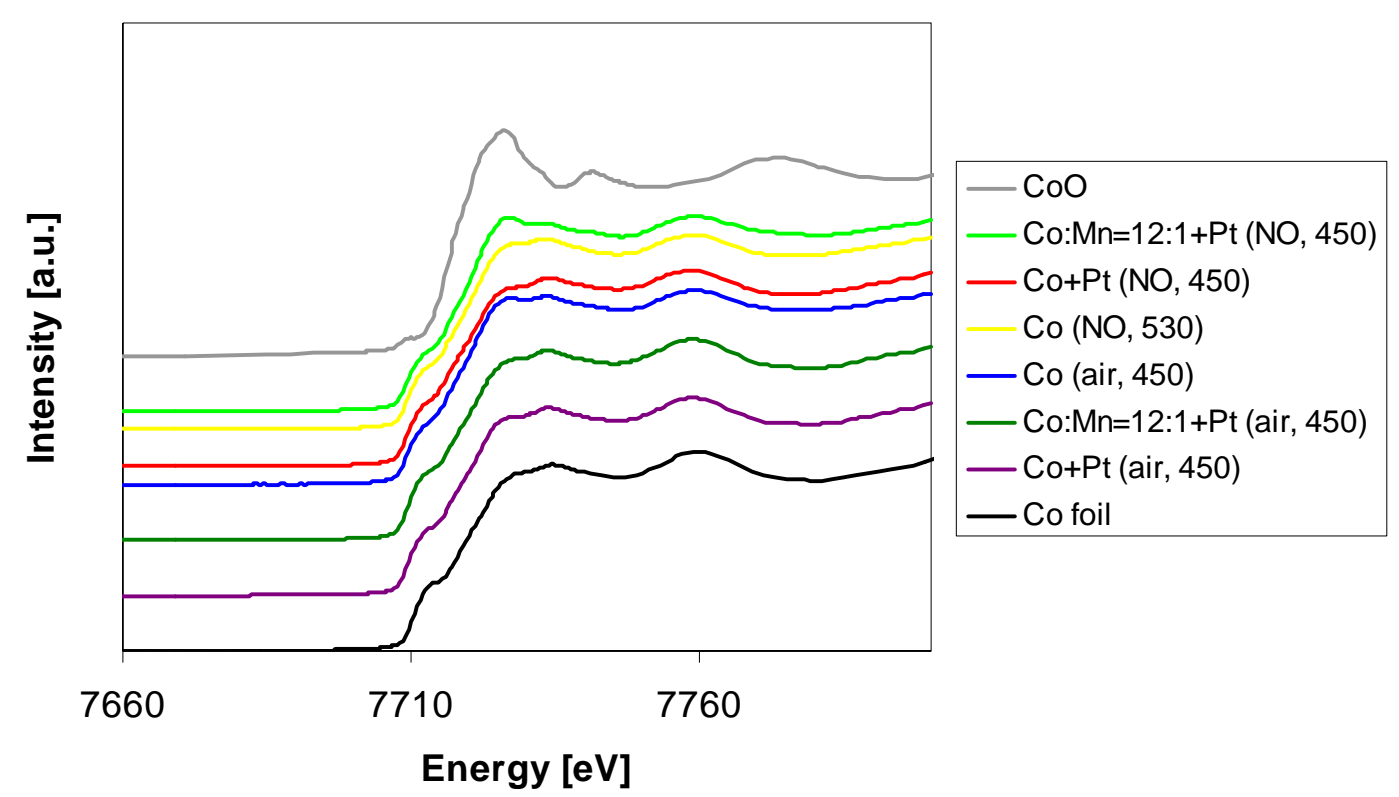

Figure 10.12 XANES of selected catalysts and cobalt (Co foil) and cobalt oxide (CoO) as references. The calcination method and the reduction temperatures are indicated in the parentheses. In all cases where $\mathrm{Pt}$ is present, it is a total loading of $0.05 \mathrm{wt} \%$.

The degrees of the reduction calculated from the spectra are summarized in Table 10.2. 
Table 10.2 Degree of reduction calculated from the XANES experiments, the numbers in parentheses show the reduction temperatures in ${ }^{\circ} \mathrm{C}$.

\begin{tabular}{|lll|l|}
\hline \multicolumn{3}{|l|}{ Degree of reduction (\%) } \\
\hline \multicolumn{2}{|l|}{$\mathrm{Co}: \mathrm{Mn}=12: 1+\mathrm{Pt}$} & $\mathrm{NO}(450)$ & 62 \\
\hline $\mathrm{Co}+\mathrm{Pt}$ & $\mathrm{NO}$ & $(450)$ & 96 \\
\hline $\mathrm{Co}$ & $\mathrm{NO}$ & $(450)$ & 78 \\
\hline $\mathrm{Co}$ & $\mathrm{NO}$ & $(530)$ & 82 \\
\hline $\mathrm{Co}: \mathrm{Mn}=12: 1+\mathrm{Pt}$ & Air & $(450)$ & 94 \\
\hline $\mathrm{Co}+\mathrm{Pt}$ & Air & $(450)$ & 96 \\
\hline
\end{tabular}

From these data several important conclusions can be extracted. If looking at the NO calcined cobalt samples with platinum it is seen to be completely reduced $(96 \%)$ at $450{ }^{\circ} \mathrm{C}$, supporting the hypothesis that this sample is especially prone to sintering which might explain the low catalytic activity. The air calcined cobalt sample with platinum is also completely reduced (96\%), but since the particle sizes for air calcined sample is expected to be quite large as already seen in the TEM image (Figure 9.2) further sintering is not as problematic in this case as it is for the NO calcined sample. The NO calcined cobalt sample without platinum is not fully reduced $\left(78 \%\right.$ ) at $450{ }^{\circ} \mathrm{C}$ and therefore sintering is not a problem in this case. Apparently, the change in degree of reduction is surprisingly small for different reduction temperatures for an NO calcined cobalt sample not containing platinum $\left(78 \%\right.$ at $450{ }^{\circ} \mathrm{C}$ and $82 \%$ at $530{ }^{\circ} \mathrm{C}$ ). The air calcined $\mathrm{Co}: \mathrm{Mn}=12: 1$ sample with platinum shows a reduction degree of $94 \%$ while the NO calcined sample shows a very low degree of reduction, namely $62 \%$. The air calcined samples seem to be protected from sintering by the manganese- at least the activity seems to stay high for this sample as mentioned previously. The low reduction degree of the NO calcined manganese containing sample is surprising, when compared to the high catalytic activity of this sample, and further characterization are needed in order to explain the effect.

\subsubsection{XRD}

XRD analyses were performed for all samples as a standard procedure. In Figure 10.13 the diffractograms are shown for a series of catalysts with different Co:Mn ratio all containing platinum. The diffractogram for a sample with given Co:Mn ratio is shown after air calcination and NO calcination, respectively. 


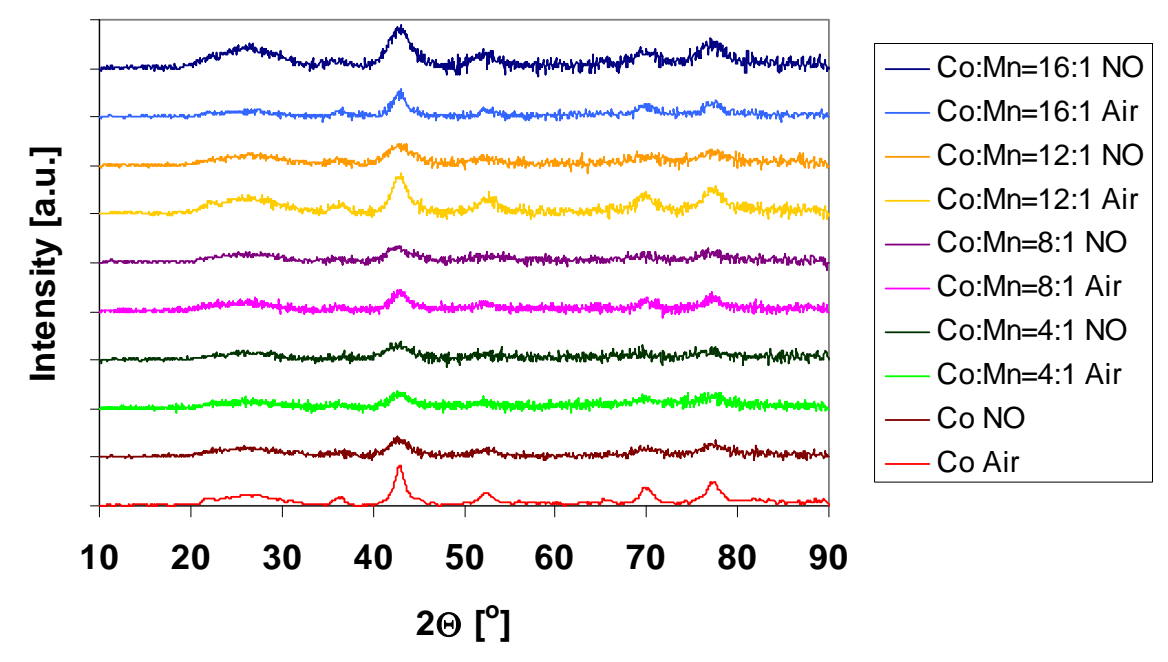

Figure 10.13 XRD diffractograms for air calcined as well as NO calcined catalysts with different ratios of cobalt manganese, all containing platinum.

The particle sizes were calculated using the Scherrer equation, evaluating the peak at $2 \theta=43^{\circ}$ originating from cobalt oxide. It is immediately clear from Figure 10.13 that this band is broader for the NO calcined samples than for the air calcined samples, showing that the NO calcined samples contain smaller particles than the air calcined samples.

Quantitatively the air calcined cobalt sample without manganese is found to have average particle sizes of $75 \AA$, while the NO calcined cobalt sample shows average particles of approximately $38 \AA$ in diameter. For the other samples, it is observed that the particle sizes are the same within the same calcination series, independent of the manganese content. However, the average particle size for the manganese containing samples is different from the pure cobalt sample. The NO calcined Co:Mn containing catalysts have an average particle size of approximately $32 \AA$, while the air calcined samples have an average particle size close to $50 \AA$. The fact that all the manganese containing samples have almost the same particle sizes within a given calcination series, makes it possible to compare the samples directly without taking a potential particle size effect into account. Within the entire NO calcination series the particle size of the cobalt is close in size to the catalysts containing manganese. This means that the activity variation as a function of the manganese content within the NO calcination series can not be ascribed to particle size effects - the manganese promoter must play an active role. For the air calcined sample the monometallic cobalt sample shows significantly larger particles than the manganese containing samples. Apparently the manganese is capable of preventing cluster formation and keeping the particle size low, which is confirmed by the TEM. 


\subsubsection{TEM and EDX}

TEM images were recorded for the platinum containing samples after ex-situ reduction, and a couple of representative examples will be depicted and discussed here. In Figure 10.14 a TEM image of an air calcined cobalt sample is shown along with an NO calcined sample.
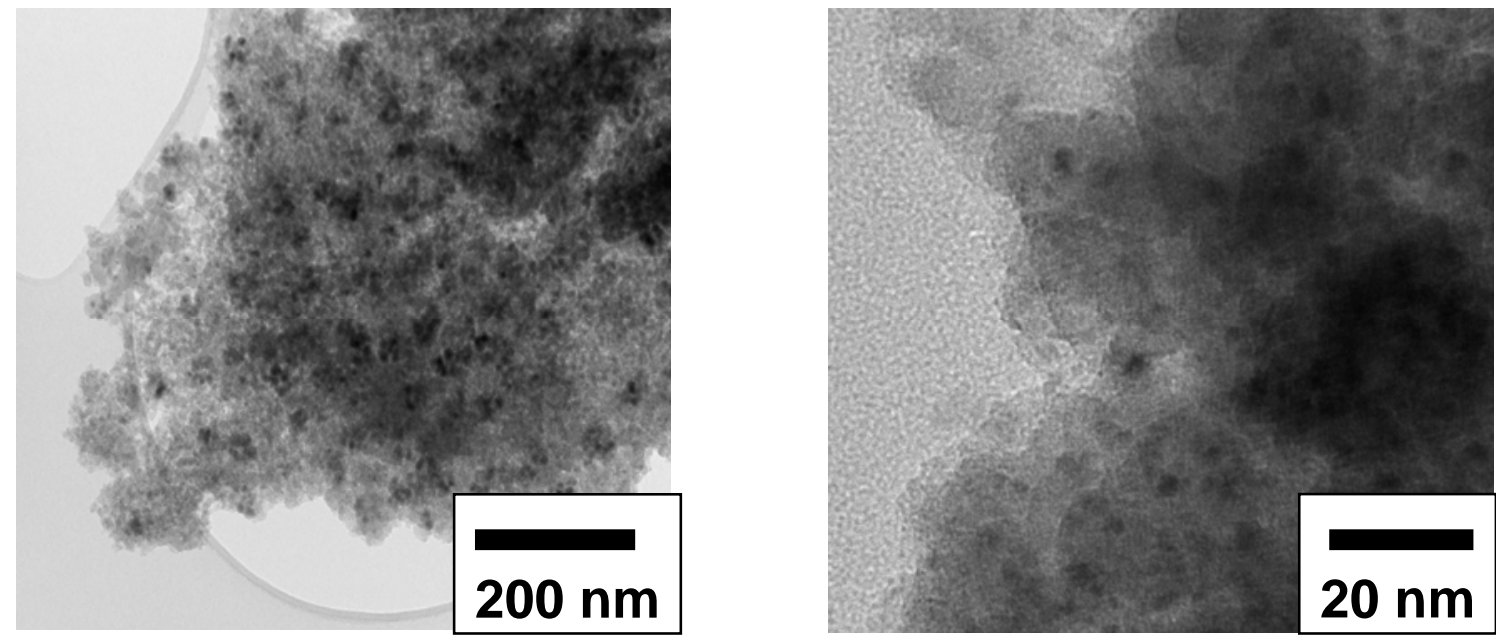

Figure 10.14 TEM images of an air calcined Co sample (left) and an NO calcined Co sample (right).

From this it is clear that the particles in the air calcined sample have clustered togethertypically 5 to 7 particles per cluster. The individual particles are found to be approximately $8 \mathrm{~nm}$. From the figure of the same catalyst after an NO calcination, no cluster formation is observed, and particles around 4-5 nm are seen. In Figure 10.15 EDX and TEM are shown for an air calcined sample containing manganese, namely the sample with the cobalt manganese ratio $\mathrm{Co}: \mathrm{Mn}=4: 1$.
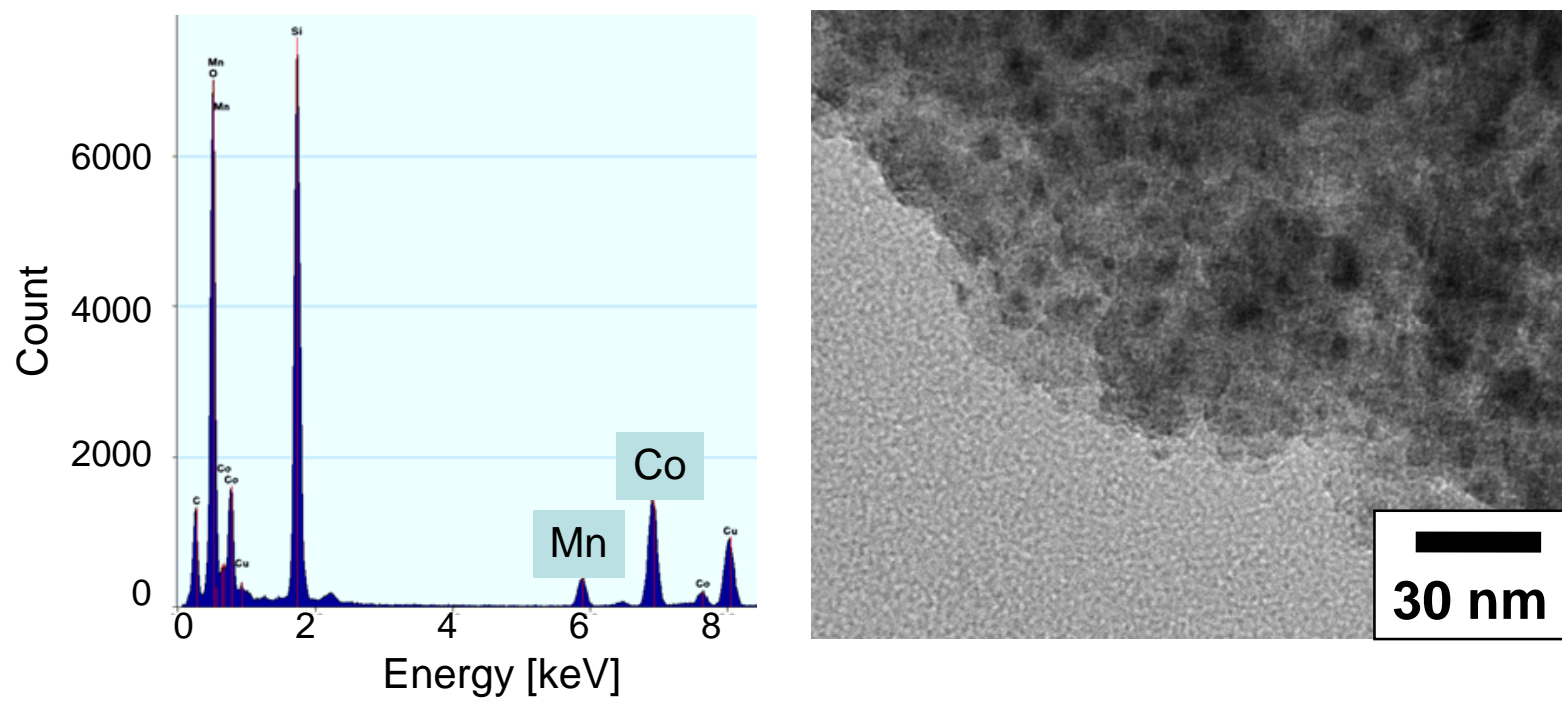

Figure 10.15 EDX (left) and TEM image (right) of an air calcined sample with Co:Mn=4:1. 
EDX was performed on several places in the sample, giving a rough indication that the Co:Mn ratio is homogeneous in the sample and that the Co:Mn ratio is in the expected range, based on the impregnation. The TEM image shows that the particle size is approximately $4 \mathrm{~nm}$ and that the particles are evenly distributed without any tendency to cluster formation.

The same is evident for all other air calcined manganese containing samples investigated.

In Figure 10.16 the EDX and TEM for an NO calcined sample with $\mathrm{Co:Mn=16:1} \mathrm{is} \mathrm{shown.}$

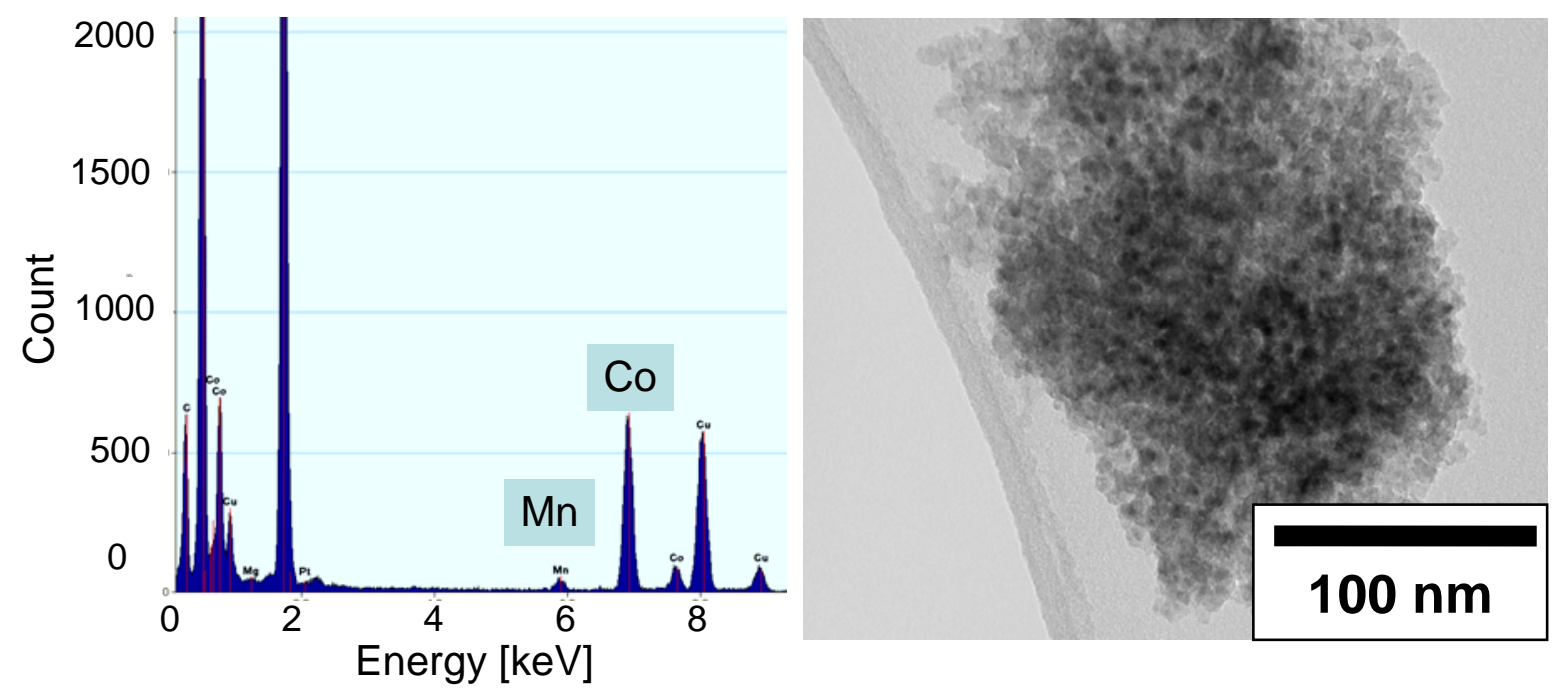

Figure 10.16 EDX (left) and TEM image (right) of an NO calcined Co:Mn=16:1 sample.

Again EDX taken at different places in the sample suggest that the distribution of cobalt and manganese is homogeneous and that the ratio is, as it should be, based on the solution used for impregnation. However, it should be kept in mind that this is just an indication, due to the nature of the methods only very small parts of the samples are investigated, and it is therefore not a final proof for the homogeneity. The particle sizes are found to be in the range 3-4 nm for all the examined manganese containing NO calcined samples and no cluster formation is observed. Overall it can be concluded that the particle sizes found by TEM are in accordance with the results obtained from XRD.

\subsection{The effect of manganese promotion}

In this chapter the study of a Co:Mn system on silica was described. Multiple parameters were investigated, which might blur the picture of the over-all improvement of the catalytic performance. In Table 10.3 the original results for a Co catalyst being air calcined and NO calcined as discussed in section 9.3, is shown again, along with the best $\mathrm{Co}: \mathrm{Mn}=12: 1$ catalysts prepared in this study. 
Table 10.3 Comparison of activity data of the original Co catalysts together with the best manganese promoted cobalt catalyst found in this study.

\begin{tabular}{|l|c|c|c|}
\hline \multicolumn{1}{|c|}{ Catalyst } & $\begin{array}{c}\text { Activity } \\
\left(10^{-5} \mathrm{molCO} \mathrm{go}_{\mathrm{C}}{ }^{-1} \mathrm{~s}^{-1}\right)\end{array}$ & $\begin{array}{c}\text { Selectivity } \mathrm{C}_{5+} \\
(\%)\end{array}$ & $\begin{array}{c}\mathrm{C}_{5+} \text { yield } \\
\left(10^{-5} \mathrm{molCO}_{\left.\mathrm{Co}^{-1} \mathrm{~s}^{-1}\right)}\right.\end{array}$ \\
\hline $\begin{array}{l}\mathrm{Co} / \mathrm{SiO}_{2} \\
\mathrm{Air} \text { calcination }\end{array}$ & 2.6 & 56 & 1.45 \\
\hline $\mathrm{Co} / \mathrm{SiO}_{2}$ & 4.7 & 35 & 1.65 \\
$\mathrm{NO}$ calcination & 4.6 & 54 & 2.47 \\
\hline $\begin{array}{l}\mathrm{Co}: \mathrm{Mn}=12: 1 / \mathrm{SiO}_{2} \\
\mathrm{NO} \text { calcination }\end{array}$ & & & \\
\hline
\end{tabular}

From the table it is clear that a lot is gained by the manganese promotion - the $\mathrm{C}_{5+}$ yield is almost twice as big if it is compared to a standard air calcined Co catalyst. The manganese promoted cobalt catalysts is very active for the FT reaction and very $\mathrm{C}_{5+}$ selective.

\subsection{Conclusions and future work}

A number of conclusions found in the study should be pointed out here. Manganese promotion of cobalt catalysts in combination with NO calcination resulted in promising FT catalysts. The manganese promoted catalysts was found to exhibit higher $\mathrm{C}_{5+}$ selectivity than the cobalt catalysts and the NO calcined catalysts are in general more active catalysts than the air calcined catalysts. The best manganese promoted catalyst exhibited almost a factor of two higher $\mathrm{C}_{5+}$ yield after $\mathrm{NO}$ calcination, than a standard air calcined cobalt catalyst. Addition of platinum has no influence on manganese promoted catalysts under the conditions used in this work; however, for the monometallic Co catalyst platinum has a significant effect. This indicates that it is most likely preferable not to add the platinum to any of the catalyst at all. The drying conditions examined were found not to influence the properties of the catalysts. The reduction temperature has a high influence on the activity, but only a slight effect on the selectivity. A temperature of $450{ }^{\circ} \mathrm{C}$ seems to be optimal for the catalysts investigated in this study.

The project leaves room for further work. First of all the catalysts could be tested under real Fischer-Tropsch conditions, meaning that high pressure should be applied. This is expected to 
improve the overall performance of the catalysts even more, since higher pressures are known to increase the activity.

The temperature and duration of the calcination are other parameters which could be interesting to study in order to determine their impact on the catalytic activity.

Finally, it would be interesting to examine catalysts prepared on silica with different pore size to see if this would be a way to control particle size, selectivity and activity. A preliminary study was begun, but more work needs to be put into it, in order to draw well-documented conclusions. 


\section{Part III}

$\mathrm{NH}_{3}$-based selective catalytic reduction of $\mathrm{NO}$ 
Design of heterogeneous catalysts 


\section{A new $\mathrm{NH}_{3}$-SCR system for automotive applications}

\section{1 $\mathrm{NO}_{\mathrm{x}}$ pollution}

Due to environmental concerns it is becoming steadily more important to reduce the release of environmental unfriendly compounds to the surroundings. Nitrogen oxides, $\mathrm{NO}_{\mathrm{x}}$, belong to this class of harmful compounds, for which emission should be reduced to a minimum. One of the main components of $\mathrm{NO}_{\mathrm{x}}$ in exhaust gas is nitric oxide, $\mathrm{NO}$, which is known to be an indirect greenhouse gas. A high level of NO can result in oxygen depletion, acid rain, and forest and crops damage. Furthermore, the gas is poisonous to humans when inhaled ${ }^{104}$. The other nitrogen oxides are known to be environmentally unfriendly as well. Thus, it is of huge importance to reduce the amount of nitrogen oxides released from combustion processes in order to protect the environment.

$\mathrm{NO}_{\mathrm{x}}$ originates from combustion of fuel in air at high temperature in stationary as well as automotive units ${ }^{105}$. Since a part of the problem is caused by the presence of nitrogen in air, if the combustion takes place at high temperatures, the pollution is seen for both fossil and bio fuels - even if nitrogen containing compounds are not present in the fuel. If the fuel contains nitrogen, this will, however, contribute significantly to the $\mathrm{NO}_{\mathrm{x}}$ pollution. In this study the main focus will be on the removal of $\mathrm{NO}_{\mathrm{x}}$ from automotive applications. Approximately one fifth of the total global emission of $\mathrm{NO}_{\mathrm{x}}$ originates from vehicles ${ }^{106,107}$. Since this is a significant part of the total pollution, it is an important task to reduce this pollution source. It should be noted that not all vehicles contribute to the pollution. For vehicles driven by normal gasoline, the NO is removed by a traditional three-way catalyst ${ }^{6}$. However, for vehicles based on lean burn, this catalyst can not be applied. This is due to the huge excess of oxygen, making the reduction of NO impossible over the three-way catalyst. The lean burn principle is always applied in diesel automotives and sometimes in gasoline driven automotives in order to improve the fuel economy. The total number of diesel cars is increasing steadily at the moment, motivating the research related to finding ways to reduce the $\mathrm{NO}_{\mathrm{x}}$ level released from these cars ${ }^{106,108}$. In several regions, such as Europe, USA, and Japan, legislations are already used to control the amount of $\mathrm{NO}_{\mathrm{x}}$ being released ${ }^{109}$. During the last years the restrictions have been continually increased, making the demand for finding new method to eliminate the $\mathrm{NO}_{\mathrm{x}}$ compounds in exhaust gases even more important ${ }^{107}$. 


\subsection{Selective catalytic reduction}

\subsubsection{Introduction to SCR}

One way to eliminate the problem with $\mathrm{NO}_{\mathrm{x}}$ pollution from automotive applications is by selective catalytic reduction, SCR. There are two important parameters in this reaction that can be changed and optimized: the reductant and the catalyst. The reaction can be performed using ammonia or hydrocarbons as reducing agents. Ammonia seems to be most promising since hydrocarbons get oxidized at high temperature ${ }^{110}$. The result of this unwanted oxidation process is that less $\mathrm{NO}_{\mathrm{x}}$ is reduced. The problem is less pronounced when $\mathrm{NH}_{3}$ is used.

When ammonia is used as the reductant it is injected into the exhaust gas prior to the SCRcatalyst ${ }^{111}$. The reaction scheme for $\mathrm{NH}_{3}-\mathrm{SCR}$ of $\mathrm{NO}$ can be written as ${ }^{112}$ :

$$
4 \mathrm{NH}_{3}+4 \mathrm{NO}+\mathrm{O}_{2} \rightarrow 4 \mathrm{~N}_{2}+6 \mathrm{H}_{2} \mathrm{O}
$$

It is well known, that the reaction proceeds more efficiently if $\mathrm{NO}_{2}$ is present. The most optimal ratio between $\mathrm{NO}$ and $\mathrm{NO}_{2}$ is found to be $1^{113,114}$ - in this case the reaction is called fast SCR and the reaction scheme is given by ${ }^{112}$ :

$$
2 \mathrm{NH}_{3}+\mathrm{NO}+\mathrm{NO}_{2} \rightarrow 2 \mathrm{~N}_{2}+3 \mathrm{H}_{2} \mathrm{O}
$$

Vanadium-based catalysts are normally used for the SCR reaction in stationary applications, but for reasons that will be discussed later, this type of catalysts is not desirable for automotive applications.

An alternative to SCR, when it comes to $\mathrm{NO}_{\mathrm{x}}$ removal, is the lean $\mathrm{NO}_{\mathrm{x}}$ trap method ${ }^{115}$, where a $\mathrm{NO}_{\mathrm{x}}$ storage catalyst is used. Such a system is based on an adsorption material, such as alkali or earth alkali metal oxides, along with palladium group metals used for oxidation and reforming, meaning that it is an expensive system ${ }^{116}$. Furthermore, the system is connected to a fuel penalty since the catalyst has to be regenerated from time to time, which is done while the engine is running outside the fuel economic interval. Another disadvantage of the lean $\mathrm{NO}_{\mathrm{x}}$ trap method is that it is very sensitive to sulfur - more than $1 \mathrm{ppm}$ sulfur in the fuel will cause problems ${ }^{111}$. At the moment the sulfur content in fuel is significantly higher and it is not expected to be lowered sufficiently in the nearest future to meet the criteria ${ }^{117}$. This means that SCR seems to be the only feasible way to approach the problem with $\mathrm{NO}_{\mathrm{x}}$ emission from vehicles at the moment. 


\subsubsection{Ammonia sources}

\subsubsection{Urea}

Ammonia seems to be the most optimal reductant in the SCR process and it can easily be applied in stationary applications, where the system can be connected to a liquid ammonia tank. However, using ammonia in automotive applications constitutes a considerable safety risk and is simply too dangerous ${ }^{118,119,120}$. Therefore, other indirect ways to supply the system with ammonia have been considered. In the literature the main focus has been on urea, $\left(\mathrm{NH}_{2}\right)_{2} \mathrm{CO}$, as an indirect ammonia storage medium ${ }^{119}$. Urea is non-toxic, which makes it easier to handle safely ${ }^{121}$. The decomposition reaction of urea liberates ammonia and forms isocyanic acid, according to the reaction scheme ${ }^{107}$ :

$$
\left(\mathrm{NH}_{2}\right)_{2} \mathrm{CO} \rightarrow \mathrm{NH}_{3}+\mathrm{HNCO} ; t>160^{\circ} \mathrm{C}
$$

The isocyanic acid can be hydrolyzed, using a hydrolysis catalyst ${ }^{122}$, whereby another equivalent of ammonia is formed ${ }^{107}$ :

$$
\mathrm{HNCO}+\mathrm{H}_{2} \mathrm{O} \rightarrow \mathrm{NH}_{3}+\mathrm{CO}_{2} ; t>200^{\circ}
$$

It should be noted that the urea system has been carefully studied and it has been found that many side reactions take place, which complicates the picture ${ }^{123}$. The complexity makes it hard to control the amount of ammonia formed and released. This is problematic since it is important to control the $\mathrm{NH}_{3} / \mathrm{NO}_{\mathrm{x}}$ ratio precisely in the SCR reaction. In addition to the system being complicated, there are several other disadvantages with urea as an indirect ammonia source, which will be briefly sketched here. Urea is often used in the form of an aqueous solution of $32.5 \mathrm{wt} \%$ urea in water (i.e. AdBlue $\left.{ }^{\circledR}\right)^{124}$. The liquid is corrosive, which can result in problems when it comes to handling it. The low ammonia density makes the storage volume non-optimal compared to other ammonia storages. Decomposition of urea takes place to a small extend at temperatures as low as $50{ }^{\circ} \mathrm{C}$ meaning that some ammonia gas will build up in the storage tank. The freezing point of AdBlue is $-11{ }^{\circ} \mathrm{C}$, which is nonoptimal when a vehicle is started on a winter day in a cold area. The urea is injected to the exhaust by spraying it as an aerosol, when it is used in the form of AdBlue. If the liquid is freezing or if decomposition and formation of deposit particles or solids takes place, clogging can occur thereby blocking the system ${ }^{125,126}$.

A slip catalyst needs to be incorporated into the system before the exhaust is released ${ }^{119}$. The purpose of the slip catalyst is to handle solid deposit released from walls of the exhaust line. Such solids appear when bursts of ammonia are formed due to increase in exhaust 
temperature related to e.g. acceleration. Slip catalysts are oxidation catalysts based on platinum or palladium, which are expensive metals.

Furthermore, a hydrolysis catalyst is needed to utilize all the ammonia or alternatively the $\mathrm{SCR}$ catalyst must be designed to handle the hydrolysis reaction along with $\mathrm{SCR}^{121}$.

In Figure 11.1 two different SCR related $\mathrm{NO}_{\mathrm{x}}$ removal schemes are shown, both describing the situation from the $\mathrm{NO}_{\mathrm{x}}$ release in the exhaust to the time when gas is emitted from the vehicle to the environment.

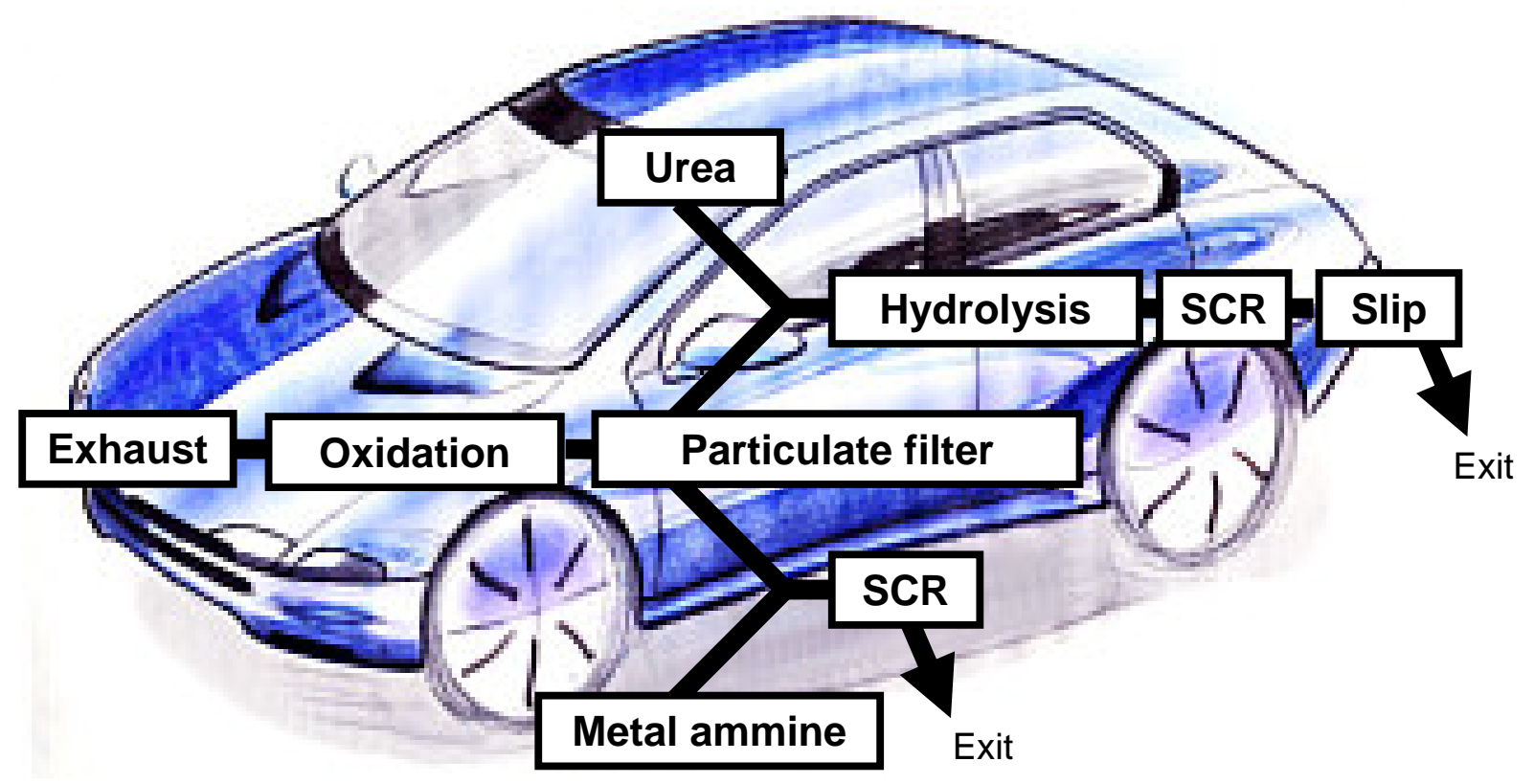

Figure 11.1 Two different paths for $\mathrm{NO}_{\mathrm{x}}$ removal by $\mathrm{NH}_{3}$-SCR are shown. The upper path in the diagram shows when urea is used as an indirect ammonia source. The lower path shows the simplified system when metal ammines are used as a direct ammonia source. The urea-based system is more complicated due to the necessary hydrolysis and slip catalyst steps.

The urea based system is shown in the upper path of the diagram. In this path a hydrolysis catalyst, an SCR catalyst and a slip catalyst is needed after the particulate filter. The hydrolysis catalyst is typically not working at low temperatures which is problematic in urban driving stop-and-go traffic, meaning that it would be desirable to develop a system where it is not needed e.g. by using another ammonia source. Moreover, if a new SCR catalyst with low temperature activity is designed, an over-all system operating at lower temperature could be established, since the conversion of urea no longer would be the bottle-neck. 
Several years of research within this field has not yet solved the problems related to urea as ammonia source for SCR, thus it seems appropriate to look at other possibilities. When designing a new system, it is important to ensure low cost, low fuel penalty, high safety, high ammonia capacity, and controlled ammonia release. A proposal for a new system will be given in the next sections where the possibilities of using metal ammines as an ammonia source in SCR combined with non-vanadium-based catalysts, such as iron-containing zeolites, will be discussed.

\subsubsection{Metal ammines}

By using metal ammines as ammonia source for the SCR reaction the ammonia is released directly opposite to urea ${ }^{111}$. The slip catalyst and hydrolysis catalyst can thus be avoided and the over-all process can be performed at lower temperatures with a proper SCR catalyst since the temperature restriction related to the hydrolysis catalyst is gone.

A range of different metal ammines has been known for many years and the compounds are in general well-described and their properties well-characterized ${ }^{127}$. As examples of these complexes $\mathrm{Mg}\left(\mathrm{NH}_{3}\right)_{6} \mathrm{Cl}_{2}, \mathrm{Ca}\left(\mathrm{NH}_{3}\right)_{8} \mathrm{Cl}_{2}$, and $\mathrm{Sr}\left(\mathrm{NH}_{3}\right)_{8} \mathrm{Cl}_{2}$ can be mentioned. The focus here will be on $\mathrm{Mg}\left(\mathrm{NH}_{3}\right)_{6} \mathrm{Cl}_{2}$. The complex can easily be prepared from $\mathrm{NH}_{3}$ and $\mathrm{MgCl}_{2}$ the latter being a non-toxic and wide-available salt.

The reaction schemes and enthalpies for the reaction between $\mathrm{MgCl}_{2}$ and $\mathrm{NH}_{3}$ are given by ${ }^{111}$ :

$$
\begin{gathered}
\mathrm{MgCl}_{2}(\mathrm{~s})+\mathrm{NH}_{3}(\mathrm{~g}) \rightarrow \mathrm{Mg}\left(\mathrm{NH}_{3}\right) \mathrm{Cl}_{2}(\mathrm{~s}) ; \Delta_{\mathrm{f}} H=-87.0 \mathrm{~kJ} / \mathrm{mol} \mathrm{NH}_{3} \\
\mathrm{Mg}\left(\mathrm{NH}_{3}\right) \mathrm{Cl}_{2}(\mathrm{~s})+\mathrm{NH}_{3}(\mathrm{~g}) \rightarrow \operatorname{Mg}\left(\mathrm{NH}_{3}\right)_{2} \mathrm{Cl}_{2}(\mathrm{~s}) ; \Delta_{\mathrm{f}} H=-74.9 \mathrm{~kJ} / \mathrm{mol} \mathrm{NH}_{3} \\
\mathrm{Mg}\left(\mathrm{NH}_{3}\right)_{2} \mathrm{Cl}_{2}(\mathrm{~s})+4 \mathrm{NH}_{3}(\mathrm{~g}) \rightarrow \mathrm{Mg}\left(\mathrm{NH}_{3}\right)_{6} \mathrm{Cl}_{2}(\mathrm{~s}) ; \Delta_{\mathrm{f}} H=-55.6 \mathrm{~kJ} / \mathrm{mol} \mathrm{NH}_{3}
\end{gathered}
$$

The adsorption of ammonia is seen to be exothermic, while the desorption is endothermic.

When considering safety for metal ammines, vapor pressure is an important parameter. The vapor pressure can be established either experimentally or by calculations using the van't Hoff relationship:

$$
\ln (p)=-\Delta H_{\text {des }} / R T+\Delta S_{\text {des }} / R,
$$

where $p$ is the vapour pressure, $H_{d e s}$ is the desorption enthalpy, $S_{d e s}$ is the desorption entropy, $T$ is the absolute temperature, and $R$ is the gas constant.

The complex $\mathrm{Mg}\left(\mathrm{NH}_{3}\right)_{6} \mathrm{Cl}_{2}$ has a vapor pressure of 2.2 mbar at $300 \mathrm{~K}$, which means that the compound is approximately 30,000 times less volatile than liquid ammonia ${ }^{128}$. A compound with such a low vapor pressure can be considered as safe. Only ammonia can be liberated during decomposition meaning that no blocking of the system due to solids will take place. 
The ammonia storage capacity is an important parameter in order for the system to be of practical use. Normally $\mathrm{Mg}\left(\mathrm{NH}_{3}\right)_{6} \mathrm{Cl}_{2}$ is a polycrystalline powder with a low density ${ }^{129}$, but it is possible to prepare solid units of the compound, e.g. AdAmmine ${ }^{130}$, with a high density. Furthermore, it has turned out that nano-pores are formed during desorption, which facilitates complete desorption ${ }^{131}$.

When it comes to storage capacity a $100 \mathrm{~g}(\sim 80 \mathrm{ml})$ block of $\mathrm{Mg}\left(\mathrm{NH}_{3}\right)_{6} \mathrm{Cl}_{2}$, AdAmmine, can store $51.7 \mathrm{~g} \mathrm{NH}_{3}$ which equals 741 of $\mathrm{NH}_{3}$ gas at 1 bar and $20{ }^{\circ} \mathrm{C}$. In Figure 11.2 the ammonia capacity in storage is shown for liquid ammonia, AdAmmine $\left(\mathrm{Mg}\left(\mathrm{NH}_{3}\right)_{6} \mathrm{Cl}_{2}\right)$ and Adblue (urea). If the storage of AdAmmine is compared to Adblue, it contains 3.1 times more ammonia per volume or 2.8 times per mass ${ }^{130}$. The storage capacity of AdAmmine is as good as the capacity of liquid ammonia stored at room temperature under a pressure of 8-9 bars.

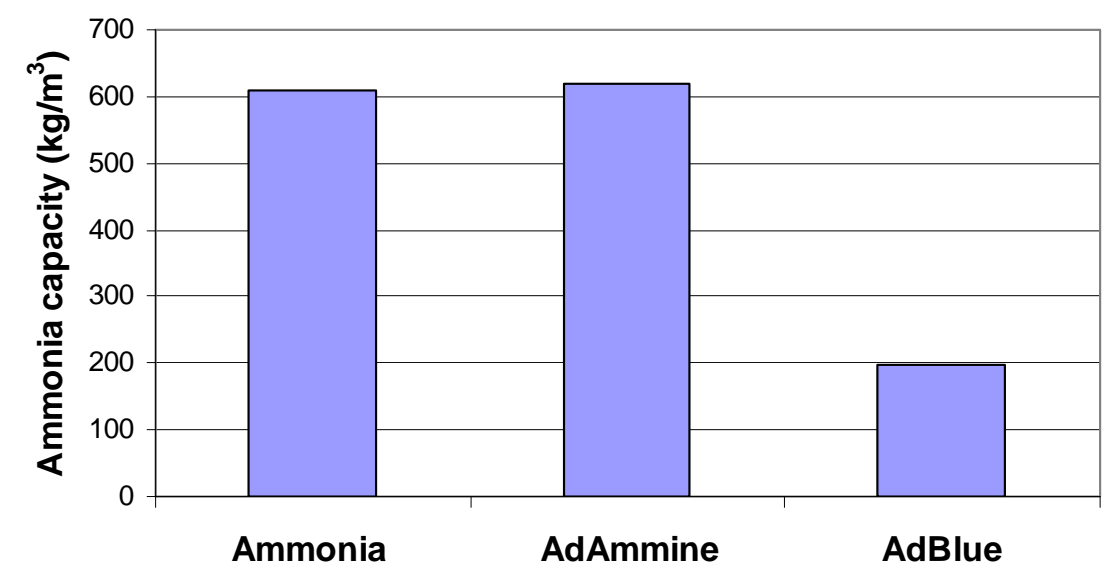

Figure 11.2 Ammonia capacity in $\mathrm{kg} / \mathrm{m}^{3}$ for ammonia $\left(\mathrm{NH}_{3}(1)\right.$, 8-9 bar, $\left.25{ }^{\circ} \mathrm{C}\right)$ AdAmine $\left(\mathrm{Mg}\left(\mathrm{NH}_{3}\right)_{6} \mathrm{Cl}_{2}(\mathrm{~s})\right)$ and Adblue (32.5 wt $\%$ urea in water $)^{130}$.

In a typical vehicle $5 \mathrm{~kg}$ of $\mathrm{NH}_{3}$ for the $\mathrm{SCR}$ reaction is needed to run the car for 25,000 $30,000 \mathrm{~km}$. This is considered to be a reasonable service interval for cars, and therefore the minimum of ammonia for which there should be storage room. The request demands 251 $(27.4 \mathrm{~kg})$ Adblue or $81(9.7 \mathrm{~kg})$ AdAmine showing that the storage capacity of a metal ammine can be optimized to be considerably higher than for a traditional urea source.

By summing up it has been shown that metal amines are safe, relatively inexpensive, easy to handle, does not take up much space (compared to the amount of ammonia which can be liberated from the solid), and furthermore no blocking of the system occur since only gas is liberated. These properties make it an interesting alternative to urea. The path for metal ammines as ammonia source in vehicles is shown in the lower path of the diagram in Figure 
11.1. The path is simpler than the urea path since both the hydrolysis catalyst and the slip catalyst can be omitted.

\subsubsection{Catalyst for the SCR reaction}

\subsubsection{Vanadium-based catalysts}

The catalyst is a very important part of the SCR reaction and it will be discussed in this section. The $\mathrm{NH}_{3}-\mathrm{SCR}$ reaction can, as mentioned previously, be applied for both stationary and automotive applications. For stationary applications a mixture of high oxidation state oxides of vanadium $\left(\mathrm{V}_{2} \mathrm{O}_{5}\right)$ and tungsten $\left(\mathrm{WO}_{3}\right)$ on titania are normally used and it can in principle be applied in automotive applications ${ }^{132,133}$. However, several disadvantages are connected to the use of vanadia, which makes it undesirable for automotive applications. During the process vanadia can be lost and thereby released to the surroundings causing an environmental risk since it is poisonous. The activities of the vanadium-based catalysts are low at low temperatures. At higher temperatures it is possible to obtain higher activity but at the same time the selectivity is lowered considerably. The low selectivity is due to the competitive ammonia oxidation. The compromise between activity/selectivity and temperature can be accepted in stationary applications. In automotive application it is, however, not satisfying. Another disadvantage with vanadia is observed when sulfur is present in the fuel, since the vanadium catalyst is capable of oxidizing sulfur dioxide to sulfur trioxide $^{134}$. This results in a decrease in selectivity along with environmental problem with acid rain from sulfuric acid. Based on these problems with the commercially used vanadium catalyst it is clear that there is a need for designing and optimizing the catalyst system for $\mathrm{NO}_{\mathrm{x}}$ removal in mobile applications. It would be attractive to find a low temperature catalyst. Intense effort has been put into developing a new catalyst system, and the most promising materials suggested to date seem to be based on zeolites.

\subsubsection{Zeolites as catalysts}

About 20 years ago research concerning zeolites and their use for $\mathrm{NO}_{\mathrm{x}}$ removal in the SCR reaction began. Since then a range of different zeolites such as FER, MFI, MOR, Y, and BEA, have been investigated ${ }^{135,136,137,138}$. Not surprisingly the performance is found to be highly dependent on the zeolite type used as well as the metal incorporated. The zeolite type that has been most investigated until now is ZSM-5. Different catalytically active metal centers have been studied. The focus with that respect has mainly been on transition metal such as Fe, Co, 
$\mathrm{Pt}$, and $\mathrm{Cu}^{139,140,141}$. Copper-containing zeolite catalysts were the first metal system found to be catalytically active in the SCR reacation, and therefore the copper system has been thoroughly studied. Cu-zeolites are known to be active in SCR both when ammonia and hydrocarbons are used as the reducing agent ${ }^{112,142}$. Many examples of high activities of copper-containing zeolites are known from the literature. A $2.4 \mathrm{wt} \% \mathrm{Cu} / \mathrm{ZSM}-5$ has e.g. been claimed to be more active than a vanadium reference catalyst for $\mathrm{NH}_{3}-\mathrm{SCR}^{143}$. However, one very critical disadvantage is found for the copper-containing zeolites - they show limited hydrothermal stability ${ }^{144}$. This means that water will poison the catalyst fast. Due to this a search for other systems has begun, since the probability of copper-containing catalyst finding use in automotive applications is low.

\subsubsection{Iron-containing zeolites}

Among the investigated metals iron seems to be a promising alternative to copper. Iron is non-toxic and therefore safe to use. At the same time the price of iron is attractive ${ }^{145}$. Regarding performance iron-containing zeolites exhibit high activities and selectivities in a wide temperature window. Over exchanged Fe/ZSM-5 is the most studied system both with respect to preparation, characterization, and activity measurements ${ }^{146,147,148,149,150,151,152}$. A few examples of these iron systems should be mentioned. Catalysts prepared by sublimation of iron(III) chloride on the zeolites are found to exhibit high activity and stability in broad temperature interval ${ }^{144}$. Other catalysts have been prepared by introducing the iron via ion exchange and these catalysts has been claimed to be even better than a $\mathrm{V}_{2} \mathrm{O}_{5}-\mathrm{WO}_{3} / \mathrm{TiO}_{2}$ reference $^{146}$. Catalysts prepared with impregnations are found to work well too. In conventional zeolites diffusion is often a rate limiting step. Recently it has been shown that this problem can be overcome by using mesoporous zeolites ${ }^{153,}{ }^{154}$. Advantages by using mesoporous zeolites instead of conventional zeolites are, that a better metal dispersion is obtained along with higher accessibility to the active sites ${ }^{155}$. At temperatures higher than $400{ }^{\circ} \mathrm{C}$ the mesoporous iron-containing zeolites, Fe/H-ZSM-5 and Fe/H-ZSM-12, are found to be more active in the $\mathrm{NH}_{3}-\mathrm{SCR}$ reaction than a $\mathrm{V}_{2} \mathrm{O}_{5} / \mathrm{TiO}_{2}$ reference catalyst ${ }^{156}$.

Since iron-containing zeolites exhibit high activities in a broad temperature window, particularly at low temperatures, they seem to be attractive not only when urea is used as the ammonia source but especially in the case where direct ammonia dosing takes place, e.g. from metal ammines. 


\section{Iron-containing zeolites}

\subsection{Introduction}

In this work the focus has been put on iron-containing zeolites. Iron-containing zeolites were synthesized and their activities were tested in the $\mathrm{NH}_{3}$-based selective catalytic reduction of NO. Especially the BEA zeolite system has been studied in detail after a comparison of different iron-containing zeolites, beta, ZSM-5, and ZSM-12, and a vanadia reference catalyst, revealed that the iron-containing beta (BEA) catalyst exhibits superior catalytic activity for the $\mathrm{NH}_{3}$-SCR reaction. The influence of the iron-content in the BEA zeolite was investigated along with the effect of different preparation methods on the catalytic performance.

In Figure 12.1 the framework type for ZSM-12 (MTW), ZSM-5 (MFI), and beta (BEA) are shown.
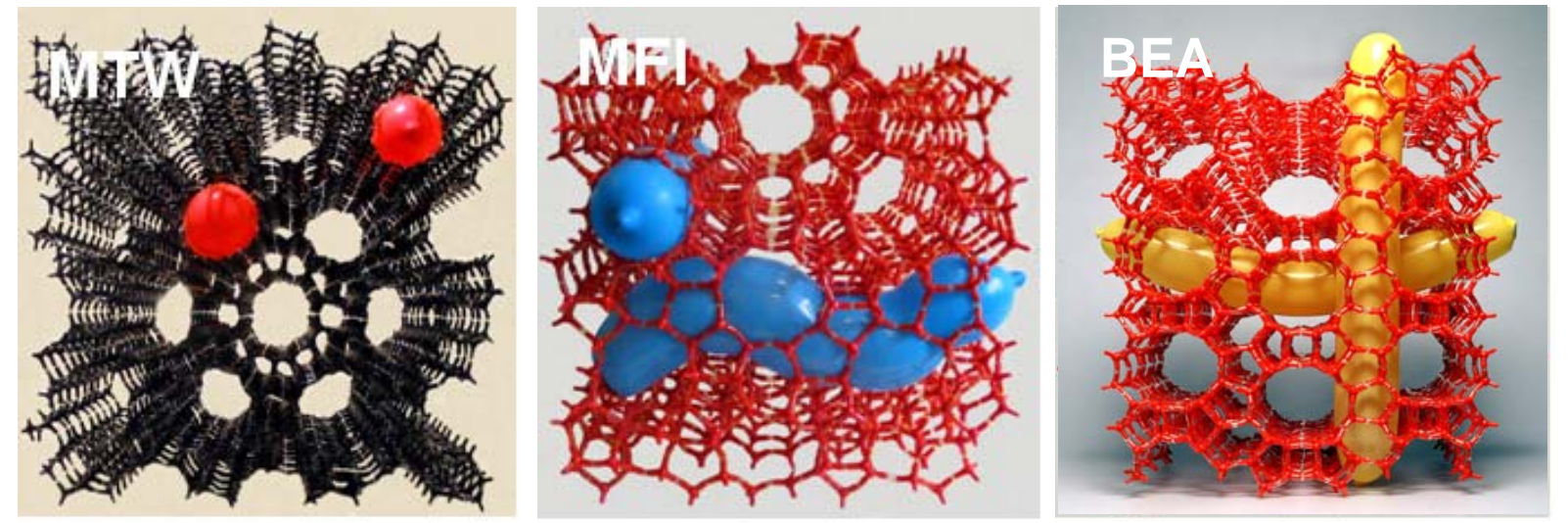

Figure 12.1 Zeolite framework types: ZSM-12 (MTW), ZSM-5 (MFI) and BEA ${ }^{157}$.

If looking into the structures of these three different zeolite types, some differences are noticed $^{158}$. ZSM-12 has only straight channels (5.6 x $6.0 \AA$ ), while ZSM-5 has both straight $(5.3 \times 5.6 \AA)$ and sinusoidal $(5.1$ x $5.5 \AA)$ channels. Thus, ZSM-5 has smaller pores than ZSM-12. The BEA zeolite has on the other hand a more open porosity than ZSM-5 as well as a tridirectional pore network consistent of both straight $(6.6 \times 6.7 \AA)$ and sinusoidal $(5.6 \mathrm{x}$ $5.6 \AA)$ channels. Due to these differences the BEA zeolite is expected to exhibit the highest diffusion rate among the examined zeolites. 


\subsection{Experimental}

\subsubsection{Catalyst preparation}

In this study three different conventional iron-containing zeolites, ZSM-5, ZSM-12, and BEA, have been compared. The ZSM-5 and ZSM-12 catalysts have previously been prepared and optimized, and detailed preparation recipes can be found elsewhere ${ }^{156}$. The synthesis of BEA is investigated and optimized in this study. The BEA catalyst was prepared in different ways; methods to synthesise respectively small and large zeolite crystals will be given, along with a description of two ways to add the iron after the zeolite has been prepared, incipient wetness impregnation (IWI) and ion exchange (IE). Finally a zeolite synthesis where the iron is introduced directly into the framework during the synthesis, called isomorphous substitution (IS), will be described.

\subsubsection{Synthesis of conventional BEA (small crystals)}

The synthesis was optimized by changing parameters such as the type of silica gel, the aging temperature, and the aging time. The best recipe found is described below.

\subsubsection{Na-BEA (Si/Al = 50)}

$3.5 \mathrm{~g}$ of sodium aluminate was dissolved in $25 \mathrm{ml}$ of water and added drop-wise to a solution of $1.5 \mathrm{~g}$ of sodium hydroxide in $10 \mathrm{ml}$ of water. The solution was stirred for $10 \mathrm{~min}$. Then $30 \mathrm{~g}$ of silicium oxide (Sigma-Aldrich Silica Gel, Grade 62, 60-200 mesh, $150 \AA$ ) was added slowly to the basic solution under stirring. Finally, $92 \mathrm{~g}$ of an aqueous $40 \mathrm{wt} \%$ tetraethylammonium hydroxide (TEAOH) solution was added slowly to the solution under stirring. The mixture was covered by parafilm and left for $2 \mathrm{~h}$ under continuous stirring at room temperature to obtain a homogeneous colorless gel. The gel was poured into a Teflon cup in a stainless steel autoclave (with a total volume of $250 \mathrm{ml}$ ) and sealed. It was placed in an oven at $140{ }^{\circ} \mathrm{C}$ for $120 \mathrm{~h}$ after which it was quenched with cold water. The resulting material was filtered and washed with multiple portions of deionised water until the filtrate was $\mathrm{pH}$ neutral (approximately a total of 21 of water was needed). The sample was dried at room temperature over night, followed by heating it to $110^{\circ} \mathrm{C}$ for $1 / 2 \mathrm{~h}$. The template was removed from the zeolite by heating it in air to $550{ }^{\circ} \mathrm{C}$ during $4 \mathrm{~h}$ and leaving it at $550{ }^{\circ} \mathrm{C}$ for $18 \mathrm{~h}$ before cooling to room temperature. 


\subsubsection{2 $\mathrm{NH}_{4}$-BEA}

In order to obtain the $\mathrm{NH}_{4}$-form of the BEA zeolite, the Na-BEA zeolite was treated with ammonium nitrate. This was done by stirring Na-BEA with $1 \mathrm{M} \mathrm{NH}_{4} \mathrm{NO}_{3}$ for $4 \mathrm{~h}$ at $80{ }^{\circ} \mathrm{C}$, in such a way that $30 \mathrm{~g}$ of solution was used for each $1 \mathrm{~g}$ of zeolite. After this step the zeolite was filtered, washed with a total of 21 deionised water and dried over night at room temperature. The next day the entire procedure was repeated in order to achieve a total substitution of the sodium ion with ammonium ions.

\subsubsection{H-BEA}

The H-BEA was obtained by heat-treatment of the $\mathrm{NH}_{4}$-BEA: The zeolite on $\mathrm{NH}_{4}$-form was placed in an oven and ramped to $450{ }^{\circ} \mathrm{C}$ during $2 \mathrm{~h}$. The temperature of $450{ }^{\circ} \mathrm{C}$ was kept for $4 \mathrm{~h}$, followed by cooling to room temperature. The yield was approximately $10 \mathrm{~g}$.

\subsubsection{Incorporation of iron in the zeolite}

The iron was incorporated into the BEA zeolite in three different ways: incipient wetness impregnation (IWI), ion exchange (IE), and isomorphous substitution (IS). In the first two methods, IWI and IE, the iron was introduced to the H-BEA zeolite after the synthesis of the zeolite was finished. In the last case, IS, the method differs by introducing the iron to the zeolite directly during the synthesis by substituting some of the aluminium with iron.

\subsubsection{Incipient wetness impregnation (IWI)}

IWI was used as a standard method to introduce iron to the zeolite. Samples with iron-content between 1 and $5 \mathrm{wt} \%$ were prepared: 1.0, 2.0, 2.8, 3.0, and $5.0 \mathrm{wt} \%$. The pore volume of the zeolite was determined by BET and the solutions of iron(III) nitrate in water was prepared in such a way that the desired iron concentration could be obtained by one impregnation or, in the cases of high iron content, by multiple impregnations: A given amount of the H-BEA zeolite was impregnated by drop-wise adding the corresponding volume of the iron containing solution. The sample was covered by parafilm and left for $1 \mathrm{~h}$ in order for the iron ions to get evenly distributed in the zeolite. The sample was then dried at room temperature over night. Finally the sample was calcined by heating it in air to $450{ }^{\circ} \mathrm{C}$ during $2 \mathrm{~h}$. The temperature was kept for $4 \mathrm{~h}$ and the sample was then cooled to room temperature.

\subsubsection{Ion-exchange (IE)}

The IE was performed by treating $1.25 \mathrm{~g}$ of H-BEA zeolite with 0.51 of a $2 \mathrm{mM}$ iron(III) nitrate solution. The suspension was stirred for $48 \mathrm{~h}$ at room temperature. The zeolite was 
filtered off and washed with 0.51 of deionised water. The sample was dried by heating it at $80{ }^{\circ} \mathrm{C}$ for $2 \mathrm{~h}$ followed by heating it to $450{ }^{\circ} \mathrm{C}$ during $1 \frac{1}{2} \mathrm{~h}$ and keeping it at $450{ }^{\circ} \mathrm{C}$ for $4 \mathrm{~h}$ thereby calcining the sample before cooling to room temperature.

\subsubsection{Isomorphous substitution (IS)}

By IS the iron is introduced directly to the gel during the synthesis on behalf on the aluminium content. Variable amount of aluminium can be substituted with iron. Two materials with different compositions were prepared: one where $100 \%$ of the aluminium was substituted with iron and one where $50 \%$ of the aluminium was substituted with iron. The description of the latter will be given here. The other zeolite can be synthesised the same way, just by omitting the addition of the sodium aluminate and doubling the amount of iron(III) nitrate.

Two solutions were prepared:

I: $0.79 \mathrm{~g}$ of $\mathrm{NaAlO}_{2}$ was dissolved in $5 \mathrm{ml}$ of water and the solution was added to a solution of $0.28 \mathrm{~g}$ of $\mathrm{NaOH}$ in $3.5 \mathrm{ml}$ of water. Moreover, $11.90 \mathrm{~g}$ of aqueous $40 \mathrm{wt} \%$ tetraethylammonium hydroxide $(\mathrm{TEAOH})$ was added.

II: $0.45 \mathrm{~g}$ of $\mathrm{Fe}\left(\mathrm{NO}_{3}\right)_{3} .9 \mathrm{H}_{2} \mathrm{O}$ was dissolved in $5 \mathrm{ml}$ water and the solution was poured into $11.90 \mathrm{~g}$ aqueous $40 \mathrm{wt} \% \mathrm{TEAOH}$.

Solution I and II were poured simultaneously into $7.5 \mathrm{~g} \mathrm{SiO}_{2}$ during stirring. Mechanical stirring was continued until a homogeneous, red gel was obtained, as shown in Figure 12.2.

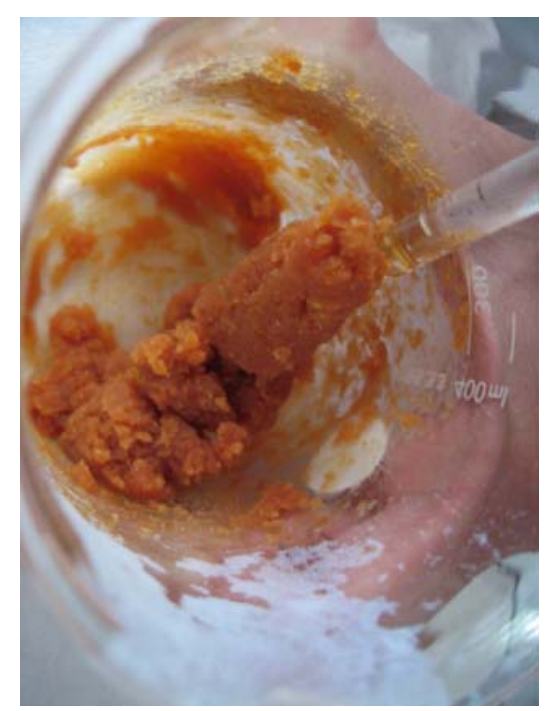

Figure 12.2 The red gel obtained by introducing iron directly during the synthesis of the BEA zeolite, is considerable more viscous than the gel obtained during the synthesis of the conventional H-BEA zeolite. 
The gel was crystallized in a sealed autoclave at $120^{\circ} \mathrm{C}$ for $140 \mathrm{~h}$. The reaction was quenched by cooling the autoclave to room temperature. The product was filtered, washed with water until the filtrate was $\mathrm{pH}$ neutral, and dried at $120^{\circ} \mathrm{C}$ for $1 \mathrm{~h}$. The isolated material was heated in an oven to $550{ }^{\circ} \mathrm{C}$ during $4 \mathrm{~h}$. The sample was kept in air at this temperature for $18 \mathrm{~h}$ and then cooled to $25^{\circ} \mathrm{C}$.

The sample was treated twice with $1 \mathrm{M} \mathrm{NH}_{4} \mathrm{NO}_{3}(1: 30 \mathrm{~g} / \mathrm{g})$ at $80{ }^{\circ} \mathrm{C}$ for $3 \mathrm{~h}$, washed with water and dried over night at ambient conditions to obtain the $\mathrm{NH}_{4}$-form. The zeolite was heated to $450{ }^{\circ} \mathrm{C}$ during $1 \frac{1 / 2}{\mathrm{~h}}$ and kept at this temperature for $4 \mathrm{~h}$ before cooling to room temperature and by this procedure the $\mathrm{H}$-form of the zeolite was obtained.

\subsubsection{Fractionizing the zeolite}

The zeolite powder was pressed to tablets at a pressure of 5 tons $(\varnothing=13 \mathrm{~mm})$. These pellets were crushed and sieved in such a way that a fraction of 180-355 $\mu \mathrm{m}$ particles was obtained. For the IWI sample, the fractionizing took place after the zeolite synthesis before the impregnation. The IE and IS samples were fractionized after the iron had been incorporated.

\subsubsection{Large conventional BEA zeolite crystals $(\mathrm{Si} / \mathrm{Al}=35)^{159}$}

$0.370 \mathrm{~g}$ of aluminum was dissolved in $55 \mathrm{~g}$ of a $35 \mathrm{wt} \%$ aqueous tetraethylammonium hydroxide $(\mathrm{TEAOH})$ solution. The solution was stirred for $1 \mathrm{~h}$ whereby a clear solution was obtained. $100 \mathrm{~g}$ of tetraethyl orthosilicate (TEOS) was mixed with $55 \mathrm{~g}$ of a $35 \mathrm{wt} \%$ aqueous TEAOH and the mixture was poured into the dissolved aluminum. The mixture was left at ambient conditions for $20 \mathrm{~h}$ to enhance the hydrolysis along with the ethanol and water evaporation resulting in a highly viscous gel. $13.20 \mathrm{~g}$ of $40 \mathrm{wt} \%$ aqueous hydrofluoric acid was added drop-wise while stirring. The gel was transferred to a Teflon cup and sealed in an autoclave. The crystallization took place under static conditions at $140{ }^{\circ} \mathrm{C}$ for 7 days. The autoclave was cooled to room temperature and the zeolite was isolated by filtration and washed with approximately 21 of distilled water. The zeolite was heated to $550{ }^{\circ} \mathrm{C}$ with a ramp of $2{ }^{\circ} \mathrm{C} / \mathrm{min}$ and kept in air at $550{ }^{\circ} \mathrm{C}$ for $12 \mathrm{~h}$ to remove the organic template.

The large BEA crystals have only been used briefly for comparison with the small BEA crystals in this study and unless specifically mentioned, the term BEA zeolite is used for the small crystals. 


\subsubsection{Activity test}

The standard experiment for catalytic testing was performed by taking $50 \mathrm{mg}$ of the catalyst and mixing it with $50 \mathrm{mg}$ silica. The catalyst was loaded in a quartz reactor to obtain a fixed bed with a diameter of $3.8 \mathrm{~mm}$ between two layers of quartz wool as shown in Figure 12.3.
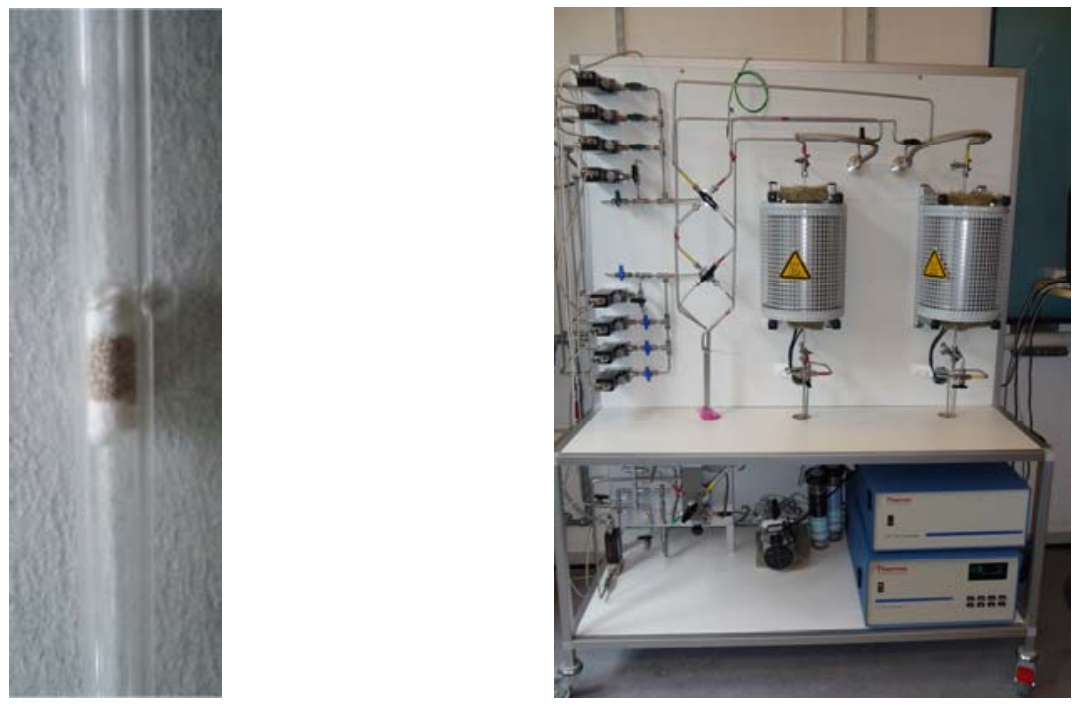

Figure 12.3 Reactor used for $\mathrm{NH}_{3}$-SCR loaded with an iron-containing BEA catalyst (left). Test set-up for catalytic activity in the $\mathrm{NH}_{3}$-SCR reaction (right).

The sample was pre-treated in the reactant flow for $2 \mathrm{~h}$ at $200^{\circ} \mathrm{C}$. A gas mixture consisting of 1000 ppm NO, $1100 \mathrm{ppm} \mathrm{NH}_{3}, 3.5 \% \mathrm{O}_{2}$, and $2.3 \% \mathrm{H}_{2} \mathrm{O}$ in $\mathrm{N}_{2}$ with a total flow of $300 \mathrm{ml} / \mathrm{min}$ was led over the catalyst under plug-flow conditions. The reactor was cooled to room temperature after the pre-treatment, and a by-pass measurement was performed to know the exact concentration of NO in the gas-flow. Then the reactor was reheated and the catalytic activity was monitored between $200-550{ }^{\circ} \mathrm{C}$ with $25{ }^{\circ} \mathrm{C}$ intervals. At each investigated temperature several measurements were performed after the system was stabilized. The activity was measured using a Thermo Electron's Model 10A Chemiluminiscent NO-NO Gas Analyzer.

\subsubsection{Characterization}

\subsubsection{XRD}

XRD was used as a standard procedure to investigate the crystallinity of the zeolites. The XRD patterns were recorded using a Bruker powder diffractometer with $\mathrm{Cu}-\mathrm{K}_{\alpha 1}$ radiation $(\lambda=1.54051 \AA)$ for $2 \theta$ values between 1 and $60^{\circ}$ in steps of $0.02^{\circ}$. 


\subsubsection{2 $\mathrm{N}_{2}$-physisorption measurements}

The zeolite materials were investigated in order to determine the surface area and the micropore volume. The $\mathrm{N}_{2}$-adsorption experiments were performed at liquid nitrogen temperature on a Micromeritics ASAP2020 analyzer. The samples were evacuated for $1 \mathrm{~h}$ at $200{ }^{\circ} \mathrm{C}$ prior to the measurement. The surface areas were determined using the BET method $^{160}$ while the pore volumes were determined using the t-plot method ${ }^{161}$.

\subsubsection{TPD}

Temperature programmed desorption (TPD) was performed by monitoring the desorption of ammonia with a computer-interfaced Jasco V-570 UV/VIS/NIR spectrometer using the characteristic ammonia band at $201 \mathrm{~nm}$. The TPD was performed by placing $100 \mathrm{mg}$ of the investigated sample in a quartz tube reactor and saturating it with $100 \mathrm{ml} / \mathrm{min} 1 \% \mathrm{NH}_{3} / \mathrm{He}$ for $1 \mathrm{~h}$ at ambient temperature. In order to remove the physisorped ammonia the sample was heated to $100{ }^{\circ} \mathrm{C}$ in a flow of $100 \mathrm{ml} / \mathrm{min}$ nitrogen. The sample was then cooled to $50{ }^{\circ} \mathrm{C}$ and from this temperature the TPD measurements began. The temperature was raised to $650{ }^{\circ} \mathrm{C}$ with a ramp of $5^{\circ} \mathrm{C} / \mathrm{min}$ while measuring. The ammonia concentration was calculated based on the intensity of the ammonia band at $201 \mathrm{~nm}$ using a calibration curve. In order to determine the total amount of desorbed ammonia, the area under the TPD curve was calculated.

\subsubsection{FTIR}

Fourier transformed infra-red (FTIR) spectra of selected samples pressed to pellets were recorded on a Perkin-Elmer 1710, Fourier Transform Infrared Spectrometer at room temperature. The pellets were pressed after mixing $0.5 \mathrm{mg}$ sample with $100 \mathrm{mg}$ dried $\mathrm{KBr}$ carefully.

\subsubsection{EPR}

EPR spectra of iron-containing zeolite samples were recorded ex-situ at room temperature using a Bruker EMX-EPR spectrometer. It was recorded at the X-band (Bruker ER 041 XGG Microwave Bridge) with microwave frequencies of around $9.35 \mathrm{GHz}$. The software WINEPR from Bruker was used for data treatment.

\subsubsection{Iron analysis}

To determine the iron content in the samples, inductively coupled plasma mass spectroscopy (ICP-MS) in SemiQuant mode was used. The amount of iron was calculated using a calibration curve from a Merck ICP multi element standard solution. 


\subsubsection{SEM}

SEM pictures of the BEA samples coated with platinum/palladium were recorded using a Philips XL30 ESEM-FEG apparatus at Haldor Topsøe A/S.

\subsection{Results and discussion}

\subsubsection{Characterization of the catalysts}

\subsubsection{XRD}

XRD patterns were recorded for all the samples to examine the crystallinity. In Figure $12.4 \mathrm{a}$ representative XRD pattern of a conventional H-BEA zeolite is shown along with the pattern of a zeolite prepared by IS.

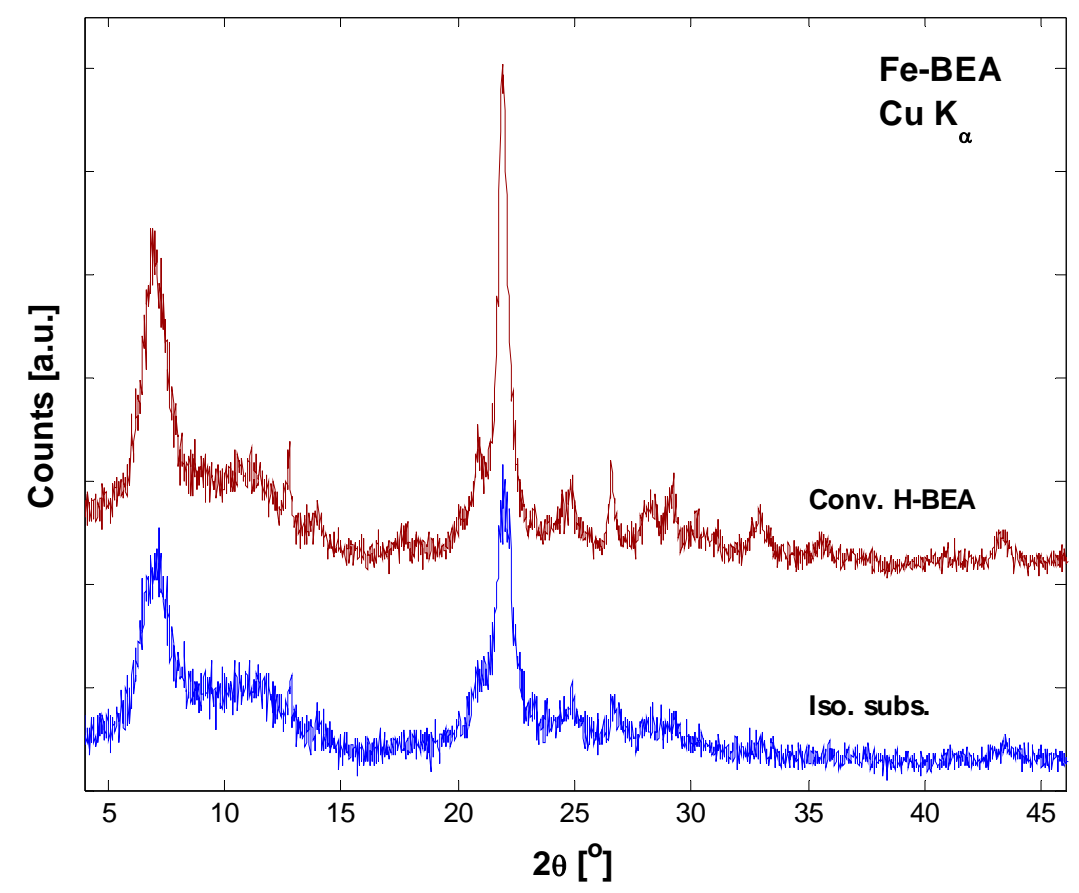

Figure 12.4 XRD pattern of an H-BEA zeolite and an IS Fe-BEA zeolite.

All the H-BEA zeolite samples investigated exhibit high crystallinity and the position of the diffraction reflections are in accordance with the literature ${ }^{162,163,164}$. The reflections are sharp and broad as often seen in samples where intergrowth of polymorphs takes place, which is the case for BEA, consisting of two different crystal forms ${ }^{162,164}$. The same is seen to be the case for the IS sample. This means that the crystallinity is not lost when iron is introduced to the framework during the synthesis and that the overall scattering density distribution is rather unaffected by the substitution of aluminium with iron. 


\subsubsection{BET areas, pore volumes, and isotherms}

The $\mathrm{N}_{2}$-desorption and adsorption measurements revealed BET areas, pore volumes, and pore sizes for a conventional H-BEA zeolite (before and after iron was introduced by IWI) and for an IS Fe-BEA sample. The values are summarized in Table 12.1.

Table 12.1 BET areas, pore volumes and pore size for an H-BEA zeolite and two iron-containing zeolites prepared by respectively IWI and IS.

\begin{tabular}{|l|c|c|c|}
\hline Zeolite & BET area $\left[\mathrm{m}^{2} / \mathrm{g}\right]$ & Micropore vol. $\left[\mathrm{cm}^{3} / \mathrm{g}\right]$ & Pore size $[\AA]$ \\
\hline H-BEA & 562 & 0.205 & 21.5 \\
\hline $2.7 \mathrm{wt} \%$ Fe/H-BEA IWI & 507 & 0.178 & 21.9 \\
\hline $1.2 \mathrm{wt} \%$ Fe-BEA IS & 340 & 0.132 & 20.0 \\
\hline
\end{tabular}

The surface area for the conventional H-BEA zeolites without any iron is found to be $562 \mathrm{~m}^{2} / \mathrm{g}$. In general all BEA zeolites prepared with IWI have areas between $490-570 \mathrm{~m}^{2} / \mathrm{g}$. Values within this range for BEA zeolites are in accordance with values reported in the literature $^{165}$. When introducing the iron to the zeolite by IE (or IWI) the surface area is typically decreased with about $10 \%$. This can be explained by the pores being partially blocked by iron particles. For the IS sample the surface area is found to be much lower, namely $340 \mathrm{~m}^{2} / \mathrm{g}$.

In Figure 12.5 an adsorption-desorption isotherm is shown for an iron-containing BEA sample prepared with IWI, and a sample prepared by IS.

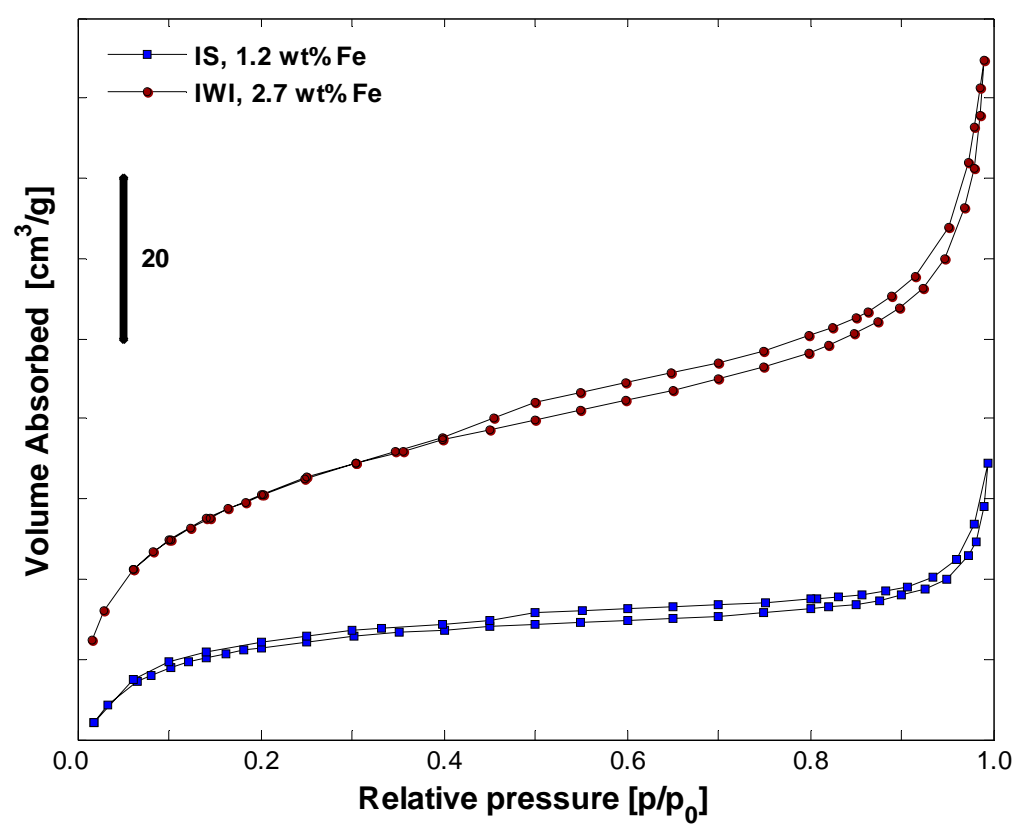

Figure 12.5 Nitrogen adsorption and desorption isotherm for iron-containing BEA zeolites prepared by IWI and IS, respectively. 
The two zeolites both show a type I isotherm, which is expected, since this is typical for microporous materials such as zeolites.

\subsubsection{Surface acidity and acid density}

Temperature programmed desorption (TPD) of ammonia was performed in order to study the surface acidity of the zeolite. In Figure 12.6 a representative TPD profile is shown, for the IS sample.

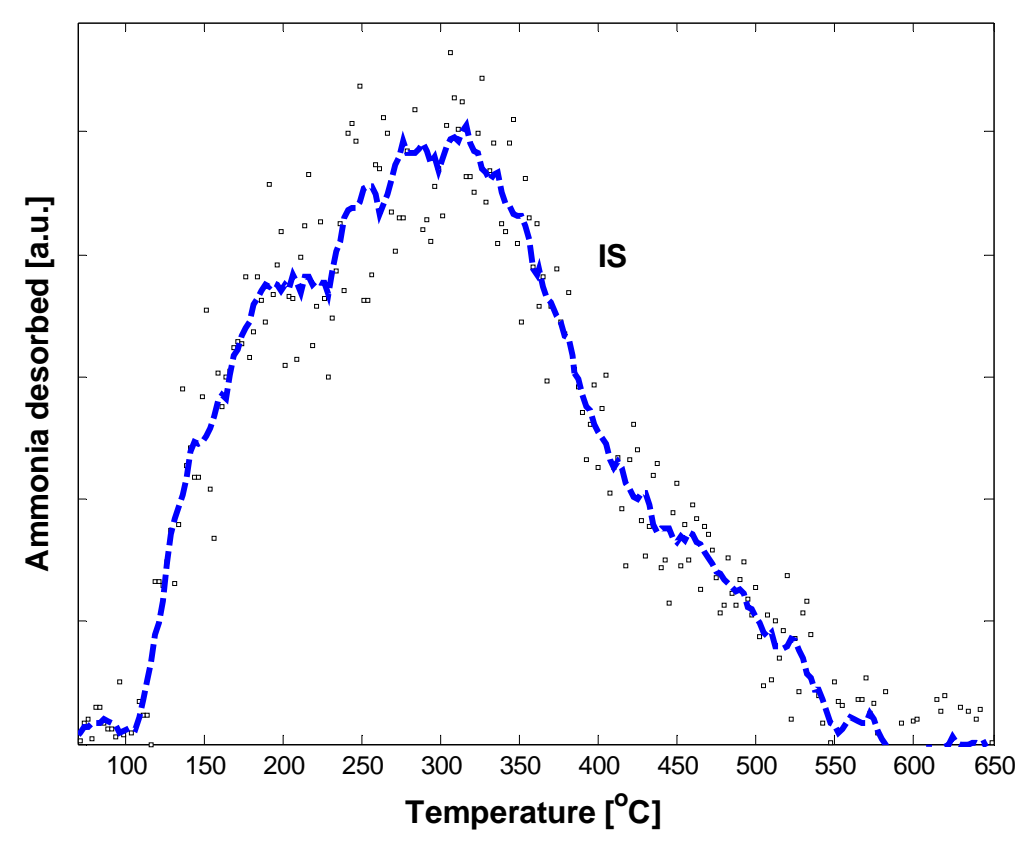

Figure 12.6 $\mathrm{NH}_{3}$-TPD profile for a BEA zeolite prepared by IS.

From Figure 12.6 it can be noted that two peaks are present - one at $\sim 200{ }^{\circ} \mathrm{C}$ and one at $\sim 300{ }^{\circ} \mathrm{C}$. These peaks, especially the one at $300^{\circ} \mathrm{C}$, might consist of two or more close laying bands. For the samples where the iron is introduced by impregnation the peaks are shifted to higher temperatures, and are found to be located at $250{ }^{\circ} \mathrm{C}$ and $400{ }^{\circ} \mathrm{C}$, respectively. An assignment of the two peaks can be made: the peak at $200-250{ }^{\circ} \mathrm{C}$ can be attributed to physisorped ammonia, while the peak at $300-400{ }^{\circ} \mathrm{C}$ originates from the acid sites at the surface $^{166,167}$. The shift in the position of the peak at higher temperatures can be explained by differences in the acidity of the surface sites for the different samples. The higher temperature the band is seen at, the stonger the acidity is expected to be. The acid densities for the samples prepared by IWI are in the range from $1550-1659 \mu \mathrm{mol} / \mathrm{g}$ while it is around $1250 \mu \mathrm{mol} / \mathrm{g}$ for the IS sample. For the IWI samples no correlation is observed between the iron content and the acid density, and the acid density does not vary much for the samples, indicating that the formation of iron oxide is dominant after calcination. These results are in accordance with 
previous experiments with Fe/H-ZSM-5 reported in the literature ${ }^{148}$. In these experiments iron was introduced to ZSM-5 by impregnation with an iron salt followed by calcination. This was seen mainly to lead to iron oxide species and therefore a rather limited degree of ionexchange, resulting in low influence of the iron content on the acidity.

\subsubsection{IR-spectra}

IR-spectra were recorded for the samples, and the spectra were found to be rather similar. In Figure 12.7 an example of an IR-spectrum for an IE sample is shown.

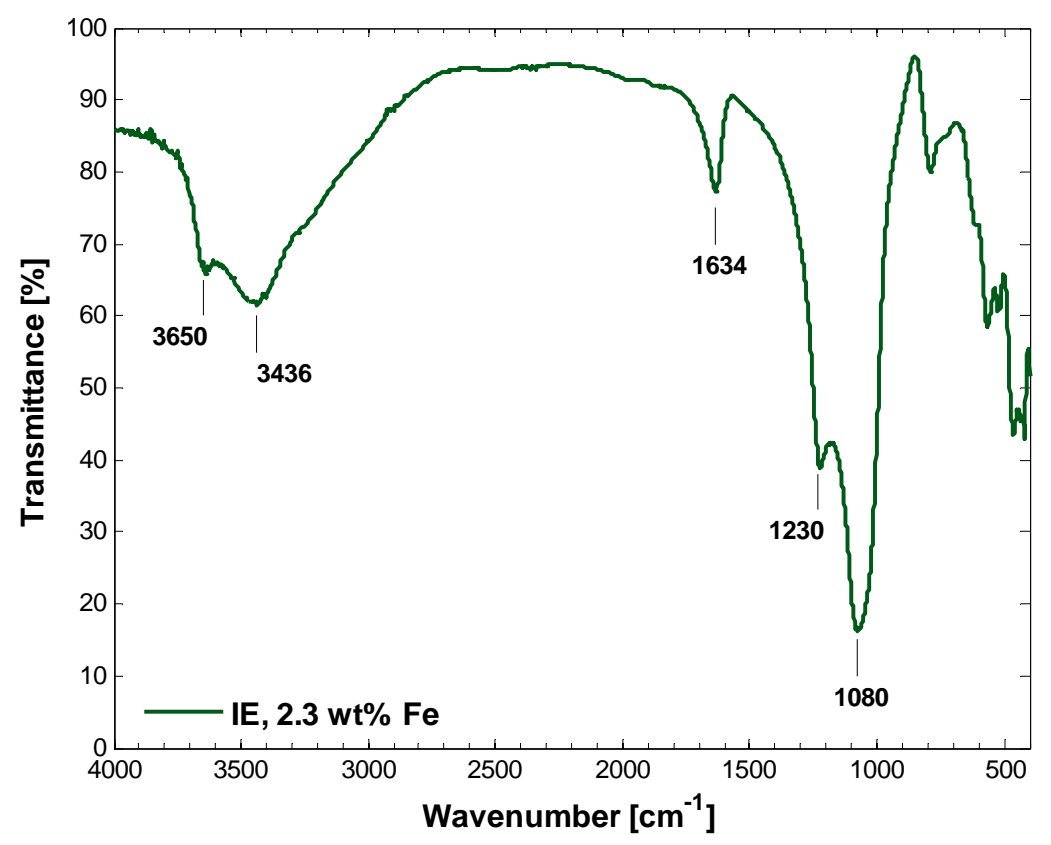

Figure 12.7 IR spectrum of an IE sample.

The framework structures for zeolites are known to show characteristic bands in IR-spectra. For BEA zeolites these characteristic framework vibrations are found at wave numbers between 1250-450 $\mathrm{cm}^{-1} 168,169,170$. All bands expected to be seen in this area, based on the literature, are found for the investigated zeolites. Hydroxyl stretching bands are observed at $4000-3200 \mathrm{~cm}^{-1}$ in form of a broad band with some fine structure. The fine structure in form of several bands is expected in this area, originating from e.g. H-bonded silanols, ironhydroxide stretching vibrations, and aluminium hydroxyls. Traces of water are observed as well, which is usual in zeolite systems. Based on this interpretation, all bands can be accounted for as being related to the BEA zeolites, except for a few weak shoulders. 


\subsubsection{EPR spectroscopy}

X-band EPR spectroscopy was used in order to obtain information about the iron-species in the samples. It should be noted that EPR spectra of $\mathrm{Fe}^{3+}$ species ( $d^{5}$ systems) normally are rather complicated. The different EPR bands in such spectra can be attributed to the different iron species being present in the sample, along with contaminants of iron-containing compounds which can complicate the picture even further. EPR spectra of zeolites containing iron(III) are normally characterized by three signals: one signal is located at g' $=4.3$, a broad signal is seen at $\mathrm{g}^{\prime}=2.0-2.3$, while the last band is a sharp band located at $\mathrm{g}^{\prime}=2.0^{171}$. The signal at $\mathrm{g}^{\prime}=4.3$ is assigned to tetrahedral $\mathrm{Fe}^{3+}$ ions. The broad signal at $\mathrm{g}^{\prime}=2.0-2.3 \mathrm{can}$ be assigned to iron in an oxide- or a hydroxide phase. The signal at g' $=2.0$ originates from iron in cation-exchange sites in the zeolite (isolated $\mathrm{Fe}^{3+}$ ions), dimmers, or iron oxide clusters. Occasionally a fourth signal at low field, g' $=6$ is observed. This signal can be assigned to $\mathrm{Fe}^{3+}$ ions in octahedral coordination ${ }^{171,172}$.

The X-band EPR-spectra for samples prepared by IWI and IS are shown in Figure 12.8.

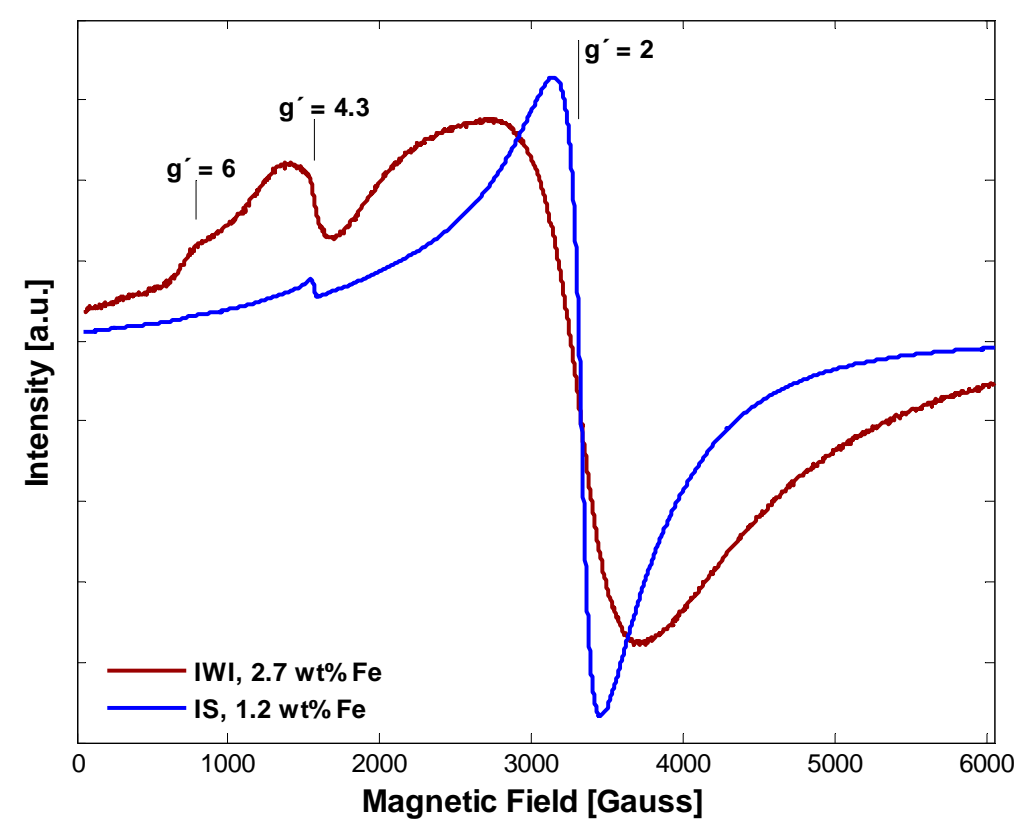

Figure 12.8 X-band EPR spectra recorded ex-situ at room-temperature for iron-containing BEA samples prepared by IWI and IS, respectively. The intensities of the IS sample is scaled down by a factor of 13 .

It can immediately be noted that the spectra of a sample prepared by IWI and a sample prepared by IS are very different. The sample prepared by IWI is dominated by the signals at low field. Signals at $\mathrm{g}^{\prime}=6$ and 4.3 are seen along with a broad and very intense signal at $\mathrm{g}^{\prime}=2.0-2.3$ originating from clustered species with antiferromagnetic interactions between 
the iron(III) ions. An interpretation based on these facts is that the iron species present in the IWI sample are distributed as small amounts of octahedral $\mathrm{Fe}^{3+}$ ions, isolated tetrahedral $\mathrm{Fe}^{3+}$, and iron oxide ${ }^{173}$.

The spectrum of the sample prepared by IS is dominated by the sharp signal at higher field, $\mathrm{g}^{\prime}=2$, while the signals at lower field exhibit lower intensity. The narrow band at $\mathrm{g}^{\prime}=2.0 \mathrm{can}$ be assigned to isolated octahedral $\mathrm{Fe}^{3+}$ and mutually interacting iron(III) in clusters and dimers.

\subsubsection{Iron content}

The iron content was determined by ICP-MS. For all the samples prepared by IWI the iron contents found by the analysis were in accordance with the expected concentrations based on the metal concentrations in the solutions the zeolites were impregnated with. The iron contents in the IE-sample was found to be $2.3 \mathrm{wt} \%$ while it was found to be $1.2 \mathrm{wt} \%$ for the IS-sample.

\subsubsection{Morphology}

SEM pictures of both the small and the large H-BEA crystals were recorded in order to examine the morphology. The pictures are shown in Figure 12.9.

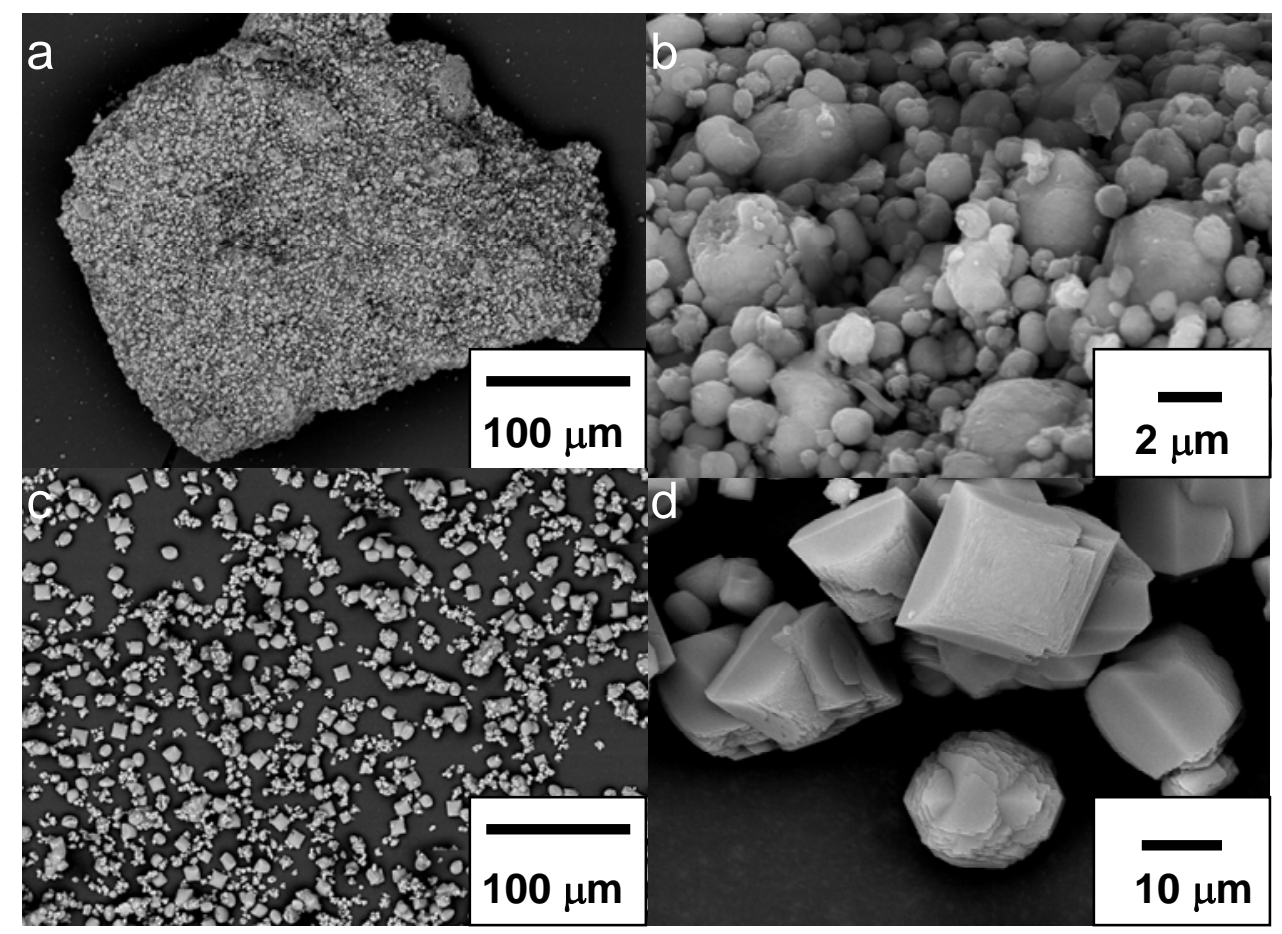

Figure 12.9 SEM pictures $\mathrm{a}+\mathrm{b}$ ) small H-BEA zeolites $\mathrm{c}+\mathrm{d}$ ) large H-BEA zeolites. 
The small H-BEA zeolite crystals show a non-regular morphology, and a size distribution between 1-3 $\mu \mathrm{m}$. The larger H-BEA crystals show incomplete bipyramidal morphology and particle sizes between 5-15 $\mu \mathrm{m}$. The difference in morphology might be related to the silica sources being different in the two syntheses. Preliminary SCR activity studies indicate that the large crystals of BEA zeolite exhibit lower catalytic activity after impregnation with iron than the small BEA crystals. This can be explained by diffusion limitations, but further investigations needs to be done including studying the influence of the $\mathrm{Si} / \mathrm{Al}$ ratio and the effect of introducing mesopores in the zeolites.

\subsubsection{Activity tests}

\subsubsection{Comparison of different zeolite catalysts}

The catalytic activity of three different iron-containing zeolites, Fe/H-ZSM-5, Fe/H-ZSM-12, and $\mathrm{Fe} / \mathrm{H}-\mathrm{BEA}$, all with $\mathrm{Si} / \mathrm{Al}=50$, were compared with a traditional catalyst consisting of $3 \mathrm{wt} \%$ vanadia on titania. All zeolite catalysts contained approximately $3 \mathrm{wt} \%$ iron, which in all cases was added by IWI. The NO conversion is plotted as a function of the temperature as shown in Figure 12.10 for the four catalysts.

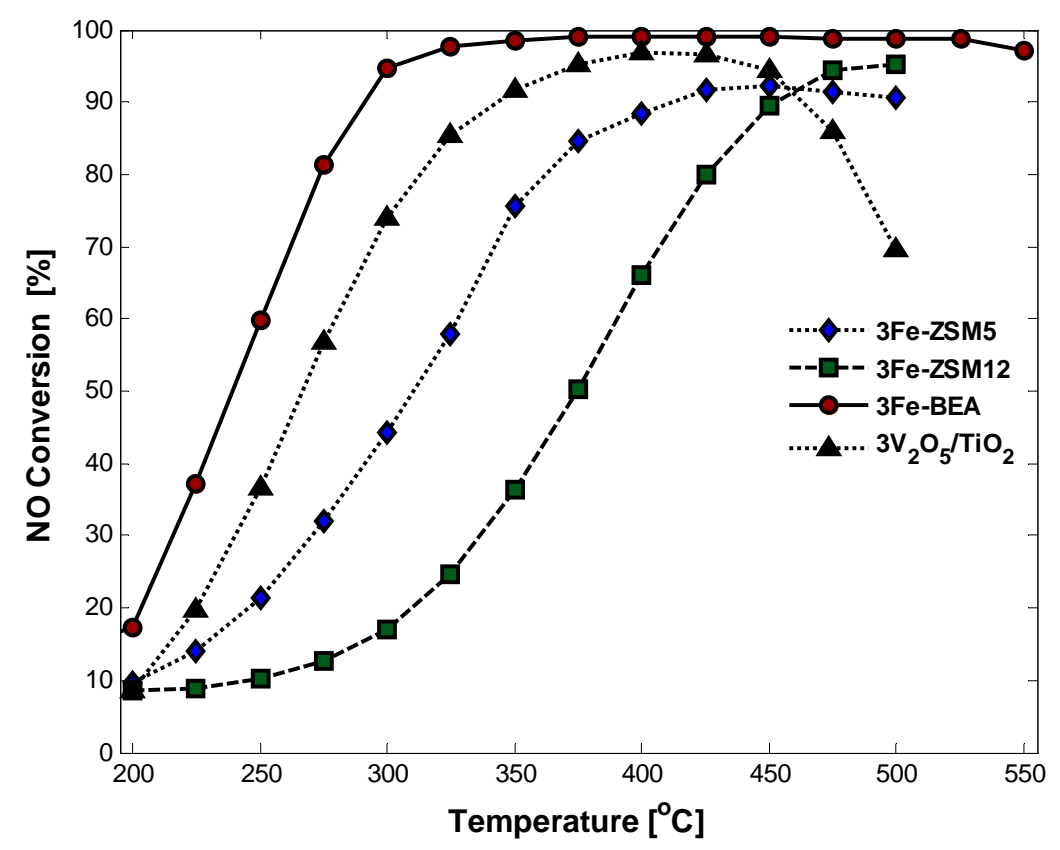

Figure 12.10 NO conversion versus temperature for Fe/H-ZSM-5, Fe/H-ZSM-12 and Fe/H-BEA zeolites compared to a traditional vanadium-titania catalyst. 
It can be seen that the Fe/H-BEA catalyst exhibits very high catalytic activity in a broad temperature range. At low temperature the activity of $\mathrm{Fe} / \mathrm{H}-\mathrm{BEA}$ is even higher than the vanadium catalyst, and it remains very active in the entire temperature interval studied. The Fe/H-ZSM-12 catalyst is less active than the Fe/H-ZSM-5 catalyst and both of these are less active than the commercially used vanadium catalyst type. The catalytic activities of all three zeolites in their $\mathrm{H}$-forms were negligible compared to the activity of the iron-containing zeolites. Based on this series of experiments, it was decided to investigate the promising ironcontaining BEA zeolite system further.

\subsubsection{Influence of the iron content}

The influence of the iron content on the catalytic activity was studied by preparing samples with different iron-content using IWI. The result of this study can be seen in Figure 12.11, where the activity data are shown at $275{ }^{\circ} \mathrm{C}$ - the trend is the same at all the investigated temperatures from $250-500{ }^{\circ} \mathrm{C}$.

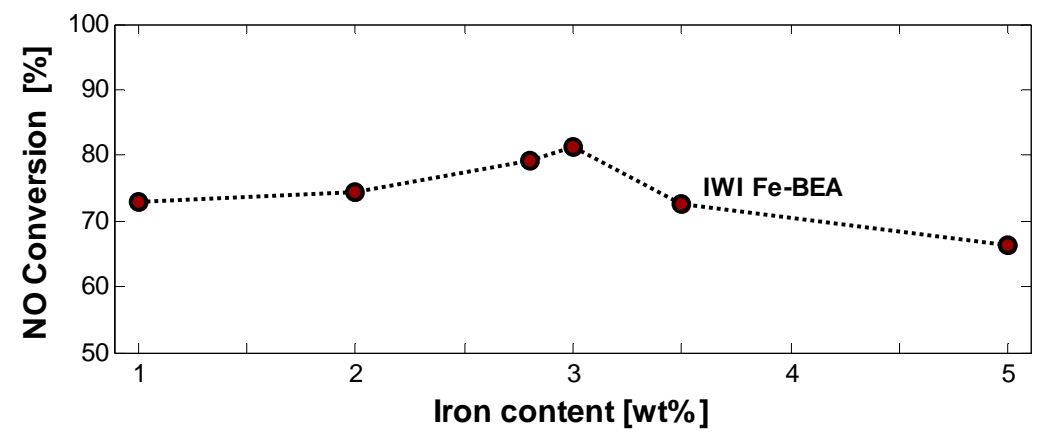

Figure 12.11 The influence of iron on the catalytic activity for $\mathrm{NH}_{3}-\mathrm{SCR}$ at $275^{\circ} \mathrm{C}$ was investigated by plotting the NO conversion versus the iron content in BEA samples prepared by IWI.

It was found that the influence of the iron content was rather limited in the range 1-5 wt $\% \mathrm{Fe}$. However, a small optimum in activity is seen for catalysts containing between $2.5-3.0 \mathrm{wt} \%$ iron.

A comparison of the intensity of the EPR bands with the iron-content and activity can be seen for a series of samples prepared by IWI in Figure 12.12. 


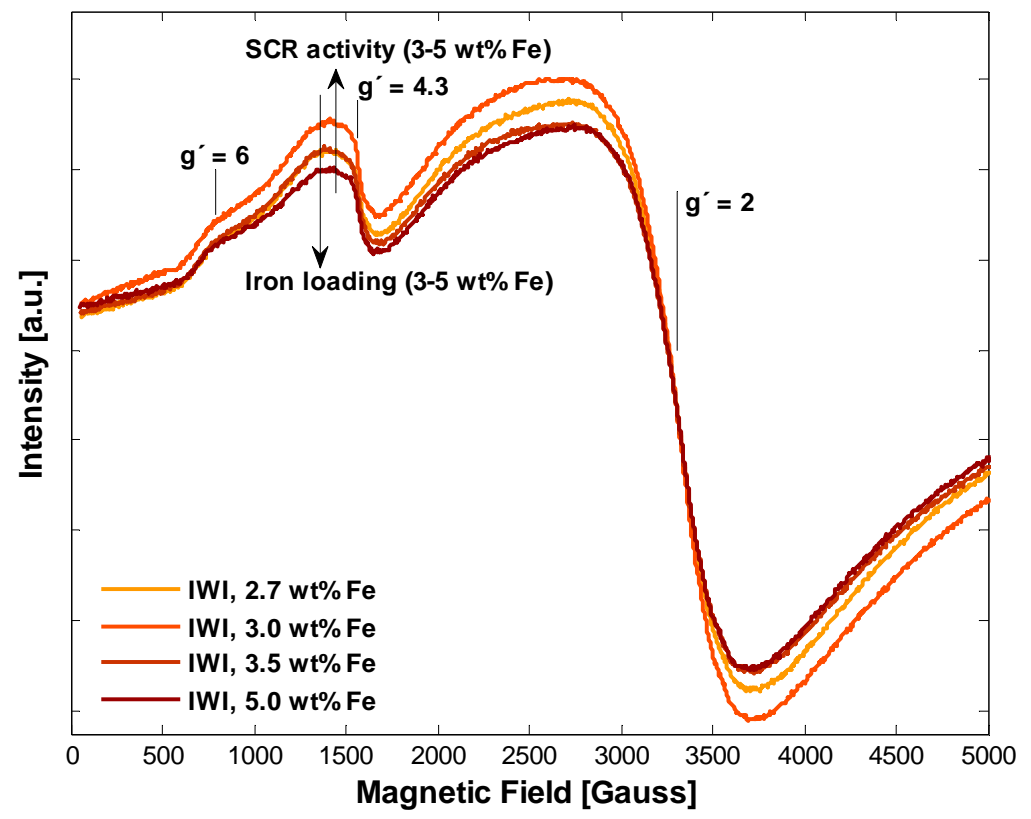

Figure 12.12 The influence of the iron content, the SCR-activity, and the intensities of the low field bands in EPR spectra of samples prepared by IWI.

From Figure 12.12 it is seen, that the EPR spectra have signals with intensities of comparable dimensions. Even though precaution should be taken when analyzing EPR-spectra quantitatively, it should be noted that a trend seems to appear when comparing the EPR signals at low field $\left(g^{\prime}=4.3\right.$ and $\left.g^{\prime}=2.0-2.2\right)$. The higher the iron content is for the sample between 3.0 and $5.0 \mathrm{wt} \%$ (and thereby lower activity cf. Figure 12.11) the lower are the intensities of these EPR bands. The sample with $2.7 \mathrm{wt} \%$ Fe show signals with intensities between those of the 3.0 and $3.5 \mathrm{wt} \%$ samples, which is in accordance with the activity trend. For the signal at $g^{\prime}=6.0$ the bands have very similar intensities.

The fact that the intensities of multiple bands vary systematically with the activity indicates that more than one iron species can be catalytically active in the reaction. Based on this, it is not possible to determine the main active species in the catalytic reduction of $\mathrm{NO}$ by $\mathrm{NH}_{3}$ using EPR spectroscopy at ambient conditions.

\subsubsection{Investigation of different iron incorporation methods}

A series of iron-containing BEA catalysts was prepared using different preparation techniques. Three samples were prepared, one using IWI (2.8 wt $\% \mathrm{Fe})$, another using IE $(2.3 \mathrm{wt} \% \mathrm{Fe})$ and the last using IS (1.2 wt \% Fe). The activity data are shown in Figure 12.13 for the three catalysts along with a $3 \mathrm{wt} \%$ vanadia/titania reference catalysts. 


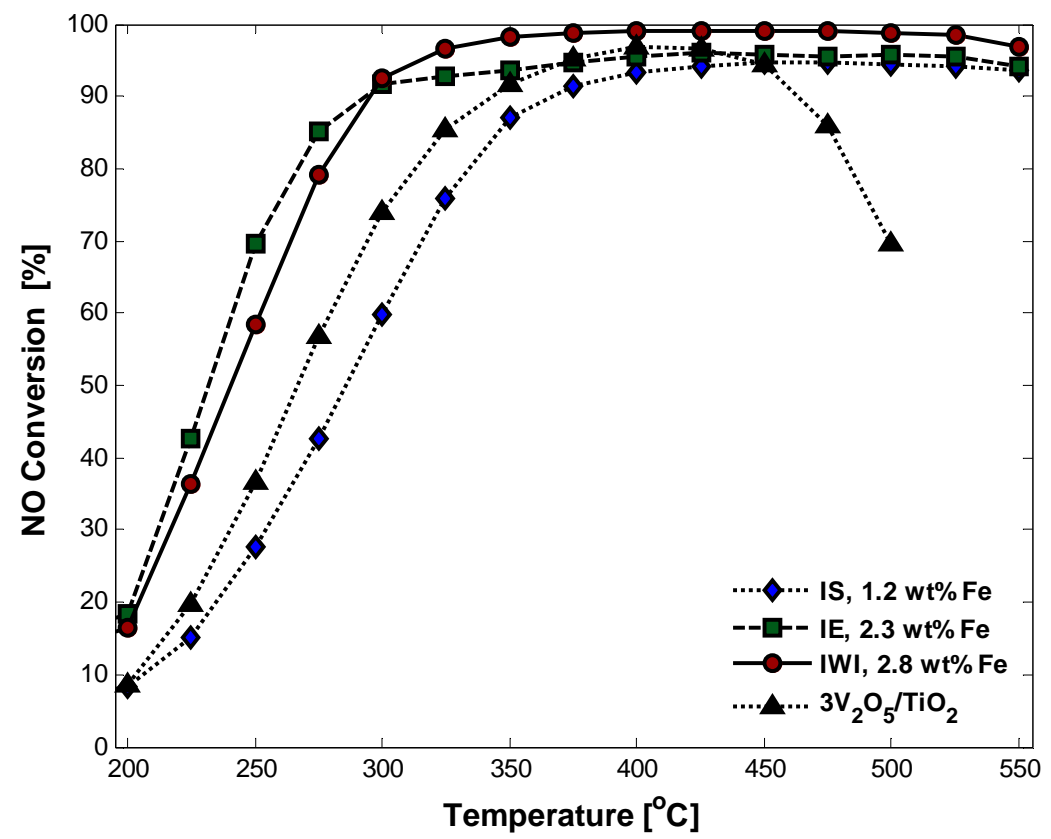

Figure 12.13 The influence of the preparation method for iron-containing BEA catalysts on the NO conversion is shown for samples prepared by IWI, IE, and IS. A vanadium catalyst is shown as a reference.

One thing that can be seen immediately from Figure 12.13 is that all the zeolite catalysts exhibit very high conversions at temperatures higher than $\sim 350{ }^{\circ} \mathrm{C}$. The fact that the catalysts show $100 \%$ conversion in a broad interval makes it hard to determine the exact temperature optimum in catalytic activity, but for the iron-containing BEA catalysts it seems to be located around $450{ }^{\circ} \mathrm{C}$ while it is at $400{ }^{\circ} \mathrm{C}$ for the vanadium-based catalysts. The decrease of the activity for the zeolite catalysts at higher temperatures is much less pronounced than for the vanadium-based catalyst.

The samples prepared by IWI and IE contain approximately the same amount of iron, and are in that respect fully comparable taking the small iron dependence on the activity from Figure 12.11 into consideration. These two samples exhibit rather similar NO conversions; both are considerably higher (almost by a factor of two) than the vanadium catalyst between 200$275^{\circ} \mathrm{C}$. This shows that these two preparation methods lead to equally good catalysts. The IS sample is on the other hand considerably worse with respect to catalytic activity, compared to both the IWI and IE sample and the vanadium catalyst. However, the sample exhibits hightemperature activity and stability - at temperatures above $450{ }^{\circ} \mathrm{C}$ it is comparable to the other iron-containing BEA zeolites. The iron content is higher for the two other iron-containing BEA catalysts than for the IS sample. Thus the iron content in the IS sample is not optimal cf. 
Figure 12.11. However, the dependence of the iron content is rather small, and this difference is not sufficient to explain the observed difference in activity between the IS catalyst and the other zeolite catalysts. One possible explanation can be that different and less active iron species are formed by IS compared to e.g. by IWI. The hypothesis that different iron species are present is supported by the EPR-spectra of the IWI and the IE samples (Figure 12.8). Another explanation can be found in the lower surface area, pore volume, and acidity of the IS sample compared to the other samples. The low catalytic activity for the IS sample might leave room for optimization of this catalyst by improvement of the preparation method.

\subsection{Conclusions and future work}

When comparing different iron-containing zeolites, ZSM-5, ZSM-12, and BEA with a vanadium catalyst traditionally used for the $\mathrm{NH}_{3}-\mathrm{SCR}$ reaction, the BEA catalyst was found to exhibit superior catalytic activity to the other catalysts. Based on this observation the BEA system was studied in more detail. The influence of the iron content was investigated for samples prepared with incipient wetness impregnation. It was found that the metal concentration dependence on the activity was relatively low, but a small activity maximum around 2.5-3.0 $\mathrm{wt} \%$ iron was seen. Iron-containing catalysts were synthesized in different ways in order to determine the influence of the preparation method. It was found that incipient wetness impregnation and ion exchange were equally good and significantly better than isomorphous substitution. In general the iron-containing BEA catalysts examined in this study were found to exhibit high activity in a broad temperature interval compared to the vanadium reference catalyst.

The over-all conclusion is that Fe-zeolite catalysts might be very interesting commercially as catalysts in automotive applications for $\mathrm{NO}_{\mathrm{x}}$ removal in the future. It seems that it is possible to achieve high catalyst performance with these materials and at the same time avoid the presence of poisonous vanadium. However, experiments studying the long term stability of the iron-containing zeolites should be carried out in the future, and be taken into account in the further development and optimization of the catalyst system. Another interesting project for the future could be to study the catalytic activity of mesoporous Fe/H-BEA zeolites after desilication of the large H-BEA zeolite crystals. This is expected to improve the over-all catalytic activity based on experience from the Fe/H-ZSM-5 and Fe/H-ZSM-12 system, where the mesoporous zeolites exhibit higher activity than the conventional zeolites. 


\section{Concluding remarks}

Due to the very broad topic "Design of heterogeneous catalysts" it was necessary to make choices regarding both the reactions that should be studied and the catalyst types that should be investigated during the three years the project has lasted.

During my $\mathrm{PhD}$ study I have mainly looked into three reactions: the methanation reaction, the Fischer-Tropsch reaction, and the ammonia-based selective catalytic reduction of NO. Thus, in all cases it is gas-phase reactions over solid state catalysts that have been investigated. I have studied a selection of different catalyst types: metals catalysts, promoted metal catalysts, and alloy catalysts - all on traditional oxide supports. Furthermore, I have investigated metal containing zeolites. The broad topic have given me the advantage of being able to gain knowledge within many different areas such as various industrial reactions, catalysis in general, synthesis of materials, and characterization techniques.

All three projects have resulted in new, interesting, and useful results within the field, as it has been summed up in the conclusions sections given at the end of each separate part. It is my hope that my contribution can be a part of a larger whole, gaining better knowledge within the very complex area of catalysis. Not only have the project resulted in scientific results which were suitable for publication- the work has also challenged my curiosity: each result led to the desire of knowing and understand more. In all three projects there are still areas to investigate and ideas that can be pursued - the highest motivation for research.

'Beautiful are the things we see

More beautiful is what we understand

But by far the most beautiful is what we do not comprehend'

Niels Steensen (1638-1686) 
Design of heterogeneous catalysts 


\section{References}

${ }^{1}$ J.J. Berzelius, Jahresberichte 15 (1835) 237

${ }^{2}$ A. D. McNaught and A.Wilkinson, IUPAC Compendium of Chemical Terminology, 2nd ed. Blackwell Scientific Publications, Oxford (1997)

${ }^{3}$ J.M. Thomas and W.J. Thomas, Principles and Practice of Heterogeneous Catalysis, VCH Verlagsgesellschaft, Weinheim (1997)

${ }^{4} \mathrm{http}: / / \mathrm{www}$.nacatsoc.org

${ }^{5} \mathrm{http}: / / \mathrm{www} . c \mathrm{crhq}$. org

${ }^{6}$ I. Chorkendorff and J.W. Niemantsverdriet, Concepts of Modern Catalysis and Kinetics, Wiley-VCH, Weinheim (2003)

7 J. Clark and D. Macquarrie, Handbook of Green Chemistry \& Technology, Blackwell Publising Company, Oxford (2002)

${ }^{8}$ P. Sabatier and J.B. Senderens, Acad. Sci. 134 (1902) 514

${ }^{9}$ M.A. Vannice, J. Catal. 50 (1977) 228

${ }^{10}$ D.P. McArthur and Y. Linda, US Patent 4191664 (1980) to Union Oil Company

${ }^{11}$ C.N. Satterfield, Heterogeneous Catalysis in Industrial Practice, 2nd ed., Krieger Publishing, Malabar, FL (1991)

${ }^{12}$ A. Nielsen (Ed.), Ammonia: Catalysis and Manufacture, Springer, Heidelberg (1995)

${ }^{13}$ C.J.H. Jacobsen, I. Schmidt, A. Boisen and K. Johannsen, Katalytisk kemi. Et spørgsmål om miljø og ressourcer, Paritas Grafik A/S, Lyngby (2004)

${ }^{14}$ K. Yaccato, R. Carhart, A. Hagemeyer, A. Lesik, P. Strasser, A.F. Volpe, H. Turner, H. Weinberg, R.K. Grassel and C. Brooks, Appl Catal A 296 (2005) 30

${ }^{15} \mathrm{http}: / / w w w . d i q u i m a . u p m . e s /$ docencia/tqi/docs/ammonia.pdf

${ }^{16}$ M.V. Twigg (Ed.), Catalyst Handbook, 2nd ed., Manson Publishing, London (1996)

${ }^{17}$ S. Takenaka, T. Shimizu and K. Otsuka, Int. J. Hydrogen Energy 29 (2004) 1065

${ }^{18}$ S.A. Bresler and J.D. Ireland, Chem. Eng. 1 (1972) 94

${ }^{19}$ A. Harms, B Höhlein, E. Jørn and A. Skov, Oil Gas. J. 78 (1980) 120

${ }^{20} \mathrm{http}: / / \mathrm{www}$. fischer-tropsch.org

${ }^{21}$ A.N. Akin, M. Ataman, A.E. Aksoylu and Z.I. Oensan, React. Kinet. Catal. Lett. 76, 2 (2002) 265

${ }^{22}$ R. Parthasarathy and S. Spring, US Patent 3933883 (1976) to W.R. Grace \& Co

${ }^{23}$ M. Nawdali and D. Bianchi, Appl. Catal. A. Gen. 231, 1-2 (2002) 45

${ }^{24}$ B. Botti, D. Cauzzi, P. Moggi, G. Predieri and R. Zanoni, Stud. Surf. Sci. Catal. 130B (2000) 1091

${ }^{25}$ M. Gratzel, J. Kiwi and K.R. Thampi, US Patent 4847231 (1989) to Gas Research Institute, Chicago

${ }^{26}$ J.N. Finch and D.L. Ripley, US Patent 3988334 (1976) to Phillips Petroleum Company

${ }^{27}$ D.W. Goodman, R. D. Kelley, T. E. Madey and J. T. Yates Jr., J. Catal. 63 (1980) 26

${ }^{28}$ T. Bligaard, J.K. Nørskov, S. Dahl, J. Matthiesen, C.H. Christensen and J. Sehested, J. Catal. 224 (2004) 206

${ }^{29}$ R.A. van Santen, A. de Koster and T. Koerts, Catal. Lett. 7 (1990) 1

${ }^{30}$ J. Sehested, S. Dahl, J. Jacobsen and J.R. Rostrup-Nielsen, J. Phys. Chem. B 109 (2005) 2432

31 T. Zubkov, G.A. Morgan Jr., J.T. Yates Jr., O. Kuhlert, M. Lisowski, R. Schillinger, D. Fick and H.J. Jansch, Surf. Sci. 526 (2003) 57 
${ }^{32}$ M. Mavrikakis, M. Bäumer, H.J. Freund and J.K. Nørskov, Catal. Lett. 81 (2002) 153

33 J.K. Nørskov, T. Bligaard, A. Logadottir, S. Bahn, L.B. Hansen, M. Bollinger, H. Bengaard, B. Hammer, Z. Sljivancanin, M. Mavrikakis, Y. Xu, S. Dahl and C.J.H. Jacobsen, J. Catal. 209 (2002) 275

${ }^{34}$ M.P. Andersson, T. Bligaard, A.L. Kustov, K.E. Larsen, J. Greeley, T. Johannessen, C.H. Christensen and J.K. Nørskov, J. Catal. 239 (2006) 501

${ }^{35}$ G.H. Watson, Methanation Catalysts, IEA Coal Research, London, 1980

${ }^{36}$ A. Logadottir, T.H. Rod, J.K. Nørskov, B. Hammer, S. Dahl and C.J.H. Jacobsen, J. Catal. $197(2001) 229$

${ }^{37}$ M.P.Andersson, T. Bligaard, A.L. Kustov, K.E. Larsen, J. Greeley, T. Johannessen, C.H. Christensen and J.K. Nørskov, Patent WO2007-025691-A1 (2007) to Haldor Topsøe A/S

${ }^{38}$ C.J.H. Jacobsen, S. Dahl, B. Clausen, S. Bahn, A. Logadottir and J.K. Nørskov, J. Am. Chem Soc. 123 (2001) 8404

${ }^{39}$ C.J.H. Jacobsen, Chem. Comm. 12 (2000) 1057

${ }^{40}$ A.V. Ruban, H.L. Skriver and J.K. Nørskov, Phys. Rev. B 59 (1999) 15900

${ }^{41}$ V. Pareto, Manuale di Economia Politia, Societa Editrice Libraria, Milano (1906)

${ }^{42}$ P. Hohenberg and W. Kohn, Phys. Rev. 136 (1964) B864

${ }^{43}$ W. Kohn and L.J. Sham, Phys. Rev. 140 (1965) A1133

${ }^{44}$ M.C. Payne, M.P. Teter, D.C. Allan, T.A. Arias and J.D. Joannopoulos, Rev. Mod. Phys. 64 (1992) 1045

${ }^{45}$ G. Kresse and J. Furtmüller, Comp. Mat. Sci. 6 (1996) 15

${ }^{46}$ D. Vanderbilt, Phys. Rev. B 41 (1990) 7892

${ }^{47}$ B. Hammer, L.B. Hansen and J.K. Nørskov, Phys. Rev. B 59 (1999) 7413

${ }^{48}$ T. Ishihara, K. Eguchi and H. Arai, Appl. Catal. A. Gen. 30 (1987) 225

49 D.J. Duvenhage and N.J. Cooville, Appl. Catal. A. Gen 153 (1997) 43

${ }^{50}$ C. Cabet, A.C. Roger, A. Kiennemann, S. Läkamp and G. Pourroy, J. Catal. 173 (1998) 64

${ }^{51}$ F. Tihay, A.C. Roger, A. Kiennemann and G. Pourroy, Catal. Today 58 (2000) 263

${ }^{52}$ E. Boellaard, A.M. van der Kraan and J.W. Geus, Appl. Catal. A. Gen. 224 (2002) 1

${ }^{53}$ J.G.Wang, C.J. Liu, Y.P. Zhang, K.L. Yu, X.L. Zhu and F. He, Catal. Today 89 (2004) 183

${ }^{54}$ B.H. Zeifert, J. Salmones, J.A. Hernandez, R. Reynoso, N. Nava, J.G. Cabanas-Moreno and G. Aguilar-Rios, Catal. Lett. 63 (1999) 161

${ }^{55}$ S. Mori, W.C. Xu, T. Ishidzuki, N. Ogasawara, J. Imai and K. Kobayashi, Appl. Catal. A. Gen. 137 (1996) 255

${ }^{56}$ Handbook of binary alloy phase diagrams, ASM International, 2th edd., Ohio (1996)

57 J. Guo, H. Lou, H. Zhao, D. Chai and X. Zheng, Appl. Catal. A. Gen. 273 (2004) 75

${ }^{58}$ X.Z. Jiang, S.A. Stevenson and J.A. Dumesic, J. Catal. 91 (1985) 11

${ }^{59}$ Ch. Li and Y.-W. Chen, Thermochimica Acta 256 (1995) 457

${ }^{60}$ P.A. Chernavskii, Catal. Lett. 45 (1997) 215

${ }^{61}$ R. Thomas, E.M. Van Oers, V.H.J. de Beer, J. Medema and J.A. Moulijn, J. Catal. 76, 2 (1982) 241

${ }^{62}$ G. Henrici-Olive and S. Olive, The Chemistry of the Catalyzed Hydrogenation of Carbon Monooxide, Springer-Verlag, Berlin, 1984

${ }^{63}$ M.A. Vannice, J. Catal. 44 (1976) 152

${ }^{64}$ F. Fischer and H. Tropsch, Brennstoff-Chemie 4 (1923) 276

${ }^{65}$ F. Fischer and H. Tropsch, Brennstoff-Chemie 5 (1924) 201

${ }^{66}$ F. Fischer and H. Tropsch, Brennstoff-Chemie 7 (1926) 97 
${ }^{67}$ H.H. Storch, N. Golumbic and R.B., Andersson, The Fischer-Tropsch and Related Syntheses, Wiley, New York (1951)

${ }^{68}$ A.N. Stranges, Proc. 3rd Top. Conf. Nat. Gas Utilization (2003) 635

${ }^{69}$ J.E. Lesch, The German Chemical Industry in the Twentieth Century, Kluwer Academic, Dordrecht (2000)

${ }^{70}$ M.E. Dry, Catal. Today 71 (2002) 227

${ }^{71}$ H. Schultz, Appl. Catal. A. Gen. 186 (1999) 3

${ }^{72}$ J.R. Anderson and M. Boudart, Catalysis Science and Technology, Springer-Verlag, Berlin (1981)

${ }^{73}$ B.E. Leach, Applied Industrial Catalysis vol. 2., Academic Press, New York (1983)

${ }^{74}$ R. Oukaci, A.H. Singleton and J.G. Goodwin, Appl. Catal. A. Gen. 186 (1999) 129

${ }^{75}$ R. Heydenrich, Howard Weil Energy Conference (2005)

${ }^{76}$ H. Scultz, Catal. Today 84 (2003) 67

${ }^{77}$ E. Iglesia, S.L. Soled and R.A. Fiato, J. Catal. 137 (1992) 212

${ }^{78}$ E. Iglesia, S.L. Soled, R.A. Fiato and G.H. Via, Stud. Surf. Sci. Catal. 81 (1994) 433

${ }^{79}$ E. Iglesia, Appl. Catal. A. Gen. 161 (1997) 59

${ }^{80}$ A.Y. Khodakov, A. Griboval-Constant, R. Bechara and V.L. Zholobenko, J. Catal. 2006 (2002) 230

${ }^{81}$ W.P. Ma, Y.J. Ding and L.W. Lin, Ind. Eng. Chem. Res. 43 (2004) 2391

${ }^{82}$ S. Storsaeter, O. Borg, E.A. Blekkan and A. Holmen, J. Catal. 231 (2005) 405

${ }^{83}$ I. Fernandez-Morales, A. Guerrero-Riuz, F.J. Lopez-Garzon, I. Rodriguez-Ramos and C. Moreno-Castilla, Appl. Catal. 14 (1985) 159

${ }^{84}$ C. Moreno-Castilla and F. Carrasco-Marin, J. Chem. Soc., Faraday Trans. 91 (1995) 3519

${ }^{85}$ B.G. Johnson, C.H. Bartholomew and D.W. Goodman, J. Catal. 128 (1991) 231

${ }^{86}$ L. Fu, C.H. Bartholomew, J. Catal. 92 (1985) 376

${ }^{87}$ L. van de Loosdrecht, M. van der Haar, A.M. van der Kraan, A.J. van Dillen and J.W. Geus, Appl. Catal. A. Gen. 150 (1997) 365

${ }^{88}$ S. Sun, K. Fujimoto, Y. Yoneyama and N. Tsubaki, Fuel 81 (2002) 1583

${ }^{89}$ A. Barbier, A. Tuel, I. Arcon, A. Kodre and G.A. Martin, J. Catal. 200 (2001) 106

${ }^{90}$ G. Jacobs, P.M. Patterson, T.K. Das, M.S. Luo and B.H. Davis, Appl. Catal. A. Gen. 270 (2004) 65

${ }^{91}$ P.J. van Berge, J. van de Loosdrecht, S. Barradas and A.M. van der Kraan, Catal. Today 58 (2000) 321

${ }_{92}^{2}$ R.C. Reuel and C.H. Bartholomew, J. Catal. 85 (1984) 78

${ }^{93}$ G.L. Bezemer, J.H. Bitter, H.P.C.E. Kuipers, H. Oosterbeek, J.E. Holewijn, X. Xu, F. Kapteijn, A.J. van Dillen and K.P. de Jong, J. Am. Chem. Soc., 128, 12 (2006) 3956

94 J.R.A. Sietsma, J.D. Meeldijk, J.P. den Breejen, M. Versluijs-Helder, A.J. van Dillen, P.E. de Jongh and K.P. de Jong, Angew. Chem. Int. Ed. 46 (2007) 4547

95 J.R.A. Sietsma, J.P. den Breejen, P.E. de Jongh, A.J. van Dillen, J.H. Bitter and K.P. de Jong, Stud. Surf. Sci. Catal. 167 (2007) 55

${ }^{96}$ D. Das, G.G. Ravichandran and D.K. Chakrabarty, Catal. Today 36 (1997) 285

${ }^{97}$ D. Das, G.G. Ravichandran and D.K. Chakrabarty, Appl. Catal. A. Gen. 131 (1995) 335

${ }^{98}$ A. Martinez, C. Lopez, F. Marquez and I. Diaz, J. Catal. 220 (2003) 486

${ }^{99}$ J.L. Zang, J. Ren, J.G. Chen and Y.H. Sun, Acta Physico-Chimica Sin. 260 (2002) 18

${ }^{100}$ B.J. Tan, K.J. Klabunde, T. Tanaka, H. Kanai and S. Yoshilda, J. Am. Chem. Soc. 110 (1998) 5951

${ }^{101}$ K.J. Klabunde and Y. Imidzu, J. Am. Chem. Soc 106 (1984) 486 
102 Q. Liang, K. Chen, W. Hou and Q. Yan, Appl. Catal. A. Gen. 161 (1998) 191

${ }^{103}$ I. Puskas and R.S. Hurlbut, Catal. Today 84 (2003) 99

${ }_{104} \mathrm{http} / / /$ www.epa.gov/airprogm/oar/urbanair/nox/hlth.html

${ }^{105}$ V.I. Pârvulescu, P. Grange and B. Delmon, Catal. Today 46 (1998) 233

${ }^{106}$ F. Klingstedt, K. Arve, K. Eranen, and D.Y. Murzin, Acc. Chem. Res. 39 (2006) 273

${ }^{107}$ P. Hauck, A. Jentys, and J.A. Lencher, Appl. Catal. B: Environ. 70 (2007) 91

${ }^{108}$ S.R. Katare, J.E. Patterson, E. Joseph and P.M. Laing, Ind. Eng. Chem. Res. 46, 8 (2007) 2445

${ }^{109} \mathrm{http} / / \mathrm{www} \cdot$ dieselnet.com/standards/

${ }_{110}^{11}$ M.V. Twigg, Appl. Catal. B: Environ. 70 (2007) 2

111 T.D. Elmøe, R.Z. Sørensen, U. Quaade, C.H. Christensen, J.K. Nørskov and T. Johannessen, Chem. Eng. Sci. 61 (2006) 2618

112 J.N. Armor, Catal. Today 26 (1995) 99

${ }_{113}$ R.Q. Long and R.T. Yang, J. Catal. 207 (2002) 274

${ }^{114}$ H.-Y. Chen, X. Wang and M.H. Sachtler, Appl. Catal. B. Environ. 194-195 (2000) 159

115 D.H. Kim, J.H. Kwak, X. Wang, J. Szanyi and C.H.F. Peden, Catal. Today 136 (2008) 183

${ }^{116}$ www.energetics.com

${ }^{117}$ S. Matsumoto, Catalysis Surveys from Japan 1 (1997) 111

${ }^{118}$ P. Forzatti, Catal. Today 62, 1(2000) 51

${ }^{119}$ M. Koebel, M. Elsener and M. Kleemann, Catal. Today 59, 3-4 (2000) 335

${ }^{120}$ M. Appl, Ullmann's Encyclopedia of Chemical Technology: Ammonia, Weinheim, WileyVCH Verlag GmbH \&Co. KGaA (2007)

${ }^{121}$ M. Kleemann, M. Elsener, M. Koebel and A. Wokaun, Ind. Eng. Chem. Res. 39 (2000) 4120

${ }^{122}$ S. Steinbach, J. Gruenwald, U. Glueckert and T. Sattelmayer, Top. Catal. 42-43, 1-4 (2007) 99

${ }^{123}$ T. Piazzesi, M. Devadas, O. Kröcher, M. Elsener and A. Wokaun, Cat. Comm 7 (2006) 600

${ }^{124}$ W.-P. Trautwein, German society for petroleum and coal science and technology, rapport 616-1 (2003)

${ }^{125}$ F. Birkhold, U. Meingast, P. Wassermann and O. Deutschmann, Society of Automotive Engineers SP-2022 (Diesel Exhaust), SP (2006) 229

${ }^{126}$ F. Birkhold, U. Meingast, P. Wassermann and O. Deutschmann, Appl. Catal. B. Environ. 70, 1-4 (2007) 119

${ }^{127}$ A. Werner, Nobel Prize Lecture: On the constitution and configuration of higher-order compounds (1913)

${ }^{128}$ R.Z. Sørensen, J.S., Hummelshøj, A. Klerke, J.B. Reves, T. Vegge, J.K. Nørskov and C.H. Christensen, J. Am. Chem. Soc. 130 (2008) 8660

${ }^{129}$ C.H. Christensen, R.Z. Sørensen, T. Johannessen, U.J. Quaade, K. Honkala, T. Elmøe, R. Køhler and J.K. Nørskov, J. Mater. Chem. 15 (2005) 4106

${ }^{130}$ www.amminex.com

131 J.S. Hummelshøj, R.Z. Sørensen, M.Y. Kustova, T. Johannessen, J.K. Nørskov and C.H. Christensen, J. Am. Chem. Soc. 128 (2006) 16

${ }^{132}$ P. Forzatti, Appl. Catal. A: Gen. 222 (2001) 221

${ }^{133}$ G. Busca, L. Lietti, G. Ramis, and F. Berti, Appl. Catal. B: Environ. 18 (1998) 1

134 H. Kamata, H. Ohara, K. Takahashi, A. Yukimura and Y. Seo, Catal. Lett. 73 (2001) 79

${ }^{135}$ B.-C. Choi and D.E. Foster, J. Ind. Eng. Chem. 11, 1 (2005) 1 
${ }^{136}$ B. Wichterlova, Top. Catal., 28 (2004) 131

${ }^{137}$ B. Wichterlova, Z. Sobalik and J. Dedecek, Appl. Catal. B. Environ., 41 (2003) 97

138 G.M. Zhidomirov, A.A. Shubin and R.A. van Santen, Computer Modelling of Microporous Materials, Elsevier, Eindhoven (2004)

${ }^{139}$ S. Kieger, G. Delahay and B. Coq, Appl. Catal. B: Environ. 25 (2000) 1

${ }^{140}$ H.-Y. Chen, X. Wang and W.M.H. Sachtler, Appl. Catal. A: Gen. 194-195 (2000) 159

141 J.A.Z. Pieterse and S. Booneveld, Appl. Catal. B: Environ. 73 (2007) 327

${ }^{142}$ A.P. Walker, Catal. Today 26 (1995) 107

143 J.A. Sullivan, J. Cunningham, M.A. Morris and K. Keneavey, Appl. Catal. B: Environ. 7 (1995) 137

${ }^{144}$ A.-Z. Ma, M. Muhler and W. Grünert, Appl. Catal. B: Environ. 27 (2000) 37

145 I. Melián-Cabrera, F. Kapteijn and J.A. Moulijn, Catal. Today 110 (2005) 255

${ }^{146}$ R.Q. Long and R.T. Yang, J. Catal. 194 (2000) 80

147 J. Perez-Ramirez, J.C. Groen, A. Brückner, M.S. Kumar, U. Bentrup, M.N. Debbagh and L.A. Villaescusa, J. Catal. 232 (2005) 318

148 A.L. Kustov, K. Egeblad, M. Kustova, T.W. Hansen and C.H. Christensen, Top. Catal. 45 (2007) 159

${ }^{149}$ M. Devadas, O. Kröcher, M. Elsener, A. Wokaun, G. Mitrikas, N. Söger, M. Pfeifer, Y. Demel and L. Mussmann, Catal. Today 119, 1-4 (2007) 137

${ }^{150}$ K. Krishna and M. Makkee, Catal. Today 114, 1 (2006) 23

${ }^{151}$ R.Q. Long and R.T. Yang, J. Catal. 188 (1999) 332

152 A.Z. Ma and W. Grünert, Chem. Commun. 1 (1999) 71

153 A.H. Janssen, I. Schmidt, C.J.H. Jacobsen, A.J. Koster and K.P. de Jong, Micropor. Mesopor. Mater. 65 (2003) 59

${ }^{154}$ C.J.H. Jacobsen, C. Madsen, J. Houzvicka, I. Schmidt and A. Carlson, J. Am. Chem. Soc. 122 (2000) 7116

${ }^{155}$ C.J.H. Christensen, I. Schmidt, A. Carlson, K. Johannsen and K. Herbst, J. Am. Chem. Soc. 127 (2005) 8098

${ }^{156}$ A.L. Kustov, T.W. Hansen. M. Kustova and C.H. Christensen, Appl. Catal. B: Environ. 76 (2007) 311

${ }^{157}$ M. Kustova, Novel Zeolite Catalysts: Preparation, Characterization and Application, PhD thesis, Technological University of Denmark (2006)

${ }^{158}$ C. Baerlocher, L.B. McCusker and D.H. Olson, Atlas of zeolite framework types, 6 Ed. Elsevier, Amsterdam (2007)

${ }^{159}$ M.A. Camblor, A. Corms and S. Valencia, J. Matter. Chem, 8 (1998) 2137

${ }^{160}$ G. Halsey, J. Chem. Phys. 16 (1948) 931

${ }^{161}$ S. Brunauer, P.H. Emmett and E. Teller, J. Am. Chem. Soc. 60 (1938) 309

162 B.-W. Lu, H. Jon, T. Kanai, Y. Oumi, K. Itabashi and T. Sano, J. Mater. Sci. 41 (2006) 1861

163 J.B. Higgins, R.B. LaPierre, J.L. Schlenker, A.C. Rohrman, J.D. Wood, G.T. Kerr and W.J. Rohrbaugh, Zeolites 8 (1988) 446

164 J.M. Newsam, M.M.J. Treacy, W.T. Koetsier and C.B. De Gruyter, Proceedings of the Royal Society of London, Series A, Mathematical and Physical Sciences 420 (1988) 375

165 B.J. Schoeman, E. Babouchkina, S. Mintova, V.P. Valtchev and J. Sterte, J. Por. Mater. 8 (2001) 13

${ }^{166}$ S.G. Hegde, R. Kumar, R.N. Bhat and P. Ratnasamy, Zeolites 9 (1989) 231 
${ }^{167}$ A.M. Camiloti, S.L. Jahn, N.D. Velasco, L.F. Moura and D. Cardoso, Appl. Catal. A: Gen. 182 (1999) 107

${ }^{168}$ R. Kumar, A. Thangaraj, R.N. Bhat and P. Ratnasamy, Zeolites 10 (1990) 85

${ }^{169}$ T. Armaroli, M. Trombetta, A.G. Alejandre, J.R. Solis and G. Busca, Phys. Chem. Chem. Phys. 2 (2000) 3341

${ }^{170}$ R. Díaz, S. Macías and E. Cázares, J. Sol-Gel Sci. Technol. 35 (2005) 13

${ }^{171}$ D. Goldfarb, M. Bernardo, K.G. Strohmaier, D.E.W. Vaughan and H. Thomann, J. Am. Chem. Soc.116 (1994) 6344

${ }^{172}$ S. Dzwigaj, J. Janas, T. Machej and M. Che, Catal. Today 119 (2007) 133

${ }^{173}$ M. Schwidder, M.S. Kumar, K.V. Klementiev, M.M. Pohl, A. Brückner and W. Grünert, J. Catal. 231 (2005) 314 